WALDEN

UNIVERSITY

A higher degree. A higher purpose.

Walden University ScholarWorks

2019

\title{
Post-Ebola Case Management of Orphaned Young Adults in Rural Sierra Leone
}

Augustine Frazer

Walden University

Follow this and additional works at: https://scholarworks.waldenu.edu/dissertations

Part of the Social and Behavioral Sciences Commons

This Dissertation is brought to you for free and open access by the Walden Dissertations and Doctoral Studies Collection at ScholarWorks. It has been accepted for inclusion in Walden Dissertations and Doctoral Studies by an authorized administrator of ScholarWorks. For more information, please contact ScholarWorks@waldenu.edu. 


\title{
Walden University
}

\author{
College of Social and Behavioral Sciences
}

This is to certify that the doctoral dissertation by

\begin{abstract}
Augustine Frazer
has been found to be complete and satisfactory in all respects, and that any and all revisions required by the review committee have been made.

Review Committee

Dr. Randy Heinrich, Committee Chairperson, Human Services Faculty

Dr. Barbara Benoliel, Committee Member, Human Services Faculty

Dr. Scott Hershberger, University Reviewer, Human Services Faculty
\end{abstract}

Chief Academic Officer

Eric Riedel, Ph.D. 


\begin{abstract}
Post-Ebola Case Management of Orphaned Young Adults in Rural Sierra Leone
\end{abstract}

by

Augustine Frazer

MSW, Howard University, 2004

BSc, University of Sierra Leone, 1994

\author{
Dissertation Submitted in Partial Fulfillment \\ of the Requirements for the Degree of \\ Doctor of Philosophy \\ Crisis and Disaster Intervention
}

Walden University

April 2019 


\begin{abstract}
The 2014-2016 Ebola pandemic in Sierra Leone significantly increased the orphan population and the need for social support programs, especially for student-orphans in higher education. Poorly prepared disaster response managers have little knowledge about how college student-orphans experience social services. The purpose of this transcendental phenomenological study was to explore how post-Ebola student-orphans enrolled in an agricultural university in rural Sierra Leone experienced post disaster specialized case management to enhance student performance. Criterion sampling techniques including specific inclusion and exclusion criteria guided the recruitment, that included 10 research participants taking part in the semi structured interviews. Ecological system theory and postpositivist ontology informed this transcendental phenomenological research. The modified van Kaam transcendental phenomenological data analysis enabled the development of themes from lived experiences of post-Ebola case management for student-orphans. The findings of the research showed that student-orphans experienced specialized case management with three characterizations: (a) sadness, (b) happiness, and (c) anger which included information helpful for crisis and disaster case management administration and staff across similar circumstances. The social change implication for the study results include information useful for human service administrators and staff in designing and employing post disaster programs for college student-orphans.
\end{abstract}


Post-Ebola Case Management of Orphaned Young Adults in Rural Sierra Leone

by

Augustine Frazer

MSW, Howard University, 2004

BSc, University of Sierra Leone, 1994

Dissertation Submitted in Partial Fulfillment

of the Requirements for the Degree of

Doctor of Philosophy

Crisis and Disaster Intervention

Walden University

April 2019 


\section{Dedication}

This dissertation is dedicated to all Ebola student-orphans in Sierra Leone who experienced trauma and confusion both by the disease and the intervention; rejection while utilizing services and endearing self-efficacy in coping strategies to meet the needs for college requirements and to enhance coping skills with the new normal. 


\section{Acknowledgments}

I want to acknowledge the many individuals who contributed to and supported my academic journey. No amount of words will be enough to express my profound gratitude to all of them. However, I want to thank the individuals whose stories and unique experiences made this study possible. Thank you for your willingness to allow me to be part of your stories. Each of you has singlehandedly made a critical piece of this study a reality. To Dr. Randy Heinrich my dissertation committee chair, I will remain significantly forever grateful for your willingness to direct this research, openness to understand my culture, mentorship, patience and your supportive directions throughout my course at Walden University. To Dr. Barbara Benoliel, I am indebted for your readiness to be part of my dissertation committee and became a very strong advocate for quality work; all of your inputs enhanced the quality of this study. Thank you to my wife Millicent and children Boi-Nancy Abigail Frazer and Giivuii Feimata Frazer, for your endurance and unconditional support throughout this process. Finally, to all my friends Moses S. Belewa, Amara Belewa, Saffa Boima, Pastor Christian Fhole, Ambrose S. Nyaley, Emmanuel Koivaya Amara, ESQ, Mark Nuwah, Munda K. Banya, Mary Jo Jo Rogers, Major Peter J. Amara, Dr. Arthur Williams, and Mr. James Juana you are duly recognized for your support, patience and understanding throughout this study. 
Table of Contents

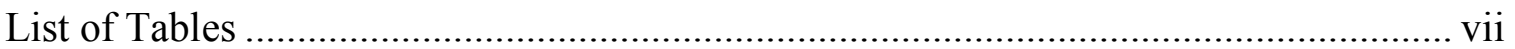

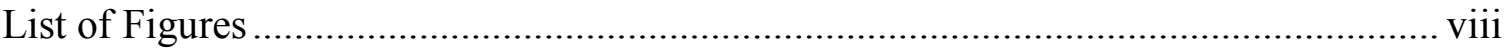

Chapter 1: Introduction to the Study ........................................................................

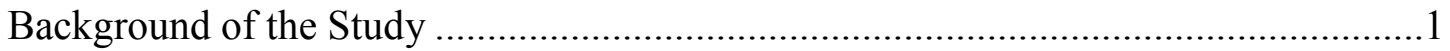

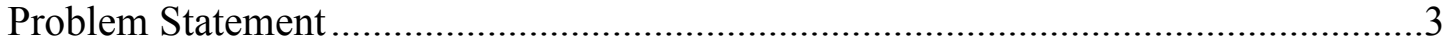

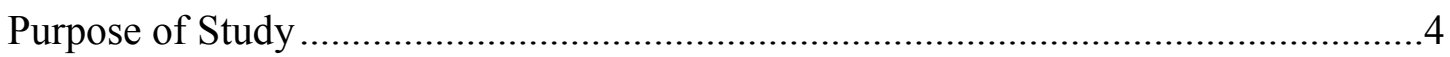

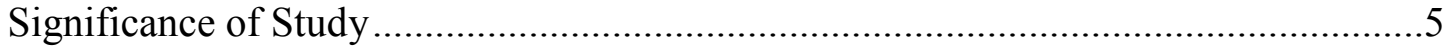

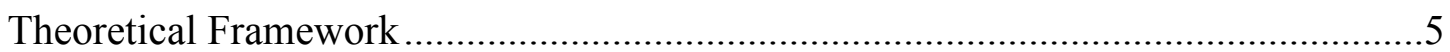

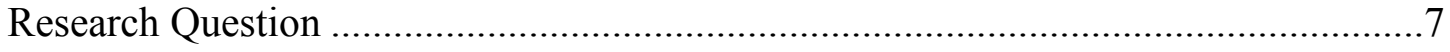

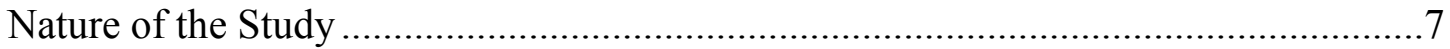

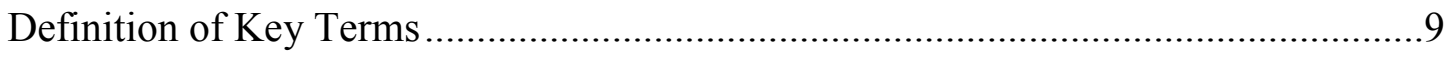

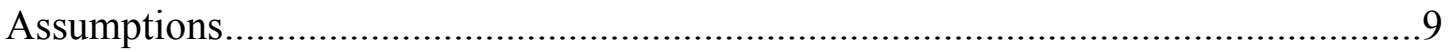

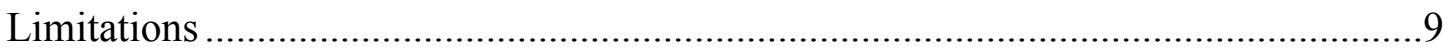

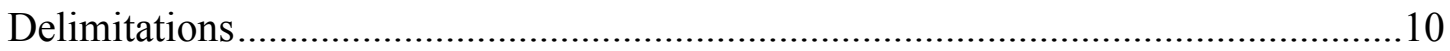

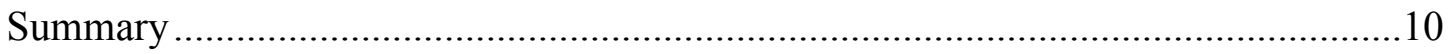

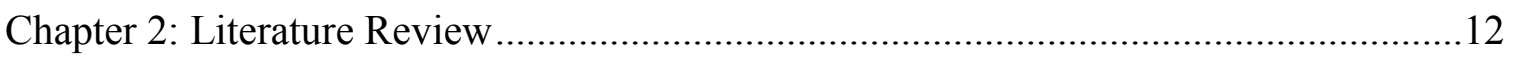

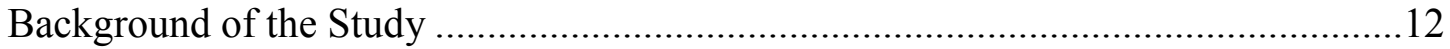

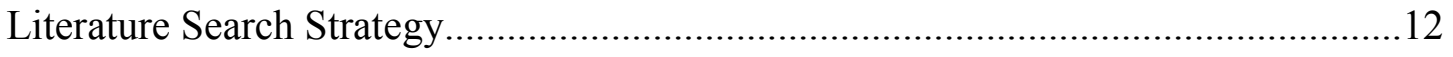

Historical Background Orphans and Orphanages ................................................ 13

Orphans and Orphanages in Antiquity...................................................... 13

Middle Ages History of Orphans and Orphanages ........................................... 15 
Industrial Ages History of Orphans and Orphanages 15

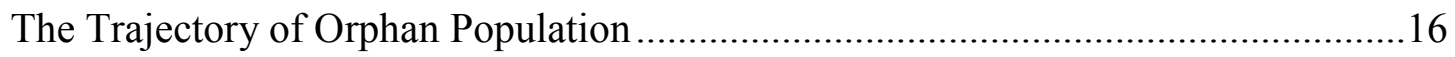

World Orphan Population Trend ................................................................... 17

Orphan and Orphanages in Sub-Saharan Africa................................................. 17

Orphans and Orphanages in Sierra Leone ....................................................... 18

Brief Historical Events of Orphans and Orphanages in Sierra Leone .........................19

Therapeutic Interventions for Orphans in Orphanages ............................................20

Historical Overview of Crises and Disasters in Sierra Leone.......................................21

Catastrophic Events and Social Support Systems in Sierra Leone ..............................24

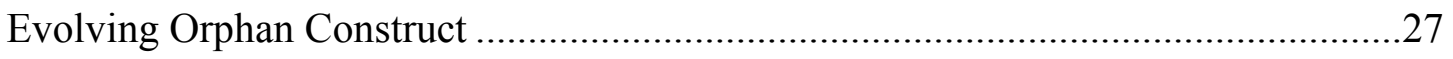

Post-Civil War Educational Resources for Orphans and Students ..............................27

Post-Ebola Educational Resources to Student-Orphans ..............................................30

Sierra Leone's Pre-Ebola Orphan Population..................................................................

Pre-Ebola Model Case Management for Orphans and Students.....................................32

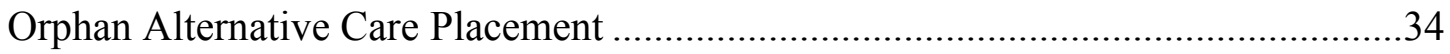

Traditional Kinship Care Placement: Sierra Leone ............................................. 35

Tribal Characteristic of Child Placement in Sierra Leone ..................................... 35

Role of Local Chiefs and Secret Societies in Sierra Leone .................................. 37

Role of Government in Foster Care Programs in Sierra Leone ......................................37

Clinical Case Management Practices in Sierra Leone ..................................................38

International Partnership in Disaster Case Management ............................................40

Traditional Perceptions of the Coping Skills of Young Adults in Sierra Leone .........40 
Struggle with Loss and Emotional Needs ................................................................

Political Influence on Policies Affecting Post Disaster Orphans...................................43

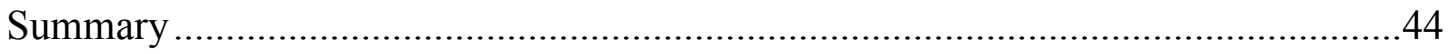

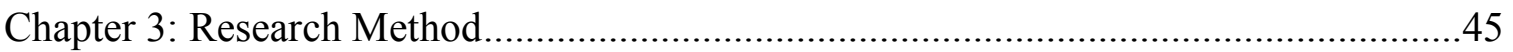

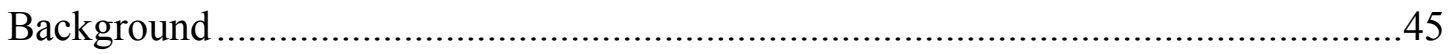

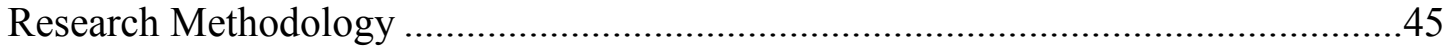

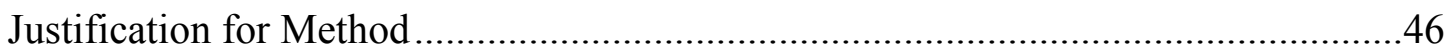

Purpose

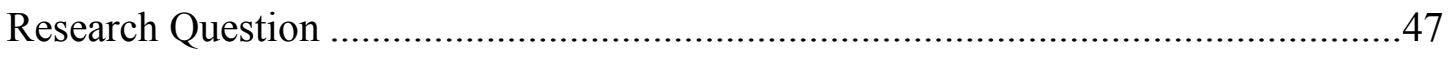

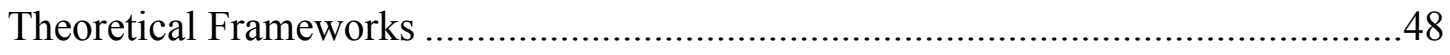

Transcendental Philosophical Viewpoint ......................................................... 48

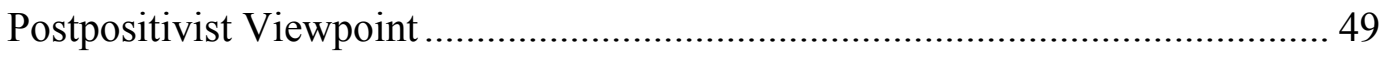

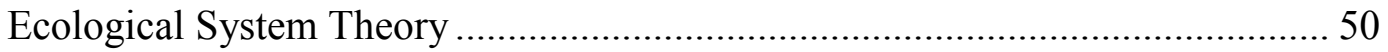

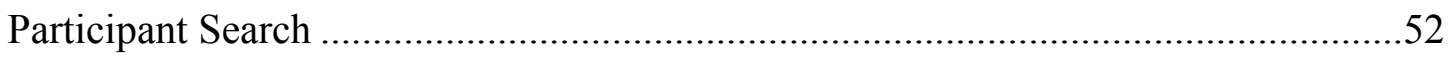

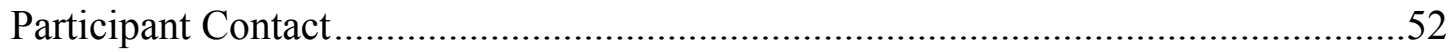

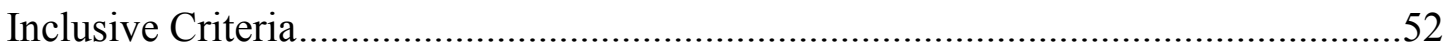

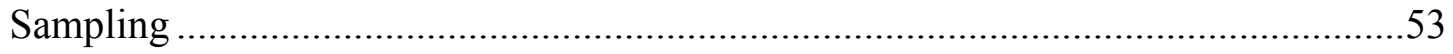

Sampling Techniques: Criterion and Snowballing .................................................53

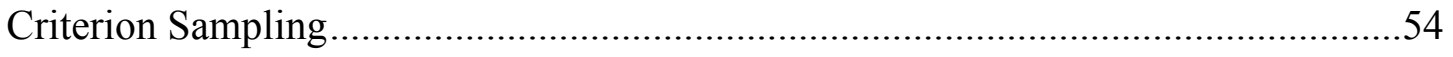

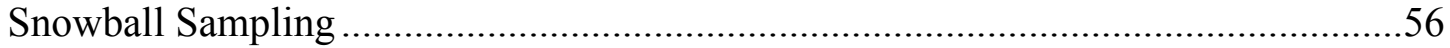

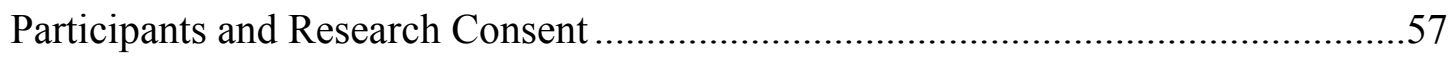

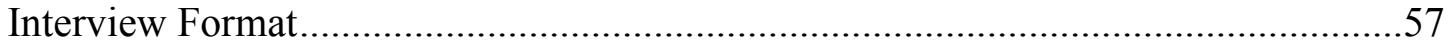




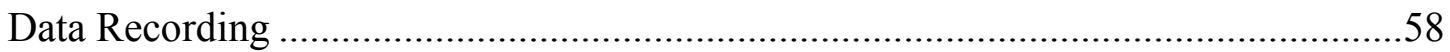

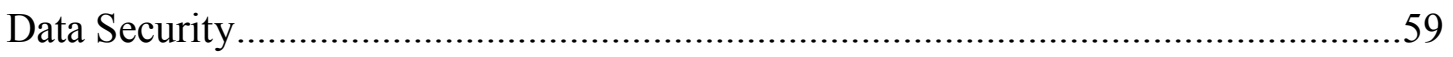

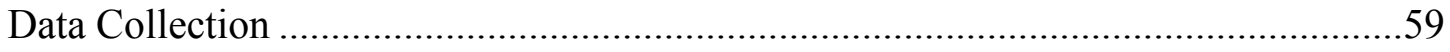

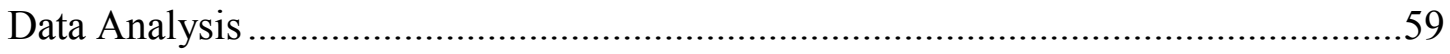

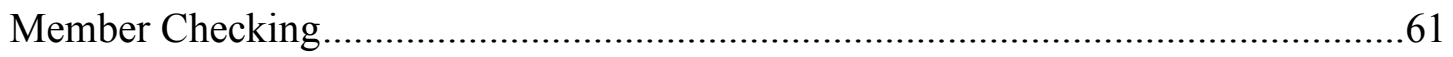

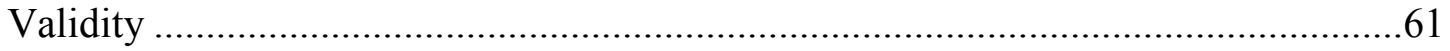

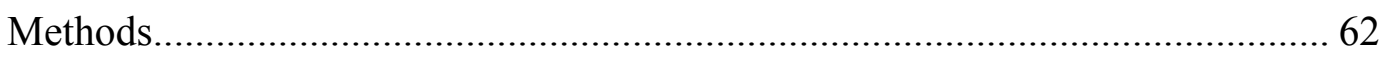

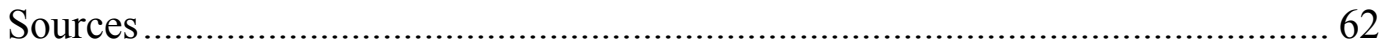

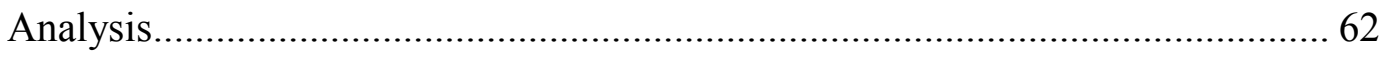

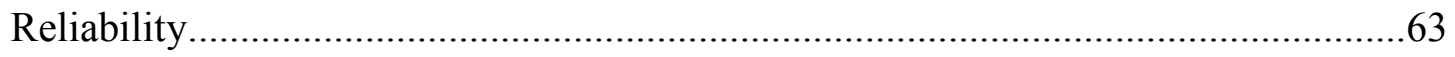

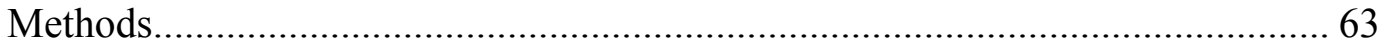

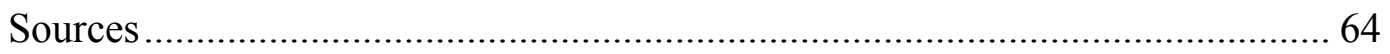

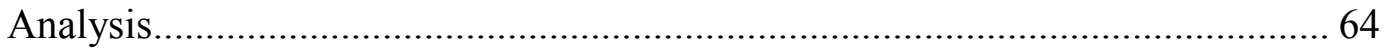

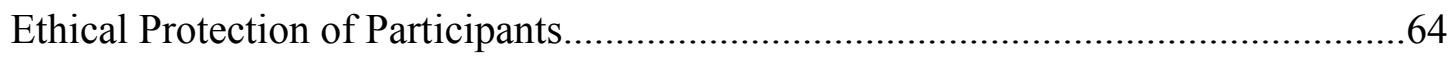

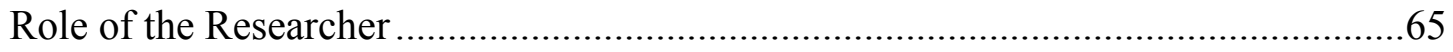

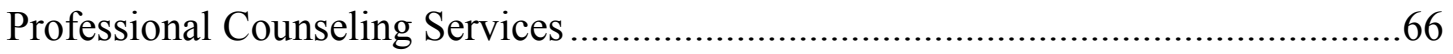

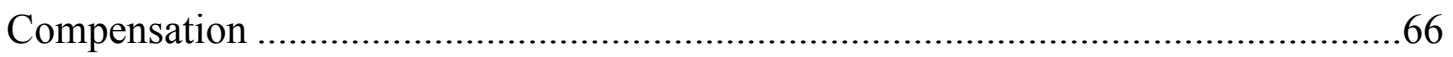

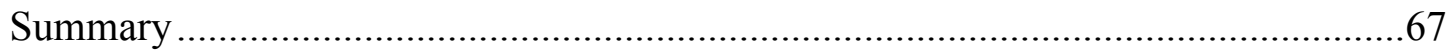

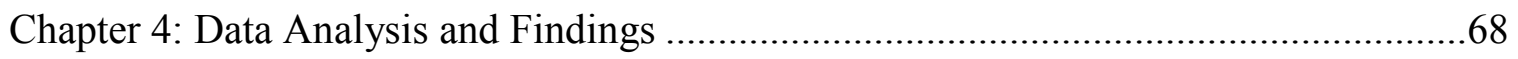

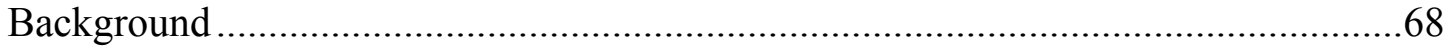

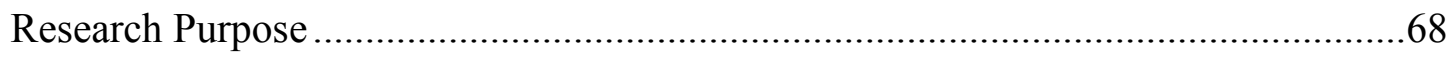

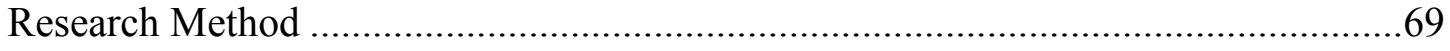




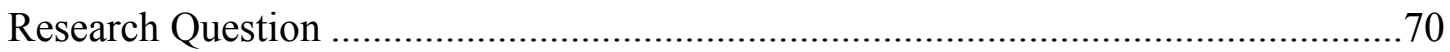

van Kaam's Analytical Tool: Presentation of Research Findings ................................72

Main Theme 1: Case Management as a Motivator ............................................. 76

Main Theme 2: Disbelief and Frustration........................................................... 77

Main Theme 3: Hopelessness and Despair ...................................................... 78

Main Theme 4: Anxiety, Fear, and Anger ......................................................... 79

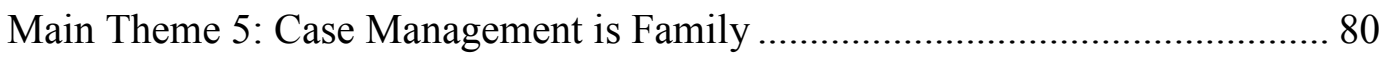

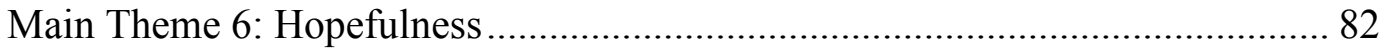

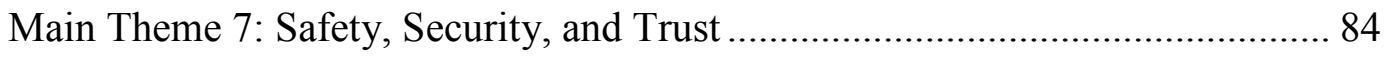

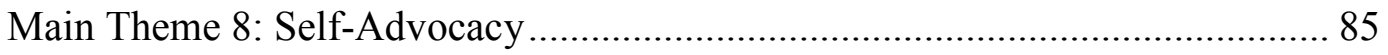

Main Theme 9: Inspiration in the Face of Persisting Trauma ............................... 87

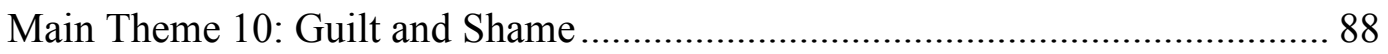

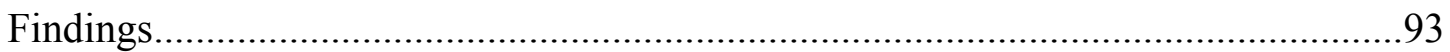

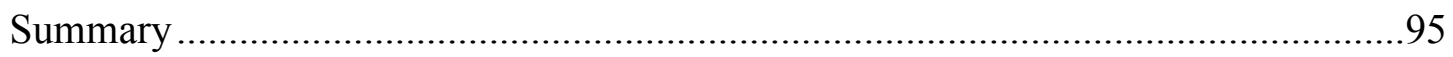

Chapter 5: Discussion, Conclusions, and Recommendations …………………...............96

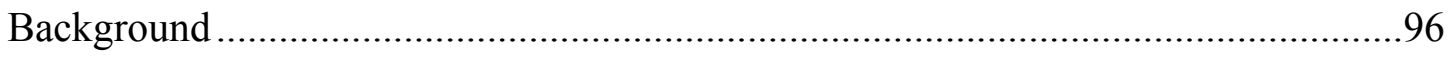

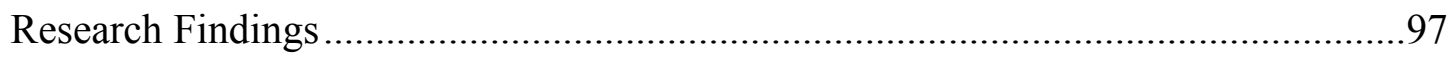

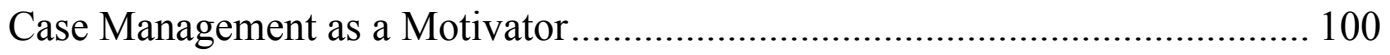

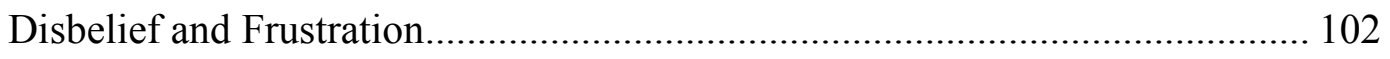

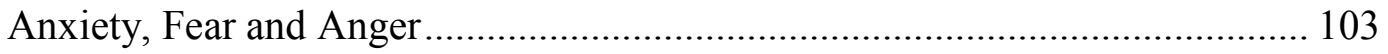

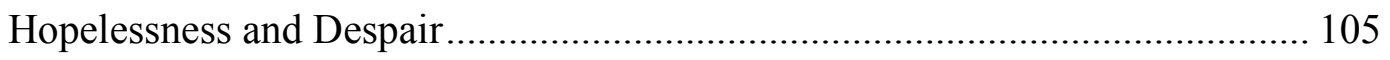

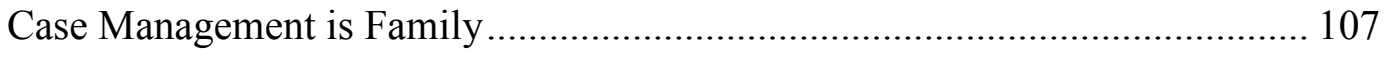




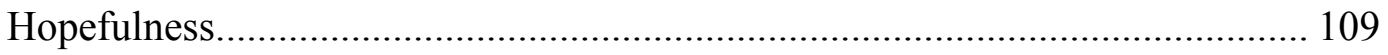

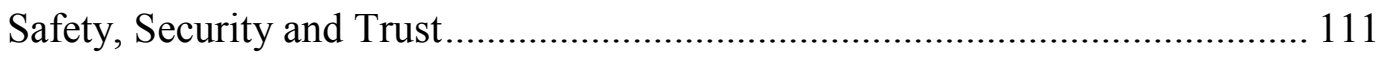

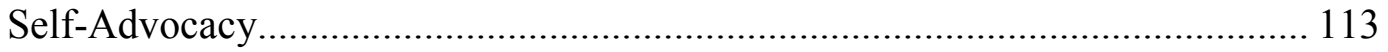

Inspiration in the Face of Persisting Trauma ................................................... 114

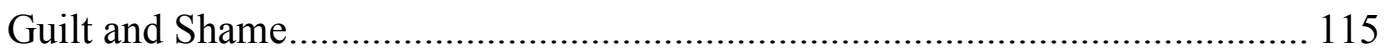

Implications for Social Change..........................................................................116

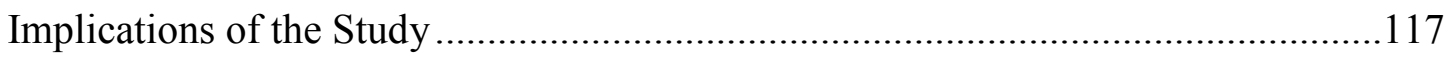

Recommendations for Further Studies.................................................................119

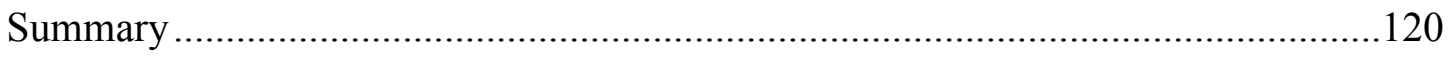

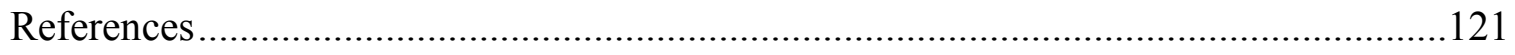

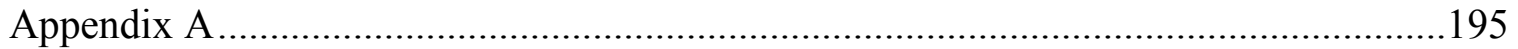

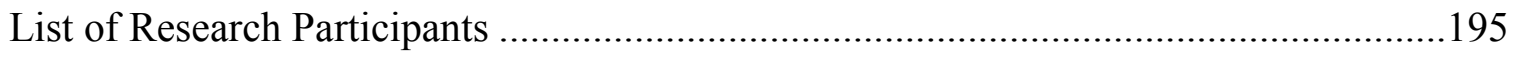

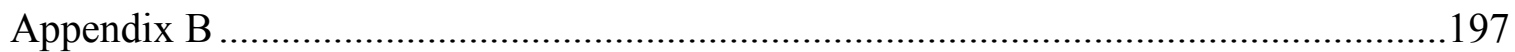

Partner University Institutional Review Board Approval................................................197

Appendix C:

Walden University Institutional Review Board Approval...............................................199

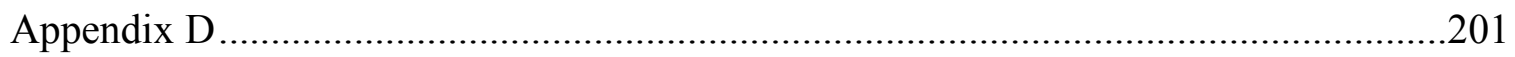

Sierra Leone Ethics Committee Approval ………………......................................201

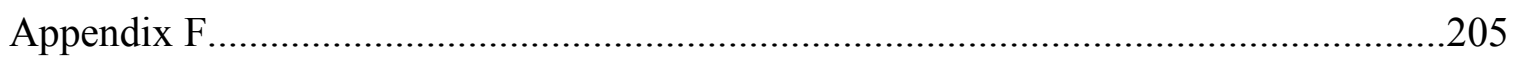

Referral to Counseling and Psychological Services .......................................................205 


\section{List of Tables}

Table 1. Types of Disasters and Frequency in Sierra Leone ........................................23

Table 2. Historical Timeline of Disasters and Crises in Sierra Leone ............................26

Table 3. Case Management to Post-Ebola Student-Orphans in Sierra Leone ....................34

Table 4. Tribal Characterization for Child Placement in Sierra Leone ...........................36

Table 5. Participant Demographics and Cultural Lineage ............................................58

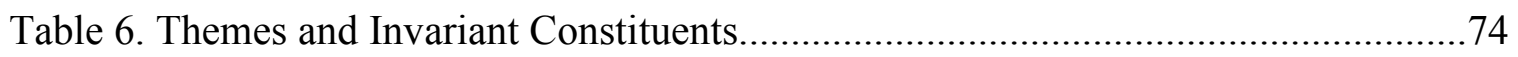

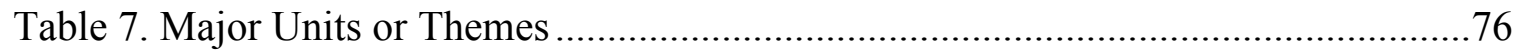

Table 8. Brief Summarized Textural Description of Feelings ....................................91

Table 9. Case Management Feelings Experienced by Student-Orphans .........................93

Table 10. Research Participant Characterizations of Case Management .......................100 


\section{List of Figures}

Figure 1. Cultural attribution by research participants ...................................................54

Figure 2. Gender distribution of research participants...................................................56

Figure 3. Ebola disaster intervention model in Sierra Leone.............................................87

Figure 4. Word frequency query results ................................................................99 
Chapter 1: Introduction to the Study

\section{Background of the Study}

The Sierra Leonean young adult population between 18 and 26 years of age accounts for $33 \%$ or 1.9 million of the estimated 7.7 million citizens (Alemu, 2016;

Efevbera \& Betancourt, 2016; Gray et al., 2018; Shepler, 2014; Leone, 2014).

Approximately $15 \%-24 \%$ of the youth population are considered orphans, either for not living with biological parents or other family members or living on the streets (Alemu, 2016). The orphan population is only an estimate because of the communal and traditional parenting patterns, as well as a poor tracking and record-keeping culture in Sierra Leone (Case, Paxson, \& Ableidinger, 2004; Kamara et al., 2017). Between 2008 and 2013, there was a decrease in the numbers of orphans in Sierra Leone; single-parent deaths fell from $1.8 \%$ to $1.4 \%$, and both parents dying decreased from $8.7 \%$ to $7.5 \%$. However, the post-Ebola orphan count indicates that the numbers significantly increased to $30 \%$, and other scholars argued that the number is much higher (Abramowitz et al., 2015; Davies, Bowley \& Roper, 2015; Denis-Ramirez, Sørensen, \& Skovgaard, 2016; Evans \& Popova, 2015a).

The large numbers of orphans resulted in economic hardship, which lowered the quality of care, reduced short-term therapeutic interventions, and resulted in a poor understanding of how orphans experience case management services (Beegle, Filmer, Stokes, \& Tiererova, 2010; Evans \& Popova, 2015b; Evans \& Miguel, 2007). Post-Ebola student-orphans experienced emotional problems and social isolation in addition to the loss of parents (DePinto, 2016; Evans \& Popova, 2015b; Shultz, Cooper et al., 2016). The 
limited funded Social Safety Nets Programs, launched in 2013-2014, met exacerbating factors during postwar economic development and reconstruction, which reduced available funds for rural areas of the country resulting in post-Ebola student-orphans reliance on community and personal resources for coping with a new normal (Bakare, Ilesanmi, Nabena, \& Famuyide, 2016; Dallatomasina et al., 2015; Salmon, McLaws \& Fisher, 2015). The secondary effects of the Ebola outbreak on rural families, including mental health and psychological distress, closure of schools and colleges, and government suspension of social functions, remains to be quantified, particularly given the limited ability of the rural population to meet essential social and emotional needs in pre-Ebola model of care for war victims, making a case for supportive services and specialized case management to the targeted population in post-Ebola intervention programs (Ansumana et al., 2015; Wolz, 2014).

Human services administrators and disaster response managers have a poor understanding of the coordination of care and services of post-Ebola specialized case management victim needs, particularly for postsecondary education (Garoff, 2015; Phrampus et al., 2016). Disaster response managers in the case management planning role have little understanding of how student-orphans experienced specialized case management, which has resulted in a significant gap in needs assessment and case management service delivery; thus, orphans attending colleges have relied on personal coping skills to meet emotional and physical needs, to improve grades, and achieve graduation (Althaus, Low, Musa, Shuaib \& Gsteiger, 2015). The next section includes the problem statement for this transcendental phenomenological study. 


\section{Problem Statement}

In the Ebola pandemic of 2014-2015, there were 14,124 cases of the disease that resulted in 3,956 deaths in Sierra Leone, which led to a $12 \%$ increase in the number of orphans, overwhelmed the health care system, separated families and communities, and created economic challenges (Evans \& Popova, 2015b; Helleringer \& Noymer, 2015; Pronyk, et al., 2016; Team, 2014). The increase in the orphan population resulted in lower quality of care, inconsistent therapeutic interventions, and poor case management coordination by human service professionals (Burton, 2015; Evans \& Popova, 2015b; Phua, 2015).

Case management programs in Sierra Leone are available for student-orphans including free college readiness programs, short-term therapeutic services, and mentorship opportunities (Bledsoe, 1990; Farrar \& Piot, 2014; Shultz, Baingana, \& Neria, 2015). However, program administrators reported issues with underfunding, inadequately trained foster care personnel and poor crisis intervention strategies, including low understanding of the demands of case management for student-orphans in higher education (Betancourt et al., 2008; Chukwudozie et al., 2015; Evans \& Popova, 2015a; Zuilkowski \& Betancourt, 2014). Post-Ebola leadership and case management teams and staff in Sierra Leone have a low understanding of how orphans are experiencing case management supports and college activities (Salazar, Roe, Ullrich \& Haggerty, 2016; Sapienza \& Masten, 2011; Ungar, 2014).

The problem is, despite case management supportive services, the post-Ebola college orphans' performance decreased by 15\% in grades from 2013 to 2015 and a 5\% 
increase in dropping out of college as compared to pre-Ebola college dropout rate for the targeted population (Nabwire \& Owino, 2015; Schenk, 2009). Decreasing post-Ebola student-orphans performance was partly as a result of the poor understanding of case management needs and supports for post-Ebola college orphans by disaster response managers and staff (Kazeem \& Jensen, 2017; Sapienza \& Masten, 2011).

Although available research about case management for orphans in Sierra Leone includes significant findings, I have not found studies about the post -Ebola case management experiences of college orphans in Sierra Leone. The poor understanding of disaster response managers, crisis intervention policy planners, and human service administrators of the lived experiences of post-Ebola orphans attending college in postEbola Sierra Leone has partly resulted in poor outcomes for the student-orphans. Thus, I conducted this transcendental phenomenology study to understand the lived experiences of student-orphans receiving post-Ebola case management services while attending a rural agricultural university in Sierra Leone. The results of this study filled a gap in the literature and included information helpful for policy and decision-makers, as well as program managers and practitioners of orphan care case management programs for subsequent programming development and delivery. The next section examines the purpose of this transcendental phenomenological study.

\section{Purpose of Study}

For this transcendental phenomenological study, I explored the lived experiences of post-Ebola student-orphans enrolled at a rural agricultural university in Sierra Leone and engaged in a specialized case management intervention intended to enhance college 
grades and promote graduation. The information assisted human service program administrators and foster care providers, as well as government and nongovernmental organizations, to design post disaster intervention services and social support systems for the orphan population to promote college graduation and improve grades. Furthermore, the findings of this research provided an understanding of how post-Ebola studentorphans experienced case management supportive services while enrolled in college (Buseh, Stevens, Bromberg, \& Kelber, 2015; Denis-Ramirez et al., 2017; Evans \& Popova, 2015b). The significance of the study discussed in the next section provides the need for this transcendental phenomenological study.

\section{Significance of Study}

For this transcendental phenomenological study, I explored the lived experiences of post-Ebola student-orphans enrolled at an agricultural university in Sierra Leone and receiving specialized care as an intervention scheme to enhance college grades and graduation. The results of this transcendental phenomenological study include helpful information to human service leaders, policy planners, and foster care providers to understand how orphans experience post disaster case management services (Ardington \& Leibbrandt, 2010; Masten et al., 2014; Sapienza \& Masten, 2011; Ungar, 2014; Ungar, Ghazinour, \& Richter, 2013). The next section contains the theoretical framework that guided this transcendental phenomenological study.

\section{Theoretical Framework}

The theoretical framework and data interpretation of this study included the following constructs. I applied the transcendental phenomenological research method 
using ecological systems theory (EST) to understand the lived experiences of young adults in foster care who are engaged in post-Ebola specialized case management while enrolled at a rural agricultural university in Sierra Leone. The use of EST helped me understand individuals in the natural community and how participants interrelated with core and subsystems to enhance efficacy in overcoming challenges in school, and within the communities, peers, and families (Bronfenbrenner, 1977; Burns, Warmbold-Brann, \& Zaslofsky, 2015; Fivush \& Merrill, 2016; Garbarino, 1980; Lindsay, McDougall, MennaDack, Sanford, \& Adams, 2015; Ungar, 2014). EST theorists seek to understand how individuals experience an event and use environmental resources to maintain normative behavior (Cote \& Nightingale, 2012; Folke, 2006; Gallopín, 2006). In understanding college orphans lived experiences with specialized case management, my perspective as a human service professional did not influence my interpretation of the qualitative results; therefore, using EST helped to improve the internal validity (Baškarada, Shrimpton \& $\mathrm{Ng}, 2016)$.

The transcendental phenomenological method allowed me to understand the lived experiences of college student-orphans' participation in specialized case management in post-Ebola Sierra Leone while enrolled at a rural agricultural university (Brown \& Wilderson, 2010; Lauver, 2010; Moustakas, 1994). Attempting to understand the individual's perception of a phenomenon is a complex construct, particularly in challenging traumatic experiences (Burns et al., 2015); however, the transcendental phenomenological qualitative method permitted me to understand the lived experiences of case management by the research subjects without allowing preconceived ideas to 
cloud the true meaning of the phenomenon to emerge as the research participants experienced such a phenomenon (Bernet, 2015; Himelhoch \& Njie-Carr, 2016; Moustakas, 1994). Through bracketing, data collection, and analysis, I obtained an understanding of the lived experiences of post-Ebola student-orphans' meaning of specialized case management to enhance grade and graduation (Cote \& Nightingale, 2012; Gallopín, 2006; Tufford \& Newman, 2012). The next section includes the research question.

\section{Research Question}

I used the following research question to guide this transcendental phenomenological study: What are the lived experiences relative to higher education of post-Ebola orphaned young adults engaged with case management activities while enrolled at a rural agricultural university in Sierra Leone? The next section addresses the nature of the study.

\section{Nature of the Study}

I used a transcendental phenomenological approach to examine the lived experiences of post-Ebola student-orphans engaged in specialized case management for 2 years while enrolled at a rural agricultural college in Sierra Leone (see Moustakas, 1994). I examined the student-orphans' experiences of post-Ebola specialized case management at a rural agricultural university in Sierra Leone through interactive interviews with 10 post-Ebola student-orphans. Data were collected through semi structured interview questions (Frith \& Gleeson, 2011; Gale, Heath, Cameron, Rashid, \& Redwood, 2013; Palinkas et al., 2015). 
Understanding the case management experiences of orphaned young adults aligns with transcendental methodology allowing me to experience the phenomenon as the research instrument (Butler-O’Halloran, \& Guilfoyle, 2015; Geiger, Hayes \& Lietz, 2013; Moustakas, 1994). The construct of investigating the post-Ebola specialized case management relating to orphaned young adults provided useful insights for human science administrators in designing post disaster case management intervention for college orphans (Masten et al., 2014; Sapienza \& Masten, 2011; Ungar, 2014). I used the previous research of Bronfenbrenner $(1977,1986)$ to form the basis for understanding the lived experiences of specialized case management of student-orphans 19 years of age and older enrolled at a rural agricultural university in Sierra Leone and to interpret and find meaning in the inscribed unique experiences. My knowledge of and professional experience with this phenomenon assisted in guiding this transcendental phenomenological research; as such, I bracketed the objective world to understand participants' applied worldviews through the transcendental phenomenology research and utilizing this process of bracketing, I identified the meaning student-orphans ascribed to specialized case management schemes designed for use in post-Ebola Sierra Leone (Band-Winterstein, Doron, \& Naim, 2014; LeVasseur, 2003; Tufford \& Newman, 2012). In the deconstruction of the lived experiences of post-Ebola student-orphans to case management enrolled at a rural agricultural college in Sierra Leone, I engaged 10 research participants identified as having lost both parents to Ebola and recruited through a homogeneous purposive sampling technique (Guarte \& Barrios, 2006). 


\title{
Definition of Key Terms
}

Orphan: An individual losing both parents or primary caregivers or an individual losing the breadwinner and with limited safety net within the extended family system (Stark et al., 2015).

Ebola: A fatal communicable disease accompanied by fever and severe internal bleeding, often transmitted through contact with contaminated bodily fluids (Qureshi, 2016).

\begin{abstract}
Assumptions
I assumed the populations sampled who have lost both parents to the Ebola pandemic would be willing to participate in the qualitative transcendental phenomenological study interview. I assumed the research participants would answer the interview questions honestly based on lived experiences and perceived constructed meanings of specialized case management. Finally, I assumed the sampled population for this study could express personal impressions, feelings, and experiences about post-Ebola case management.
\end{abstract}

\section{Limitations}

The results of this study do not apply to different populations, even to other orphans of disaster in urban Sierra Leone as I concentrated data collection primarily to 10 post-Ebola student-orphans enrolled at an agricultural university in rural Sierra Leone and engaged in specialized case management. Participants were not observed navigating the community, and I relied on answers to interview questions not taking into consideration participants' cultural and other variables such as friends and community 
resources (Lowes \& Prowse, 2001; Shorter \& Stayt, 2010). The selection of research subjects for the transcendental phenomenological study influenced the results (Marshall, Cardon, Poddar \& Fontenot, 2013; Suri, 2011).

\section{Delimitations}

The samples for this transcendental phenomenological study are post-Ebola student-orphans enrolled at a rural agricultural university in Sierra Leone and engaged in specialized case management. Participants collectively experienced loss of parents to the Ebola pandemic and engaged in specialized case management (Wertz, 2005).

\section{Summary}

Case management to post-Ebola orphans is primary to the adjustment for studentorphans enrolled in higher education; the poor understanding of and improper coordination of services has run counter to improving grades and enhancing college graduation (Althaus et al., 2015). Therefore, the poor understanding of human service administrators and disaster managers as to how post-Ebola student-orphans experienced case management affected the design and implementation of such services to the affected population (Masten et al., 2014; Sapienza \& Masten, 2011; Ungar, 2014; Ungar et al., 2013). In this transcendental phenomenological qualitative study, I examined how postEbola student-orphans enrolled at an agricultural university experienced case management.

Chapter 2 includes a comprehensive review of related literature of case management practices to college students and orphans in the post-Ebola reconstruction of Sierra Leone and resources and case management policies with attention to how post- 
Ebola orphans experienced supportive services. This chapter will also include a brief historical outline of orphans and orphanages and disaster in Sierra Leone with current case management practices, resources for clinical intervention in postwar, pre- Ebola and post-Ebola disaster intervention services and a brief review of political influence on case management policies for orphans. 
Chapter 2: Literature Review

\section{Background of the Study}

In this transcendental phenomenological study, I examined how post-Ebola student-orphans experienced specialized case management while enrolled in an agricultural university in rural Sierra Leone. This chapter comprises a review of literature including (a) historical background of orphans and orphanages, including antiquity, midages, and industrial ages; (b) history of orphans and orphanages in Africa, sub-Saharan Africa, and Sierra Leone; (c) crises and disasters in Sierra Leone; (d) timeline of catastrophic events and social support systems in Sierra Leone; (e) postwar educational resources for orphans and students; (f) Sierra Leone's pre-Ebola orphan population; (g) model of case management for orphans and students in pre-Ebola era; (h) post-Ebola case management model for students and orphans in Sierra Leone; (i) alternative placement for orphans in Sierra Leone; (j) clinical case management practices in Sierra Leone; (k) international partnership in disaster case management; (1) traditional and cultural perceptions of coping skills of young adults in Sierra Leone; and (m) political influences that shape disaster recovery programs and policies.

\section{Literature Search Strategy}

The subjects and keywords I examined for this literature review included phrases and words relating to human services, crisis and disaster intervention, social and disaster leadership management, Ebola response, and case management of school and studentorphans. Furthermore, I consulted peer-reviewed journals in child welfare, foster care, and mental health, and seminal sources utilizing multiple databases, including 
SocINDEX, PsycARTICLES, ProQuest Central, Google Scholar, and Thoreau through the Walden University Library system. The review of the literature includes approximately 95 peer-reviewed journals and 100 articles on disasters, case management of disaster victims, the challenges orphans experienced during and after disasters, and the corresponding long-term effects of disasters. The next sections include the orphans and orphanages in three periods: (a) antiquity between 400 A.D. to the 15th century; (b) midhistorical period between the16th century to the 17th century; and (c) the industrial revolution era from 1806-1930, through the agricultural revolution from the 18th century to the 20th century.

\section{Historical Background Orphans and Orphanages}

Wards and children's social living arrangements and legal statuses had taken various regulatory formats for standardization and service delivery (Chui \& Jordan, 2016; Rotabi, Roby \& Bunkers, 2016). Human service managers charged with the responsibility of providing systems for the increasing orphan population adopted orphanages as living arrangements to meet such goals (Nelson, 2011; Winter, 2010). Orphanages, therefore, became the alternative care option for the increasing global population of orphans (Frimpong-Manso, 2013; Porter, 2014). To understand the historical perspective of orphans and orphanages, In the following sections I briefly examined the periods from 400 A.D. to the 21 st century.

\section{Orphans and Orphanages in Antiquity}

The Romans formally started the orphanage model of childcare in 400 A.D.; this prototype of service delivery inspired the development of regulatory policies for the Jews 
to care for orphans (Hacsi, 2013; Nathan, 2012). Fitzgerald (2016) and Hacsi (2013) posited that the Athenian law enacted to support military orphans during the economic decline of the Greek Empire was timely and provided necessary services for the increasing numbers of orphans that resulted from the war. Szreter, Kinmonth, Kriznik, and Kelly (2016) suggested that the Elizabethan Poor Laws charged churches and communities with providing care for needy children. Placement of orphans in orphanages during this period provided relief for orphans and human service managers (Disney, 2017; Efron, 2008).

Between the 960-1279, during the Sung Dynasty, human service administrators in China began feeding children in orphanages, which continued until 1644 when public agencies gained legislative support to sponsor orphanages from the consolidated funds (Wu-Chi, 1953; Pao, 2014). Between 1492 and 1540 Spanish authorities began consolidating resources for indigent children an idea that prompted human service managers in England and the United States to replicate programs for orphans (Gibbs, 2017; Nelson, 2011; Winter, 2010). Religious organizations initiated housing orphans in convents in 1570 and human service managers established the first orphanage in the United States in 1729 to care for orphans due to the conflict between the Native Americans and the Whites in the Natchez region of Mississippi (Webster, Wente, Parris \& Rus, 2017). The Middle Ages of orphans and orphanages between the 16th and the 17 th centuries included a shift in understanding the challenges in service delivery to orphans as discussed in the next section. 


\section{Middle Ages History of Orphans and Orphanages}

In the 16th century, the European states and colonies through the poor and relief administrative managers provided the framework for child care, which allowed France in 1570 to host 280 street children in shelter-like homes identified as orphanages (Broomhall, 2006; Nelson, 2011; Winter, 2010). The framework designed by the European states orchestrated the city orphanages to admit street children between the ages of 6 and 17 (Stoler, 2001). In the late 17th century, with an increase in human suffering, philanthropic actions assisted churches with funds to provide care for orphans (Nathan, 2012; Nelson, 2011). Between 1756 and 1834, the orphan crisis in London became a primary concern for human service administrators. The increase in the orphan population without corresponding design and delivery of social service programs resulted in the creation of workhouses to care for orphans (Nathan, 2012; Trost, 2013). The industrial historical era between 1806 and 1930 of orphans and orphanages appear relevant to understanding the evolving changes in the design of housing for orphans.

\section{Industrial Ages History of Orphans and Orphanages}

The maltreatment of children in workhouses and other similar settings led to an orphanage movement in the 19th century (Guy, 2004; Lorenz, 2016). In the United States, the Orphan Asylum Society established a sanctuary for orphans in New York in 1806 (Boylan, 1984; Netting \& O'Connor, 2016). During the Great Depression in the 1930s, parents abandoned children and wards, which increased the number of children living on the streets and led to the Orphan Train Movement, which transported approximately 150,000-200,000 orphan children to new homes (Chiodo \& Meliza, 2014; 
Riley \& Holt, 1993). The term orphan had been applied very loosely to street children at that time because while some children were true orphans, others did not have caregivers (Agutter, 2016; Shoko \& Ibisomi, 2016). Many children had living parents who lacked the capacity to provide essential support, which resulted in children opting to live on the streets (Frost, 2005; Shoko \& Ibisomi, 2016). While some children ran away from abusive and neglectful parents or caregivers, others left home because of inconsistent care and ended up on the streets, which crowded the field and complicated orphan censuses (Hill, Taylor, Richards, \& Reddington, 2014; Marsh, 2005; Meinck et al., 2017; Shoko \& Ibisomi, 2016).

The rise of poverty and the increasing need for orphans with minimum funds pushed human service managers to use older orphans as cheap labor on farms (Humphries, 2013; Horrell \& Humphries, 1995). The increasingly complex needs for social programs for permanent shelters for the growing number of orphans in the 20th century bred the urge in social service managers to design and place a premium on policies to govern orphanages (Baldwin 2012; Schalk, 2017; Winter, 2010). The complex nature of the orphan population can be understood from the global and regional and local trends of the targeted population.

\section{The Trajectory of Orphan Population}

I reviewed the trend of orphan population and the level of service provided, together with the challenges for human service administrators in the following order: (a) the world trend, (b) sub-Saharan Africa, and (c) the Sierra Leone experience. 


\section{World Orphan Population Trend}

Bourdillon (2017) claimed that poverty is one of the primary contributors for the increase in the global orphan population. As the number of orphans increased, the need for orphanages gained the attention of human service administrators (Humphries, 2013; Horrell \& Humphries, 1995). The world's orphan population has been estimated to be 168 million documented, 153 million orphans registered as orphans receiving some form of social service around the world, 1.2 million trafficked children who remain unconnected to service, and 10 million undocumented orphans (Bryant \& Beard, 2016;

Gray et al., 2016).

\section{Orphan and Orphanages in Sub-Saharan Africa}

Approximately 60 million of the global orphan population live in sub-Saharan Africa, with $27 \%$ of that population resulting from HIV/AID (Balding, Feng, \& Atashband, 2015; Finlay et al., 2016). Gray et al. (2016) advanced that 13-17 million of the global orphans have lost one or both parents or primary caregivers. Orphan and orphanage systems gained prominence in regional policy discussions during the 1990s in sub-Saharan Africa when HIV/AIDS increased the orphan population to 20 million (Balding et al., 2015; Finlay et al., 2016; Kidman \& Anglewicz, 2016). Between 1990 and 2001 Bryant and Beard (2016) posited that the orphan population losing parents to HIV/AIDS in sub-Saharan Africa increased from 3.5\% to $32 \%$.

Characteristically, the orphan population in sub-Saharan Africa falls into the following categories: (a) 0-4 years old orphans composed of $15 \%$ of the total orphan population in sub-Saharan Africa, (b) 5-9 years old orphans made up of 35\% of the 
orphan population, and, (c) orphans over 10 years old composed $50 \%$ of the total orphan population in sub-Saharan Africa (Bryant \& Beard, 2016; Goldberg \& Short, 2016; Kidman \& Anglewicz, 2016).

Poverty accounted for $40 \%-60 \%$ of children becoming orphans in sub-Saharan Africa (Gray, Ariely, Pence \& Whetten, 2017; Govender, Reardon, Quinlan, \& George, 2014; Sinha, Lombe, Saltzman, Whetten, \& Whetten, 2016; Sharer, Cluver, Shields \& Ahearn, 2016). Approximately 570-800 million young adults and children live below the poverty line in sub-Saharan Africa living on $\$ 1.25$ per day on average; $40 \%$ of this population end up as orphans (Bryant \& Beard, 2016; Drah, 2012). Rizk, Rifai \& Aboulghar (2017) suggested that about 150 million street children are not counted in the orphan census. Providing care for the growing number of orphans remains a concern for human service administrators (Gray et al., 2017; Sharer et al. 2016).

\section{Orphans and Orphanages in Sierra Leone}

Orphanages in Sierra Leone began in 1866 when the Missionary Sisters of St. Joseph of Cluny arrived with a mission to strengthen the Catholic faith among newly resettled freed slaves; the first orphanage on Bonthe Island and later in the Moyamba District in the Southern Province marked the new childcare model (Pasura, 2010; Porter, 1953). The original aim of the orphanage was to meet the basic needs of children whose parents believed that through education and Christian values children may become successful in adult life (Akram, Anjum, \& Akram, 2015; Banya \& Fyle, 1995; Caserta, Punamäki, \& Pirttilä-Backman, 2016; Lindenfeld, 2005). However, traditional family belief systems created challenges for orphanage placement — the idea of placing children 
with strangers yielded strong opposition to the new system of childcare (Sanou, TurgeonObrien, Ouedraogo, \& Desrosiers, 2008; Zinn, 2016). The historical events in Sierra Leone provide an understanding of how orphan crises prompted the design of housing, service, and programs for the targeted population.

\section{Brief Historical Events of Orphans and Orphanages in Sierra Leone}

In the early 1780s, after the abolition of slavery, British abolitionist Granville Sharp relocated several freed slaves to the West African coast of Sierra Leone as an experiment with the intention that freed slaves would own properties (Banya \& Fyle, 1995; Kaifala, 2016). Freetown became a refuge for freed slaves, the flow of new occupants without housing and social services promoted street living for orphans (Banya \& Fyle, 1995; Keefer, 2017). In 1896, the British administrators in Freetown imposed a sanction taxing system in an effort to locate housing spaces for the freed slaves, which led to conflict with the chiefs until 1898 resulting in an increase in the orphan population and need for orphanages (Gardner, 2010; Kaifala, 2016). A poor and disorganized formal orphan care system existed during the pre-colonial era in Sierra Leone (Shetler, 2016). Between 1899 and 1960 human service administrators depended on non -governmental efforts to provide care to orphans through religious organizations (Akram et al., 2015; Banya \& Fyle, 1995; Caserta et al., 2016).

Between 1960 and 1962, the street living phenomenon and poor housing conditions quickly became a public concern for human service administrators, and the development of formal government institutions that later become known as approved schools that housed orphans (Fyfe, 1987; Mouser, 2009; Tefera, 2015). Human service 
administrators' poor record-keeping and orphan tracking between 1963 and 1971 mirrored the orphan services (Asogwa, 2012; Tabutin \& Schoumaker, 2004). Sierra Leone's formal orphan system of care gained national recognition in the 1960s, immediately after the country achieved independence from Britain, when human service administrators and legislators realized that the increasing street children phenomenon in the capital city demanded formal intervention (Hounmenou, 2016; Oleke, Blystad, \& Rekdal, 2005; Pratt, 1970). Sierra Leone, human service administrators, modeled the orphan system after an alternative care mechanism termed approved school and residential placement, where orphans enrolled to receive care in an institutional setting (Monasch \& Boerma, 2004; Zeanah, Humphreys, Fox, \& Nelson, 2017). The approved school system of care of orphan - the initial design of orphanages drew criticism from the public and prompted families to withdraw children and wards, which led to the closure of the government-sponsored programs and limited such activities to urban centers (Lautze, Leaning, Raven-Roberts, Kent, \& Mazurana, 2004; Monasch \& Boerma, 2004; Zeanah et al., 2017). The clinical interventions for orphans in orphanages provide an understanding of social services offered in Sierra Leone to the targeted population.

\section{Therapeutic Interventions for Orphans in Orphanages}

Programs for orphans adopted by administrators of orphanages in Sierra Leone provides therapeutic curricula which are delivered through schools, kinship care, or supportive interventions with wrap-around services including mental health, social and life skills training (Forenza, 2016; Schenk, Michaelis, Sapiano, Brown \& Weiss, 2010). Orphanages in advanced economies have organized systems of oversight and regulatory 
policies governing the program operations to deliver comprehensive services to the orphans such as behavioral and clinical needs that meet determined standards than orphanages in developing countries (Bush et al., 2013; Gray et al., 2017; Wolff \& Fesseha, 1998). However, the establishment of orphanages in developing countries like Sierra Leone remained limited to policies and negating personal, social and mental health needs of orphans - such practice with limited therapeutic interventions with opposition to adoption disadvantage the orphans in developing countries (Drah, 2012; Gray et al., 2017). The construct of managing orphanages requires an understanding of complex interconnected elements of child development, history, and regulatory policies (Bhargava \& Bigombe, 2003; Gray et al., 2017). Programs and funding for orphanages in Sierra Leone remain poorly managed, coupled with poorly trained foster care workers, mental health personnel with inadequate physical structures, and, resulting in poor delivery of services to orphans (McCall, 2013; Wolff \& Fesseha, 1998). The affect of crises and disasters on orphans in Sierra Leone provides an understanding of how disaster response managers model types of disasters interventions techniques.

\section{Historical Overview of Crises and Disasters in Sierra Leone}

Sierra Leone has had two types of disasters, natural and man-made. Man-made disasters historically account for most of the disasters that have affected Sierra Leone, including civil unrest, military coups, civil war, and industrial fires (Schleussner, Donges, Donner, \& Schellnhuber, 2016; Sodhi, 2016). Additional man-made disasters include rainforest deforestation, intensive slash and burn methods used in primitive to subsistence farming, water crises, and poor waste management services (Djalante, 2012; Halkos, 
Managi \& Tzeremes; 2015). Nevertheless, Sierra Leone's natural disasters tend to cause significant deaths and result in economic hardships to the population, including children and vulnerable individuals, more often than other disasters, due, in part, to the magnitude of the disasters, poor communication with the vulnerable communities, and poor preparation for such crises (Djalante, 2012; Lumbroso, Brown, \& Ranger, 2016). However, Shultz, Espinola, Rechkemmer, Cohen, and Espinel (2016) posited that hybrid forms of disaster, including one or two types of disaster at the same time, also affect Sierra Leone (see Table 1). 
Table 1

Types of Disaster and Frequency in Sierra Leone

\begin{tabular}{|c|c|c|}
\hline Natural disaster & Percentage affected & Intervention \\
\hline Flooding & $\begin{array}{l}\text { Flooding affects } \\
\text { approximately } 40-70 \text { of } \\
\text { individuals each year }\end{array}$ & $\begin{array}{l}\text { Model includes education, food } \\
\text { distribution through aid and relief } \\
\text { agencies, use of community } \\
\text { resources } \\
\text { for housing displaced persons, } \\
\text { and } \\
\text { grief and loss counseling }\end{array}$ \\
\hline $\begin{array}{l}\text { Wildfires/Industrial } \\
\text { fires }\end{array}$ & $\begin{array}{l}\text { Wildfires and industrial } \\
\text { fires affect } 5-10 \text { of } \\
\text { disaster victims }\end{array}$ & $\begin{array}{l}\text { Encompasses community } \\
\text { education, } \\
\text { food distribution through aid and } \\
\text { relief agencies, community } \\
\text { rehabilitation and compensation, } \\
\text { and } \\
\text { community counseling }\end{array}$ \\
\hline Landslides & $\begin{array}{l}\text { Landslides cause } \\
\text { approximately 8-20 of } \\
\text { disaster deaths }\end{array}$ & $\begin{array}{l}\text { Education of farming practices, } \\
\text { building construction, grief, and } \\
\text { loss } \\
\text { counseling, and regulatory laws }\end{array}$ \\
\hline Storms & $\begin{array}{l}\text { Storms account for } 8-10 \\
\text { of total disaster victims }\end{array}$ & $\begin{array}{l}\text { Includes community education } \\
\text { and } \\
\text { food distribution through aid and } \\
\text { relief agencies }\end{array}$ \\
\hline $\begin{array}{l}\text { Other (riots and } \\
\text { electricity) }\end{array}$ & $\begin{array}{l}\text { Other causes such as } \\
\text { riots and electricity are } \\
\text { responsible for } 0.5-0.8 \\
\text { of disaster victims }\end{array}$ & $\begin{array}{l}\text { Comprises of education, food } \\
\text { distribution through aid and relief } \\
\text { agencies }\end{array}$ \\
\hline
\end{tabular}

Note. Sources: Aitsi-Selmi, Egawa, Sasaki, Wannous, and Murray, 2015; Briand et al., 2014; Chege, 2002; Dumbuya and Nirupama, 2017; Fimbel, 1994; Salama, Laurence, and Nolan, 1999. 


\section{Catastrophic Events and Social Support Systems in Sierra Leone}

Sierra Leone's 7.5 million population has a significant urban dimension, with $48 \%$ living in cities; therefore, disaster relief support remains concentrated in urban centers rather than rural communities (Ali et al., 2016; Hillson et al., 2014; Jefferson \& Buch Segal, 2019; Lynch, Maconachie, Binns, Tengbe, \& Bangura, 2013). Alkire and Santos (2014) and Alkire, Roche, Seth, and Sumner (2015) noted that Sierra Leone's poverty ratio would stay at $70 \%$ with poor social safety nets and social service support systems: the country ranked 176th out of 189 countries measured by social and economic indices. Sierra Leone's disaster response system's close alliance with military operations tends to worry the citizenry; as such, victims of disasters in rural communities remain disadvantaged because of a lack of trust in the army that developed during and after the country's civil war (Bruch, 2017; Hamer et al., 2016).

Sierra Leone's mental health system management is the responsibility of qualified psychiatrist in the Ministry of Health plus a team of poorly trained mental health workers and operates under the guidance of the mental health policy developed in 2010, but remains under-supervised (Bertone, Samai, Edem-Hotah, \& Witter, 2014; Shackman \& Price, 2013). Post-disaster orphans tend to rely on traditional kinship care and community support mechanisms for coping with the new normal and psychological challenges (Bledsoe, 1990; Tambo et al., 2017). Therefore, post-Ebola orphans encountered challenges in harnessing traditional resources because of stigmatization, which increased the vulnerability of the targeted population, including problems of psychological 
maladjustment to grief and loss (Davtyan, Brown, \& Folayan, 2014; Vetter, Kaiser, Schibler, Ciglenecki, \& Bausch, 2016).

Sierra Leone's social support in disaster resettlement largely depends on a crisis mode of intervention, and psychological first aid, with little follow-up care or clinical discharge planning (Ansumana et al., 2015). While food, shelter, and water are critical for sustenance, disaster managers often do not provide for victims' mental and physical wellbeing and other secondary social needs for long-term healing (Abdulmalik, Kola, \& Gureje, 2016; McMahon et al., 2016). Sierra Leone's emergency managers have a poor understanding of how victims experience post-disaster services that are often complicated by poor coordination with NGOs and relief organizations, poor allocation of roles, or lack of clear responsibilities for disaster managers, which confuses rural victims of disasters and prompt reliance on personal efforts in post-disaster reconstructions (Brett \& Guida, 2013; Chouliaraki, 2010; Fullerton \& Ursano, 2005). The effect of a disaster is particularly significant for women, children, and the disenfranchised; however, social support efforts for such populations are not a priority for human service managers in Sierra Leone (Emerson, 2012; Enarson \& Fordham, 2001). Family and community support remain a fundamental component in the post-disaster adjustment building block for victims in Sierra Leone (Adejuwon \& Oki, 2011; Murray \& Jordans, 2016; Ventevogel \& Spiegel, 2015) (see Table 2). The evolving orphan constructs discussed in the next section with relating meanings appear relevant to understanding orphans and orphanages. 
Table 2

\section{Historical Timeline of Disasters and Crises in Sierra Leone}

\begin{tabular}{|c|c|c|}
\hline Historical Event & Orphan Incidence & Support System and Intervention \\
\hline $\begin{array}{l}\text { Small Pox } 1801,1824, \\
1856-1859,1872 \text { and } \\
1905\end{array}$ & $\begin{array}{l}\text { approximately } 800,000 \\
\text { orphans in Sierra Leone }\end{array}$ & $\begin{array}{l}\text { Social services through religious } \\
\text { organizations, government, private } \\
\text { local and international non- } \\
\text { governmental agencies }\end{array}$ \\
\hline Leprosy: in $1840-1849$ & $\begin{array}{l}\text { parental stigma and isolation } \\
\text { resulting in an increase in } \\
\text { the orphan population }\end{array}$ & $\begin{array}{l}\text { Human service administrators } \\
\text { provided leprosy hospitals and } \\
\text { community education, grant in aid to } \\
\text { orphans }\end{array}$ \\
\hline $\begin{array}{l}1870-1880 \text { Malaria } \\
\text { was officially } \\
\text { discovered in Sierra } \\
\text { Leone }\end{array}$ & $\begin{array}{l}\text { Malaria-related illnesses } \\
\text { contribute to } 38 \% \text { of the } \\
\text { death of children and } 25 \% \\
\text { for adults }\end{array}$ & $\begin{array}{l}\text { Malaria control mechanism to enhance } \\
\text { the community outreach including the } \\
\text { supply of nets and drainages }\end{array}$ \\
\hline $\begin{array}{l}1916 \text { Polio Discovered } \\
\text { in Sierra Leone }\end{array}$ & $\begin{array}{l}\text { Polio victims remained } \\
\text { abandoned on the streets }\end{array}$ & Mass Polio vaccination \\
\hline $\begin{array}{l}\text { 1925-1961 fire, } \\
\text { mudslide and civil } \\
\text { unrests }\end{array}$ & $\begin{array}{l}\text { Household earnings } \\
\text { decreased by } 31 \% \\
\text { increase in orphans }\end{array}$ & $\begin{array}{l}\text { Poverty and mechanized farming } \\
\text { subsidies and food for work scheme }\end{array}$ \\
\hline $\begin{array}{l}\text { HIV Discovered in } \\
\text { Sierra Leone in } 1984\end{array}$ & $\begin{array}{l}\text { HIV increased the orphan } \\
\text { population by } 18 \% .32 \% \\
\text { losing parents to HIV/AIDS }\end{array}$ & $\begin{array}{l}\text { Public education through local } \\
\text { traditional town hall meetings, public } \\
\text { health campaigns }\end{array}$ \\
\hline 1991: RUF civil war & $\begin{array}{l}\text { The } 11 \text {-year civil war } \\
800,000 \text { children affected }\end{array}$ & $\begin{array}{l}\text { The accelerated school system, Truth } \\
\text { and reconciliation, increased social } \\
\text { services and employment for youths }\end{array}$ \\
\hline $\begin{array}{l}\text { 2014: Ebola Virus } \\
\text { discovered in Sierra } \\
\text { Lone }\end{array}$ & $\begin{array}{l}\text { Ebola epidemic caused, } 12 \% \\
\text { increase orphans }\end{array}$ & $\begin{array}{l}\text { counseling, grief and loss counseling, } \\
\text { specialized case management }\end{array}$ \\
\hline $\begin{array}{l}2017 \text { Mudslide in the } \\
\text { capital city }\end{array}$ & $\begin{array}{l}\text { Killed } 4000 \text { people } 2 \% \\
\text { increase in orphans }\end{array}$ & $\begin{array}{l}\text { Counseling, housing, and social } \\
\text { services }\end{array}$ \\
\hline
\end{tabular}

Note. Sources: Betancourt, et al.; 2008; Evans \& Popova, 2015b; Frenkel \& Western, 1988; Foege, Millar and Lane, 1971; Grant and Yeatman, 2012; Hanlon, 2005; Osuteye, Johnson \& Brown, 2017; Sim and Mackie, 2017; Zack-Williams, 2001. 


\section{Evolving Orphan Construct}

People use the orphan construct loosely, while this population is sometimes referred to as social orphans, or children and young adults who have lost one or both parents with no caregiver and no connection to social services (Agutter, 2016), other terms for orphans include double orphans, denoting individuals who have lost both parents (Bicego, Rutstein, \& Johnson, 2003; Danhoundo \& Khanlou, 2016). Some also call orphans foundlings (Pullan, 2016; Vassberg, 1998); waifs (Kim, 2010); half-orphans (Muller, Munslow, \& Odempsey, 2015); street Arabs (Cheetham, 2012); and street urchins (Ayub, Kumar, \& Shora, 2016; Lusk, 1992). The outline of Sierra Leone's educational, supportive services offered to orphans in the post-war reconstruction appeared applicable in understanding service delivery in post-disaster intervention schemes to student-orphans.

\section{Post-Civil War Educational Resources for Orphans and Students}

The need for social services for orphans increased in the post-war reconstruction of Sierra Leone which prompted The Demobilization Disarmament and Reintegration Commission (DDRC) and the Truth and Reconciliation Commission (TRC) of Sierra Leone to recommend the development of accelerated education programs to engage young adults, orphans, and street children that included technical education oriented to decrease the high unemployment among the targeted population (Ager, Stark, Olsen, Wessells, \& Boothby, 2010; Fanthorpe \& Maconachie, 2010).

Between 2001 and 2004, of the total of 6,900 schools - private and governmentsponsored, approximately 4,270 primary schools, six technical, 900 secondary schools, 
three teachers' educational colleges, and four tertiary institutions remained unusable (Zuilkowski \& Betancourt, 2014). The poor distribution and allocation of school resources across Sierra Leone immediately after the war affected the attendance as $67 \%$ of primary - school-aged children (ages 6-12) and 80\% of secondary (ages 12-18) and college students (ages 19 and older) remained out of school between 2001 and 2004 (Archibald \& Richards, 2002; Bellows \& Miguel, 2009; Kline \& Mone, 2003). The educational programs in the postwar reconstruction of Sierra Leone included the Complementary Rapid Education for Primary Schools (CREPS), which aimed to make up for lost learning time for primary school children and the Rapid Response Education Program (RREP), targeted younger students (Betancourt et al., 2008; Moyi, 2013). Such programs targeted an accelerated curriculum that accounted for the advancement of 13,529 students between 2001 and 2002 (Zuilkowski \& Betancourt, 2014). Despite the provision of the accelerated education programs in post-war Sierra Leone, orphans continued to have limited access to educational services (Barrios-Tao, Siciliani-Barraza \& Bonilla-Barrios, 2016; Edwards \& Yilmaz, 2016).

Secondly, $40 \%$ of primary school teachers did not have a college education, and the inadequate supply of textbooks with a literacy rate of $60 \%$ among 15 - to 24 -year-olds (Betancourt et al., 2008). The dropout rate for orphans in Sierra Leone was between 2530\% from 2008 and 2012 (Betancourt et al., 2008; González \& Miguel, 2015). Furthermore, secondary school attendance between 2008 and 2012 was pegged at 39.9\% for males and 33.2\% for females (Betancourt, Agnew-Blais, Gilman, Williams \& Ellis, 2010; González \& Miguel, 2015). However, González and Miguel (2015) claimed that 
the postwar educational resources for orphans and students made significant gains, with $77 \%$ of students completing primary school, as compared to $55 \%$ before the war.

Sierra Leone's legislators enacted the Education Act of 2004, which provides for the education of children up to Junior Secondary School (JSS) and accounts for nine years of free education — a developmental benchmark set by the international Millennium Development Goals (MDGs) on education (Johnson, 2008a, 2008b; Nishimuko, 2009). However, the war and the subsequent Ebola pandemic affected the educational system in Sierra Leone, shifting to emergency management programs in establishing essential alternative educational services through radio and television (Gellman, 2015; Kuppens \& Langer, 2016). This mode of delivery for education programs has a limited reach as, in the cities, only 12-16 individuals in every 1,000 own a TV set, which reduces to only 510 in rural populations; furthermore, with inconsistent electricity, TV sets may not be useful (Kamanda, Madise, \& Schnepf, 2016). However, radio audiences are more extensive, with $72 \%$ of the Sierra Leonean population regularly receiving daily news updates on the radio (Jackson, 2007). About 25-30\% of primary-school-aged children remain out of school even with the Education for All (EFA) policy; this setback may be due, in part, to associated charges and surcharges that families could not afford (Briand et al., 2014; Nishimuko, 2009). The post-Ebola educational resources designed for studentorphans in Sierra Leone appears pertinent to provide an understanding of how human service managers intervene in resource allocation. 


\section{Post-Ebola Educational Resources to Student-Orphans}

The Sierra Leone government through the crisis and disaster managers working with local and international partners, initiated several interventions to help post-Ebola orphans and students, including fee waivers, educational supplies, periodic site visits by caseworkers, and group counseling to enhance psychological and emotional wellbeing (Bakare et al., 2016; Chalk, 2017). The assessment conducted by the World Bank for Sierra Leone's post-Ebola needs asserted that the Radio Education Program (REP), organized by the Ministry of Education Science and Technology (MEST), was a successful model of intervention for supportive services to student-orphans (Moon et al., 2017). Challenges remained in the Ebola education delivery program; such as the affordability of radio sets, and often the timing of the transmission conflicted with household chores, farming, trading, and other daily activities (Marais et al., 2015), this minimized the targeted audience (Marais et al., 2015; Moon et al., 2017). The program became a learning tool for student-orphans (Marais et al., 2015; Moon et al., 2017). The REP broadcast five days a week on local FM bands in 30-minute increments for core curricula in math, English, and civic education (Marais et al., 2015). However, REP anchors' and presenters' accents posed a challenge to the listening audience (Marais et al., 2015; Moon et al., 2017). In support of the program, the United Nations International Children's Emergency Fund (UNICEF) staff, a partner in the community and investor for education, provided 25,000 radios to communities, which helped to relieve the challenge of affordability for many individuals (Romero, 2015). Investing in REP-type programs, online education, improving the radio signals to include a wider audience like rural Sierra 
Leone, and providing subsidies for batteries may benefit student-orphans during crises and disasters (Comfort, Bert, \& Song, 2016; Jiménez, Mediavilla, Portús, López, \& Vicente, 2015).

There are limited programs for orphans in higher education, although college readiness services, including tuition waivers, and school supplies from post-Ebola intervention provide relief to college orphans (Shetty \& Powell, 2003). The poor national budget's funding for education and inconsistent private sponsorships remains the primary reasons for the lack of programs in college education for orphans (Banya, 1991; Betancourt et al., 2008; Martin \& Zulaika, 2016). Sierra Leone, human service administrators, spend $2.83 \%$ of the national GDP on education, but tertiary education spending increased from $17.93 \%$ of education spending in 2011 to $25.93 \%$ in 2013 ; however, the percentage allocated to primary schools fell from $52.56 \%$ in 2011 to 48.86\% in 2013 (Kamanda, 2016; Betancourt et al., 2008). Disparities in access to education in Sierra Leone affect vulnerable individuals, including female students, rural people, and orphans, with the gaps widening at the higher education level (Dabalen et al., 2014; Miyagishima, 2016). The orphan population trends between 2008 and 2016 provide an understanding of the affect of Ebola on the targeted population in Sierra Leone.

\section{Sierra Leone's Pre-Ebola Orphan Population}

An estimated 340,000-400,000 orphans existed in Sierra Leone between 2008 and 2013; the available data on orphans indicated that $30 \%$ lived in extreme poverty and or on the streets (Evans \& Popova, 2015a). The orphan's census in Sierra Leone may not be 
accurate due in part to the traditional family system of child care, poor record keeping by human service administrators and complex orphan reporting system (Asogwa, 2012;

Evans \& Popova, 2015a; Shaman, Yang, \& Kandula, 2014).

\section{Pre-Ebola Model Case Management for Orphans and Students}

This section includes a brief overview of the case management model in the preEbola intervention scheme for student-orphans in Sierra Leone. After the postwar intervention, the authorities reduced the case management protocol in Sierra Leone to regular social services and redirected funding for postwar efforts at community rehabilitation, including water supplies, school reconstruction, road resurfacing, and community health centers (Maclure \& Denov, 2009; Svärd, 2010). The unemployment rate for young adults remained at $70 \%$, access to healthcare remained at $20 \%$, and education access remained at 40\% (Abdullah, 2002; Richards et al., 2015; Elston, Cartwright, Ndumbi \& Wright, 2017). A phenomenon known as the youthman problem re-emerged (Richards et al., 2015; Wai, 2015). The youthman term refers to unemployed, young adults - school dropouts with a high-school education who gather on the streets to harness resources to survive through music and soccer (Shepler, 2010; Wai, 2015).

Illiteracy and school dropout rates remained high, among orphans in Sierra Leone (Barrios-Tao et al., 2016; Betancourt, Borisova, Soudière \& Williamson, 2011). Because of economic turndowns, legislators did not find funds to manage job skills programs or partially funded some programs including free education for orphans (Betancourt, Borisva et al., 2010; Novelli \& Higgins, 2016). 
Less than $40 \%$ of the population has access to health care, and the mortality rate is among the highest in the world, with orphans experiencing less access to health care and dental care, and higher occurrences of early death than the rest of the national population (M'Cormack-Hale \& McGough, 2016; Trani et al., 2011). Approximately $26 \%$ of the Sierra Leone orphan population has access to services, while $74 \%$ remain unconnected to core services; $70 \%$ of the orphan population have limited access to mental health services, while $30 \%$ may be linked to some form of clinical services (Betancourt, et al., 2011; Sharma, Fine, Brennan, \& Betancourt, 2017). Additionally, 61\% of the orphan population is engaged in some form of education, but orphans experience $30-45 \%$ school dropout rate in the nation as compared to non-orphans (Ainsworth \& Filmer, 2006; Beegle, Weerdt, \& Dercon, 2006; Dorsey et al., 2015; Greenaway \& Heckert, 2013). The next section addresses the case management model for students and orphans in the postEbola reconstruction of Sierra Leone (See Table 3). 
Table 3

Case Management to Post-Ebola Student-orphans in Sierra Leone

\begin{tabular}{|c|c|c|}
\hline Orphan population & Case management & Regions affected \\
\hline $3,300-12,030$ & $\begin{array}{l}\text { Tracking, monitoring, } \\
\text { isolation of suspected } \\
\text { cases. Public } \\
\text { education, design, and } \\
\text { distribution of resource } \\
\text { centers, counseling, } \\
\text { burial intervention. } \\
\text { Also, specialized case } \\
\text { management including } \\
\text { fee waiver, college } \\
\text { resources for student- } \\
\text { orphans remained part } \\
\text { of the intervention } \\
\text { protocol }\end{array}$ & $\begin{array}{l}\text { The South-Eastern regions and } \\
\text { three districts in the Northern } \\
\text { region and the capital city } \\
\text { Freetown. }\end{array}$ \\
\hline
\end{tabular}

Note. Sources: Anebonam and Ossai, 2016; Buseh et al., 2015; Clark et al., 2015; Evans \& Popova, 2015a; 2015b; Team, 2014

Child placement in Sierra Leone including, (a) traditional kinship care placement, (b) the role of local chiefs and secret societies, and (c) the role of government in orphan placement may provide an understanding of the complex interconnected role of the subsystems in child development and breeding examined in the ensuing sections.

\section{Orphan Alternative Care Placement}

Social service managers concerned with the safety of orphans often look for stable housing through orphanages, as this type of model of care is often a solution to the increasing social problem of housing orphans without addressing the underlying issues of poverty, child abuse and neglect, mental health, and physical health (Jones, 1993; Zeanah et al., 2017). In the short term, this solution reduces the pressure on human service 
administrators to provide comprehensive and intensive social services to enhance the support system for family reunification (Allen \& Vacca, 2011; Petrowski, Cappa, \& Gross, 2017). Orphanage living has an adverse effect on child development, with some exhibiting delayed development, physical stunting, low intelligence, and psychological damage, whereas others may exhibit trauma associated with orphanage living for an extended period (Balding et al., 2015; Finlay et al., 2016).

\section{Traditional Kinship Care Placement: Sierra Leone}

Kinship care is when the child lives with relatives other than biological parents, and this is popular with grandparents and economically stable relatives (Borenstein \& McNamara, 2012; Kiraly \& Humphreys, 2013). Kinship care in Sierra Leone is a central and intricate part of the transfer of cultural norms and traditions, as well as a way of fostering family ties and or bonds between and within generations, and, as such, the traditional authorities only consider institutional placement as an alternative option (Bledsoe, 1990; Roelen, Delap, Jones, \& Chettri, 2017; Swanke, Yampolskaya, Strozier, \& Armstrong, 2016). Although human service professionals usually recognize traditional kinship care, though statutory laws and policies neither sanction nor regulate such model of child care, as a viable, alternative system of child care when compared to the limited, government-operated programs for fostering and orphanages, which are primarily in urban centers in Sierra Leone (Bellows \& Miguel, 2006; Roelen et al., 2017).

\section{Tribal Characteristic of Child Placement in Sierra Leone}

The cultural and traditional practices of the 15 tribes in Sierra Leone are an important element in the planning of post-disaster intervention and case planning for 
orphans, because each culture has implicit preferences for placement and child care includes characterizations of child placement (Abramson et al., 2015; Measham et al., 2014) (see Table 4).

Table 4

Tribal Characterization for Child Placement in Sierra Leone

\begin{tabular}{|c|c|c|}
\hline Tribes & Population percentage & Preference for child placement \\
\hline Mende & 32 & $\begin{array}{l}\text { Reject placing children with } \\
\text { strangers }\end{array}$ \\
\hline Temne & 31 & $\begin{array}{l}\text { Open to placing children out of the } \\
\text { traditional family system }\end{array}$ \\
\hline Limba & 8 & $\begin{array}{l}\text { Believes that children belong to the } \\
\text { community accept placement }\end{array}$ \\
\hline Kono & 5.1 & $\begin{array}{l}\text { Maintains strong familial ties with } \\
\text { caregivers of orphans. }\end{array}$ \\
\hline Kuranko & 4.4 & $\begin{array}{l}\text { As a result of the strictly religious } \\
\text { adherence of tribal group children } \\
\text { are easily placed in care. }\end{array}$ \\
\hline Fulani & 3.8 & $\begin{array}{l}\text { Share the same belief as the Kuranko } \\
\text { tribal individuals }\end{array}$ \\
\hline Others & 15.7 & $\begin{array}{l}\text { Comprises the other nine tribes and } \\
\text { cultures each accounting between } 1- \\
2 \% \text { of the national population }\end{array}$ \\
\hline
\end{tabular}

Note. Sources: Dorjahn, 1966; Forehand and Kotchick, 2016; Gamble, 1963; Hareven, 2015. 


\section{Role of Local Chiefs and Secret Societies in Sierra Leone}

The Sierra Leonean cultural groups identify with secret societies and local tribal authorities, and the influence of such institutions on the welfare of the child continues to evolve. This section will briefly examine the role of local chiefs and secret societies on the welfare of student-orphans. The Sierra Leonean cultural lineage is central to the welfare of orphans in rural communities of Sierra Leone, as this incorporates traditional practices such as the role of Paramount Chiefs in handling and resolving domestic violence, foster care placement, and nomination of parental proxies (Fanthorpe, 2006, 2010). Furthermore, traditional secret societies; a central piece of cultural hegemonies, have considerable power and influence in child placement (Yovsi, 2013). However, because of the mysterious nature of the traditional societal institutions, comprehensive assessment and implication of child placements may be difficult, which complicates the inclusion of such systems under regulatory policies in Sierra Leone (Acemoglu, Chaves, Osafo-Kwaako, \& Robinson, 2014; Bledsoe, 1990; Yovsi, 2013).

\section{Role of Government in Foster Care Programs in Sierra Leone}

The Ministry of Social Welfare, Gender and Children's Affairs is the primary overseer of government-funded programs for orphanages in Sierra Leone, and staff monitors the treatment of orphans to try and prevent abuse and neglect (FrimpongManso, 2013; Motha \& Frempong, 2013). The government's social programs for orphans remain centralized in major cities (Bourdillon, 2017; Monasch \& Boerma, 2004). There are limited government-operated and sanctioned programs in Sierra Leone for young adult orphans (Bledsoe, 1990; Richards, 1996; Thurman, Kidman, \& Taylor, 2015). 
Furthermore, local and international organization staff provide funds through religious and or non-governmental organizations (NGOs) and relief organizations to deliver programs for orphans (Baldé, 2011; Kanyako, 2011; Zuilkowski \& Betancourt, 2014). However, the increase in the post-Ebola orphan population overwhelmed the traditional family system and other private agencies, resulting in human service administrators to operate specialized case-management services for orphans in higher education through partnerships with international organizations (Lee-Kwan et al., 2014; Cancedda et al., 2016; Peter, et al; 2016).

Sierra Leone's traditional family systems in child care presented challenges in implementing government-sponsored foster care systems due to the trust issues between the government and families; parents prefer community-extended family care for orphans; therefore, the numbers of reported orphans in rural communities may be less than the numbers in urban communities (Caserta et al., 2016; Madhavan, 2004). However, the Ebola-increased orphan population presented an unexpected challenge to the extended family system, and disaster managers designed new programs; such problems exacerbated the already reduced resources, fear, and stigma associated with Ebola and poor resource allocation (Ali et al., 2016; Folayan, Haire, \& Brown, 2016). The clinical case management protocol in Sierra Leone may provide an understanding of the coordinated continuum of care with both internal and external partners.

\section{Clinical Case Management Practices in Sierra Leone}

The case-management model used in Sierra Leone continues to be formatted in group session like a town hall-style - where participants gain support from each other 
with a trained facilitator who may follow up with victims and provide referrals for services or advanced clinical care (Muriuki \& Moss, 2016; Weinmann \& Koesters, 2016). In post-disaster case management like the Ebola crisis, World Health Organization (WHO) employees and other multinational partners provide mental health and psychosocial support to post-disaster victims, offer guidance to stakeholders responsible for planning, and advocate and monitor social systems to build a resilient mental health system during the reconstruction of communities (Yoder, Tol, Reis, \& Jong, 2016). WHO staff also assisted in training Health Care Workers (HCWs) through the mental health Gap Action Program (mhGAP) and offered Humanitarian Intervention Guide (HIG) communication skills, compassionate community engagement, psychological first aid, and cultural diversity training (Betancourt et al., 2016).

In Sierra Leone, the Ministry of Health and Sanitation (MoHS) monitors the established clinical case-management protocol, in close collaboration with the Ministry of Social Welfare, Gender, and Children's Affairs, charged with the obligation to monitor, license, regulate, and promote clinical case-management practices and to enhance collaboration with partners including NGOs (Bennett et al., 2014; McMahon et al., 2016). The multi-level integration and sharing of responsibilities by government functionaries including the Ministry of Justice, Ministry of Education, and law enforcement presents a challenge and can create bureaucratic setbacks when designing standardized case-management protocols (Ben-Arieh, 2010; Krueger, Thompstone, \& Crispin, 2013). The nature of the mixture of a local and international approach to crises intervention in Sierra Leone may be understood by the interactions between the 
international communities and disaster response managers in post-disaster case management intervention.

\section{International Partnership in Disaster Case Management}

Local and international NGOs work in close concert with national authorities, using the psychological first aid model and the mental health continuum of care to provide case management to disaster victims, orphans, and domestic violence victims (McDonald, 2010; Rapeli et al., 2017). However, complex, traditional cultures present resistance to care; case managers often confer with traditional authorities before committing to fundamental case management protocols (Lemarchand, 2013, 2005; McDonald, 2010). The respective ministries work to build partnership with international and local organizations, to supervise treatment plans and to coordinate the activities of orphanages, foster care programs, and child welfare regulatory operations; however, there is a poor central mechanism to hold individuals and organizations accountable when deficiencies occur in orphanages (Fluke et al., 2012; Krueger et al., 2013). The traditional views of Sierra Leone may provide an understanding of the cultural perception of gender role and coping skills of young adults in crises and disasters.

\section{Traditional Perceptions of the Coping Skills of Young Adults in Sierra Leone}

Societal expectations of young adults vary based on culture, country, and gender; while societal members assume Sierra Leonean young adult males to maintain a masculine nature and sees females as mothers and housewives (Alesina, Giuliano, \& Nunn, 2013). Societal and cultural beliefs call for young adults to maintain independence regardless of economic readiness, psychological, and emotional stability of young adults 
(Alesina et al., 2013; Staab, 2016). Sierra Leone's communal living and interrelatedness do provide ongoing supports, and inbuilt social capital at community and family levels and such traditional practice assist with farming and living arrangements (Fanthorpe \& Maconachie, 2010; Zulu \& Wilson, 2012).

The Sierra Leone traditional members believe that children remain community progenies, seemingly regardless of age and the social status, this view cuts across traditional tribes and cultures in Africa (Betancourt et al., 2008; Verhoef, 2005). Young adults who may have little education and leave school with poor social skills and without a primary source of income have fewer opportunities for employment; therefore, becoming independent involves facing severe challenges, and such young people instead rely on networks for survival including friends and families (Dercon, 2002; Zulu \& Wilson, 2012). Young women may rush into marriage to seek the protection and supportive mechanisms imbued in the relationship; whereas young men struggle with the transition to adulthood and opt to relocate from rural communities to cities in the search for opportunities (Collinson, 2010; Thieme, 2017). The evolving clinical interventions to student-orphans in post-Ebola Sierra Leone may provide an understanding of the continued struggle with grief and loss (Murray, Drew, Memmott, Bangura \& Maring, 2017; Sprecher, Herp \& Rollin, 2017).

\section{Struggle with Loss and Emotional Needs}

The social and emotional complexities present in the post-Ebola coping system for student-orphans pose challenges to core functioning of this population, including coming to terms with loss, adjusting to the new normal, balancing school and self-care, 
and maintaining links with traditional communities (Davis, Wilson, Brock-Martin, Glover, \& Svendsen, 2010; McManus \& Saucier, 2012). The means of healing and recovering from a disaster-related trauma varies from client to client; however, there are interwoven variables that may augment recovery, including post-disaster coping skills, the level of social support, and the type and level of catastrophe (Goenjian et al., 2005; Kadak, Nasıroğlu, Boysan, \& Aydın, 2013).

The emotional challenges student-orphans face may lead to secondary effects including physical health issues, behavioral problems, anxiety, sleep and eating disorders, depression, and posttraumatic stress disorder (PTSD) (Rivera \& Kapucu, 2015).

However, Jaycox et al., (2010) posited that a brief reaction to trauma is common and may heal over a short period without clinical intervention. The apparent recovery from the trauma exposure without clinical intervention might indicate an incomplete adjustment to the disaster, like grief and loss of friends, family, and possessions may linger (Greca, Silverman, Lai, \& Jaccard; 2010; Neal \& Neal, 2013; Salloum \& Overstreet; 2012). Postdisaster victims who enrolled in college may suffer from poor concentration or experience social withdrawal, which may affect school performance and graduation (McManus \& Saucier, 2012; Roberts \& Hitchcock, 2017). Somatic reactions remain with young adults in post-disaster adjustment as such expression of internalized feeling and emotions are difficult (McManus \& Saucier, 2012). Culture and gender may also modulate the reactions, expression of feelings, and help-seeking patterns of victims (Davis et al., 2010). The anxiety and depressive episodes in post-disaster behavioral expressions continue as orphans and students struggle with and remain anxious about the 
future threat to personal welfare, loss of home, possessions, and lifestyle (Hewlett \& Hewlett, 2005; Salloum \& Overstreet, 2008). The roles of politics in shaping postdisaster policies remain an intricate part of the program that may affect post-disaster orphans in Sierra Leone.

\section{Political Influence on Policies Affecting Post Disaster Orphans}

The role of government, through the direct and indirect functionaries such as human service administrators and disaster managers in policy design, practice guidance, and program implementation, remains essential in disaster preparedness, intervention, and reconstruction (Frieden et al., 2014; Jackson, 2007). Such political influence may include the identification of vulnerable communities and individuals, and resource mapping in pre-disaster planning, education, and prevention (Frieden et al., 2014). Human service administrators need to draft and deliver such services in languages and culturally sensitive media that community members understand (Omelicheva, 2011; Pelling \& Dill, 2010). However, the role of politics in planning disaster management policies often evolves based on needs, type of disaster, the magnitude, and level of disaster (Cancedda et al., 2016; Cavallo \& Ireland, 2014; Madsen \& O’Mullan, 2016). The level and degree of innovation in disaster planning and management depend on the strategic plan, implementation, budgetary allocations, design and delivery, training personnel, and decentralization of command structures with logistics and leadership (Laverack \& Manoncourt, 2016; Moon et al., 2015). 


\section{Summary}

The literature review contains, (a) the historical background of orphans and orphanages in antiquity covering the period between $400 \mathrm{AD}$ to 1540 , the mid-ages from the $16^{\text {th }}$ century to the $17^{\text {th }}$ century, and the industrial ages from the $17^{\text {th }}$ century to the $21^{\text {st }}$ century, (b) the orphan population trajectory with emphasis on the global, subSaharan African and Sierra Leone trends, (c) the affect of crises and disasters on orphans and the services offered by human service administrators in post-disaster intervention, (d) educational services and resources provided to student-orphans in post-disaster Sierra Leone, (e) alternative orphan placement in Sierra Leone, and (f) the role of government and non-governmental organizations in service delivery to orphans in Sierra Leone. Chapter 3 includes the research methodology for the transcendental phenomenological study. 
Chapter 3: Research Method

\section{Background}

This transcendental phenomenological study related to how post-Ebola studentorphans experienced specialized case management during a 2-year period while enrolled at a rural agricultural university in Sierra Leone. The use of a transcendental phenomenological research method allowed me as researcher to experience the phenomenon through understanding the case management experiences of post-Ebola student-orphans (Butler-O'Halloran, \& Guilfoyle, 2015; Forsman, 2015; Moustakas, 1994). The results of this transcendental phenomenological study provided useful insights for human service administrators and foster care providers, as well as for disaster managers who design and manage post disaster case management intervention for orphans and students in higher education (Masten et al., 2014; Ghali, 2014). The sections to follow include the research methodology, justification of the methods, purpose, research question, theoretical frameworks, the process of participant selection, the role of the researcher, and validity, reliability, and ethical considerations.

\section{Research Methodology}

For this transcendental phenomenological research method, I elicited the lived experiences of post-Ebola student-orphans who received specialized case management while enrolled at a rural agricultural university. The justification of the methodology and research purpose provided the fundamental yardsticks to understand the research methods for this transcendental phenomenological study. 


\section{Justification for Method}

For this transcendental phenomenological study, I examined the lived experiences of student-orphans of post-Ebola case management as this method provided a lens for considering this social phenomenon from diverse perspectives (see Armour, Rivaux, \& Bell, 2009; Giorgi, 1997, 2012; Moustakas, 1994; Pereira, 2012). The transcendental phenomenological research method appeared to be the appropriate instrument to explore how student-orphans experienced post-Ebola specialized case management. By using transcendental phenomenological research methods to guide this study, I was able to analyze how student-orphans in higher education experienced post-Ebola case management (see Flood, 2010; Giorgi, 2012, Moustakas, 1994). Additionally, this method provided the opportunity to uncover themes across the research subjects' experiences (Moustakas, 1994; Sterett, 2015; Wertz, 2005; Winn, 2016). In summary, this design provided the mechanism to understand how post-Ebola student-orphans experienced specialized case management (see Butler-O'Halloran, \& Guilfoyle, 2015; Moustakas, 1994; Park \& Kim, 2015). Transcendental phenomenological design for this study allowed for the opportunity to examine and manage personal worldviews, focus on the phenomenological wholeness from the lived experiences as advanced by the research subjects, search for essence and meaning of the experiences through the re-storying of the individual's unique experiences, and, obtain individualized accounts of the phenomenon (Moustakas, 1994). The ensuing construct includes potential uses of this transcendental phenomenological study of how post-Ebola student-orphans experienced specialized case management. 


\section{Purpose}

For the transcendental phenomenological study, I explored the lived experiences of post-Ebola orphan-students enrolled at a rural agricultural university in Sierra Leone and engaged in a specialized case management intervention intended to enhance college grades and promote graduation. The information benefits human service program administrators and foster care providers as well as governmental and nongovernmental organizations to design post disaster intervention services and social support systems for the orphan population to promote college graduation and improve grades. Furthermore, the findings of this research supported an understanding of how post-Ebola orphans experienced case management supportive services while enrolled in college (Buseh et al., 2015; Evans \& Popova, 2015b). The findings of this research helped in understanding how post disaster student-orphans experienced case management support services while enrolled in college (Berry \& Finnoff, 2016; Buseh et al., 2015; Hamblen, Norris, Symon \& Bow, 2016; Peter et al., 2016; Ssewamala, Karimli, Han \& Ismayilova, 2010). The next section contains the research question I used to inquire as to how post-Ebola studentorphans experienced case management

\section{Research Question}

The research question for this transcendental phenomenological study was: What are the lived experiences of post-Ebola orphan-students engaged in case management activities while enrolled at a rural agricultural university in Sierra Leone? The theoretical framework is an integral part of the research design (Yüksel \& Y1ldırım, 2015); the framework for this study is contained in the next section. 


\section{Theoretical Frameworks}

The theoretical frameworks for this transcendental phenomenological study was based on my ontology and EST. As a researcher, I see the world and make sense of its constructs to form my own perceptions and belief system, which determines how I interpret worldviews (Moustakas, 1994). Postpositivist ontology and ecological system theory provided unique perspectives that channeled and helped with answering the research question and additionally modulated how I analyzed data (Bronfenbrenner, 1977; Moustakas, 1994). Additionally, I subscribed to social-ecological theory, which provided a baseline approach to understanding the linkages between individual interactions with the environment and informed my thinking like an analyst for this transcendental phenomenological study.

\section{Transcendental Philosophical Viewpoint}

The exploration of the lived experiences of post-Ebola student-orphans includes a philosophical construct; transcendental philosophy provided insight into the lived experiences of student-orphans regarding specialized case management provisions in the post-Ebola reconstruction of Sierra Leone (Padilla-Díaz, 2015; Yüksel \& Y1ldırım, 2015). I examined the understanding of post disaster case management from individuals who lived the experience (Flood, 2010; Sadala \& Adorno, 2002). As researcher and analyst for this transcendental phenomenological study, I view the world through certain lenses and make sense of reality based on certain constructs; as such, attempting to understand the lived experiences of post disaster student-orphans regarding specialized case management can be explained by how individuals with this experience view and 
interpret that world (Moustakas, 1994). To help in explaining my worldviews, the next sections outline the anticipated post positivistic analysis of this transcendental phenomenological study.

\section{Postpositivist Viewpoint}

In experiencing the deductive worldview as a human service professional, data collector, and analyst for this transcendental study, postpositivist constructs related to how causal linkages and environmental factors including social relationships, peers, schools, families, and friends influence behavior and thought processing (Charnley et al., 2017; Wasserman, Chatlosh \& Neunaber, 1983). Moustakas (1994) and Benedetti, Cohen, and Taylor (2013) posited that researchers with postpositivist ontological worldviews should: (a) be mindful of personal biases that may cloud the meaning of the phenomenon from the research-participants viewpoints, (b) account for how the investigators' knowledge and worldviews on social phenomenon based on different personal experiences may play a role in presenting social issues, and (c) relate to the investigators' knowledge of the phenomenon under review directly and in a varied manner to different environmental constructs. As such, as principal investigator with the postpositivistic ontological construct, I interpret the world around me by using causal linkages with environmental paradigms (Charnley et al., 2017, Moustakas, 1994). A postpositivist ontological viewpoint includes my experience as a human service professional seeking to understand the world through the lived experiences of how post-Ebola studentorphans experienced specialized case management (Fischer, 1998; Scotland, 2012). Post positivistic ontology allowed me to experience the authenticity of specialized case 
management with the understanding that such realities directly interface with limitations of the environment, personal worldviews, and sensory constructs (Clark, 1998; Moustakas, 1994). In addition to my personal ontological viewpoint, the EST provided an understanding of how environmental linkages influence human behavior in post disaster reconstruction as examined in the next section.

\section{Ecological System Theory}

The understanding of the lived experiences of post disaster intervention is a complex process that is interwoven with several factors including (a) past experiences with disaster, (b) coping skills, (c) environmental factors, and (d) support systems (Aldrich, 2017; Blosnich \& Bossarte, 2011; Shibl, Lawley \& Debuse, 2013). Bronfenbrenner's (1977) EST is an integrative, multilevel framework that contains the explanatory potential for understanding the interfaces and affects of lived experiences of post disaster victims (Abramson et al., 2015; Marín, Bodin, Gelcich \& Crona, 2015). EST contains descriptions of influences of human behavior on multiple levels: (a) thought processing (cognition), (b) the internal and expressed feelings (affect), (c) the will to accept the new life (volition, conation), and (d) the expressed explicit behaviors for survival (Bronfenbrenner, 1977,1986; Masten \& Narayan, 2012; Masten \& Obradović, 2008; Ostrom, 2009). EST characteristics become obvious due to the following interrelationships and attributes: (a) the environmental impress on the individual together with the influence of the individuals on the environment, (b) responses from feedbacks from interactions with the environmental factors due to the evident behaviors, (c) transactions with components in the systems and interpretation of such feelings, and (d) 
biological and spiritual dimensions (Bronfenbrenner, 1977, 1986; Castelfranchi, 2015; Masten, 2011; Masten, 2014; Norris, Stevens, Pfefferbaum, Wyche, \& Pfefferbaum, 2008). Given the multifaceted nature of the interrelationship between the environment and individual behaviors, EST appeared appropriate for this transcendental phenomenological study in exploring how student-orphans experienced post-Ebola specialized case management (see Bronfenbrenner, 1977).

EST theorists divide the environment into different facets, or levels, each of which uniquely influences the individual in life adjustment in post disaster construction; such levels include the mesosystem, the ecosystem, and the macrosystem (Boon, Cottrell, King, Stevenson \& Millar, 2012; Masten \& Obradović, 2008; Masten, 2014). The use of EST explained the intricate roles including the immediate environment, social network, social and cultural values, and changes in the new normal in the post-Ebola recovery experiences of student-orphans, as well as on the coping mechanisms adopted in postEbola recovery endeavors (see Bronfenbrenner, 1977; Burns, et al., 2015). The use of EST also complemented the transcendental phenomenological methods employed in this study by providing a lens for understanding how individuals in the natural community interrelate with core and subsystems to enhance efficacy in overcoming challenges with schools, communities, peers, and families (see Bronfenbrenner, 1977, 1986; Burns et al., 2015; Fivush \& Merrill, 2016; Garbarino, 1980). The next section provides the participant search for this transcendental phenomenological study, including, (a) participant search, (b) participant contact, and (c) sampling. 


\section{Participant Search}

For this transcendental phenomenological study, as the primary data collector, I contacted the university faculty of the Rural Agricultural University (pseudonym) in Sierra Leone and secured the list of the case management of individuals engaged in the post-Ebola specialized intervention (see Appendix A). I obtained permission to conduct this study from university faculty. I secured the IRB approval in lieu of the letter of cooperation (see Appendix B) from the agricultural university to initiate contact with potential research participants. Additionally, I secured IRB approvals from Walden University and the Sierra Leone Ethics Board (see Appendix C and D).

\section{Participant Contact}

I initially relied on the list provided by the university registrar and or faculty to make contact with potential participants via, (a) e-mail, (b) texting, and or (c) telephone. In this initial e-mail, text and or phone call, I explained the purpose of the study, provided information about confidentiality, and informed the participant of potential benefits and risks associated with participating in the study. The next section outlines the sampling techniques used for this transcendental phenomenological study.

\section{Inclusive Criteria}

From the pool of potential participants, the following predetermined criteria formed the premise to recruit research participants for this transcendental phenomenological study, (a) student lost both parents to the 2014-2016 Ebola outbreak, (b) student is 19 years of age or older, (c) student is enrolled at a specific agricultural 
university in rural Sierra Leone, and (d) student is engaged in specialized case management at agricultural university.

\section{Sampling}

Moustakas (1994) and Hartmann-Boyce, Boylan, Jebb, Fletcher, and Aveyard (2017) suggested that the sampling techniques for a transcendental phenomenological study targets the interpretation of collected data from data-rich sources that gave meaning to the phenomenon under review. The sampling techniques used for this transcendental phenomenological study to examine how post-Ebola student-orphans experienced specialized case management provided an understanding of how case management was experienced by research subjects.

\section{Sampling Techniques: Criterion and Snowballing}

For this transcendental phenomenological study, to explore how post-Ebola student orphans experienced specialized case management, I used the list provided by the registrar to target research participants by using contact information to employ the criterion sample technique. Although snowball sampling techniques was part of the sampling strategies I did not use it as I achieve theoretical saturation with criterion sampling technique. The sample for this transcendental phenomenological study includes post-Ebola orphans-students enrolled at a rural agricultural university in Sierra Leone and engaged in specialized case management (see Figure 1). Moustaska (1994) and Malterud, Siersma, and Guassora (2016) claimed that at least three research participants with information power about a phenomenon are sufficient to explore the lived experiences of a phenomenon. The targeted sample size of ten participants falls within the suggested 
guidelines proposed by Moustakas (1994) and Simpson and Che (2016) claiming that for phenomenological studies the sample size falls between 5-25 research subjects. Search for research participants did not continue after reaching point of theoretical saturation (Cleary, Horsfall \& Hayter, 2014).

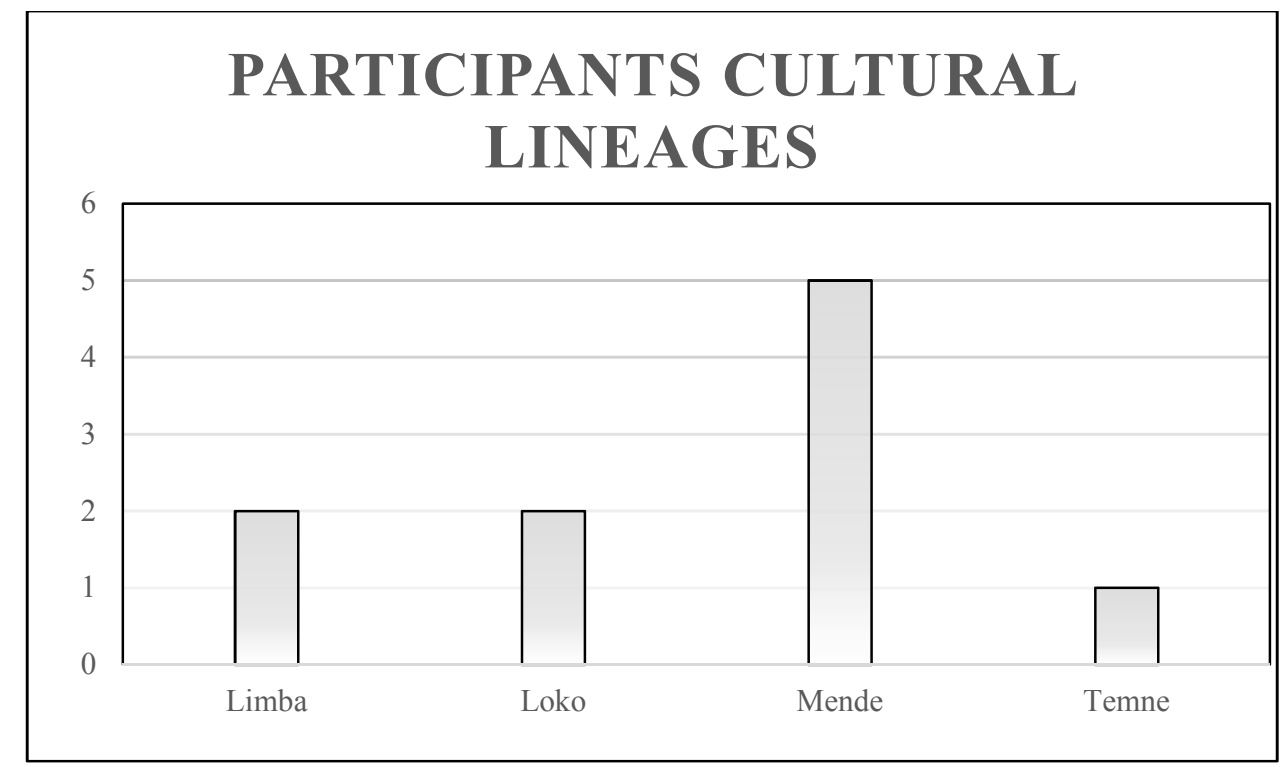

Figure 1. Cultural attribution of research participants.

\section{Criterion Sampling}

The targeted population for this transcendental phenomenological study includes individuals who, (a) lost both parents to the 2014-2016 Ebola in Sierra Leone, (b) engaged in post-Ebola specialized case management at a rural agricultural university, and (c) are between the ages of 19-35 years old. For this transcendental phenomenological research, I used the criterion sampling model to sample for potential research subjects (see Figure 2). Palinkas et al. (2015) argued that the criterion sampling technique might give the researcher individuals with experience of the phenomenon under review. Suri 
(2011) claimed that for phenomenological studies, research participants have to possess the lived the experienced under review. Participants with the knowledge of the phenomenon under review communicated the lived experiences in an articulate manner and with an increased reflective capacity of the phenomenon (Palinkas et al., 2015).

Additionally, Goodman-Scott, Carlisle, Clark and Burgess (2016) noted that in phenomenological research, the emphasis is on the population that provides a deeper understanding of the phenomenon under review to collect reflective descriptions, making meaning of the lived experiences and interpreting essences rather than recruiting more research participants to be able to make generalizable statements. To make sure that potential research subjects have knowledge of the lived experience, I used inclusion criteria in this transcendental phenomenological study including, (a) participants orphaned by the Ebola of 2014-2016, (b) enrolled at the agricultural university, (c) engaged in specialized case management, (d) willing to explore the meaning of specialized case management, (e) predominately domicile in rural Sierra Leone prior to the Ebola Outbreak, and (f) participants age ranging between 19 -35. If theoretical saturation point were not achieved under the criterion technique, snowball sampling technique would have been used. However, I did not use the snowball sampling technique as theoretical saturation was achieved with the tenth research participant recruited through purposive criterion sampling modalities. 


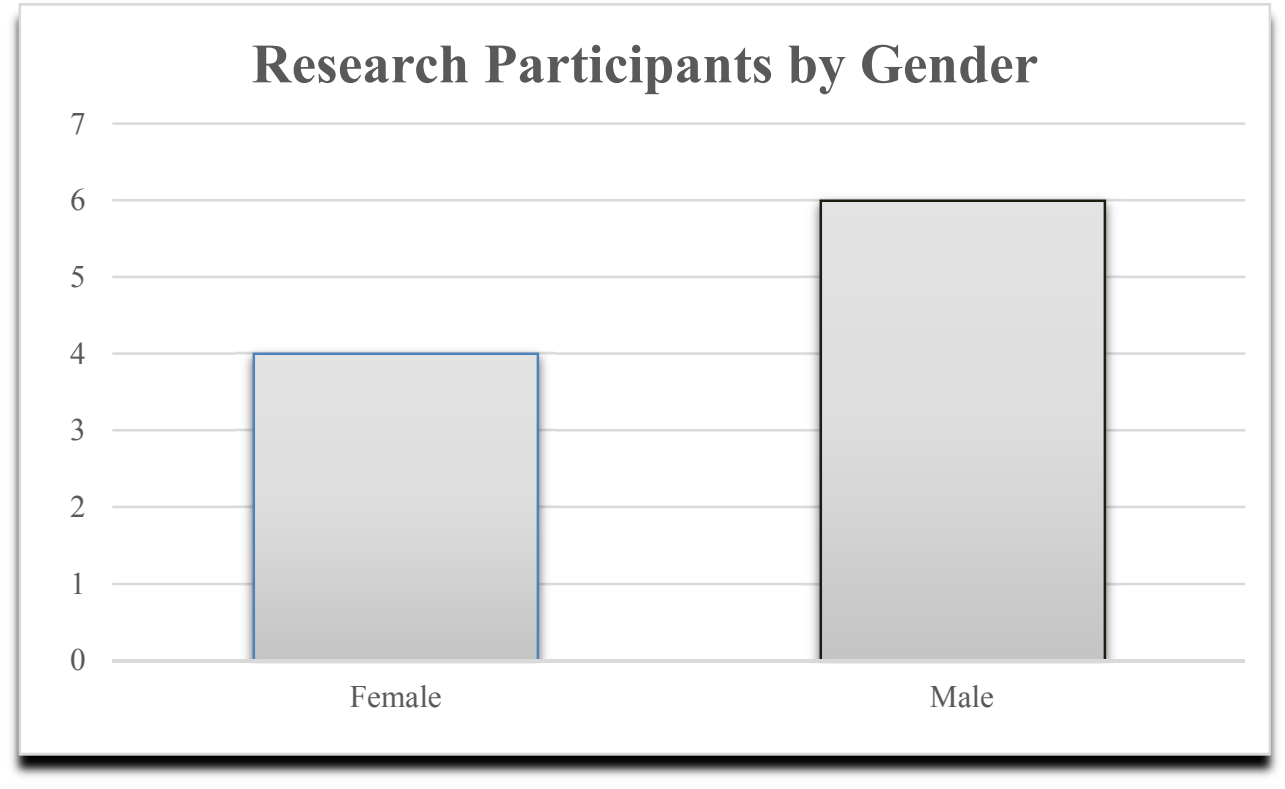

Figure 2. Research participants by gender.

\section{Snowball Sampling}

At the initial recruitment process, as needed, I used the initial point of connection to ask participants to encourage others to contact me about possible participation in this study (Malterud, Siersma \& Guassora, 2016). Etikan (2016) and Valerio et al., (2016) and Ziakas and Boukas (2014) posited that the snowball sampling technique allows the researcher to enlist hard-to-reach populations. Snowballing sampling technique appeared appropriate for finding suitable study participants for this transcendental phenomenological study (Ziakas \& Boukas, 2014). Snowball sampling techniques was an appropriate tool to limit my search to only participants who meet the pre-determined criteria (Heckathorn \& Cameron, 2017). The snowball sampling strategy identifying the foundation or seed willing to participate in the study, as such seed and or information foundation provided a network for chain recruiting, including a list of references by other participants in a multi-stage approach for the transcendental phenomenological study 
(Goodman, 2011; Sadler, Lee, Lim \& Fullerton, 2010). I used the sampling techniques as my primary method to find samples in the following manner, (a) use the list provided by the university faculty to contact participants via email and phone explaining the purpose of the study, benefits and option to opt out of the study at any time without consequence, (b) in the initial email, I informed the research participants to encourage others to contact me should they be interested in the study, this referral format continued until I recruit 10 research participants or reach theoretical saturation, and (c) I informed the participants who engaged with me and expressed willingness to participant in this transcendental phenomenological study about the inclusion criteria. The consent process discussed in the next section emphasizes the need for obtaining informed consent prior to interviews.

\section{Participants and Research Consent}

Once the recruitment was completed, I traveled to Sierra Leone to meet with selected research participants and presented each with consent form and answered any questions that arose prior to the face-to-face interviews. The participants had the option to opt out of the study without consequence. I collected the signed consent forms before initiating the interviews. Data collection took place in Sierra Leone at a place and time convenient to each research participant.

\section{Interview Format}

I used a semi-structured face-to-face interview format for this transcendental phenomenological study to explore the lived experiences of student-orphans of specialized case management. Questions for this semi-structured interview (see Appendix E) provided the direction of the interview details. The interviews were spaced out over a 
one-week period in the evenings to avoid disrupting classes. Interviews for each research participant took between 30-45-minute, detailing gender, age and tribal lineage (see Table 5). I sent a thank you letter to each research participant after the interviews. The next section includes the data recording for this transcendental phenomenological study.

Table 5

Participant Demographics and Cultural Lineage

\begin{tabular}{cccc}
\hline Participant code & Tribal lineage & gender & Age range \\
\hline PAR1 & Mende & Male & $19-25$ \\
\hline PAR2 & Limba & Female & $30-35$ \\
\hline PAR3 & Mende & Male & $30-35$ \\
\hline PAR4 & Temne & Male & $25-30$ \\
\hline PAR5 & Limba & Female & $19-25$ \\
\hline PAR6 & Loko & Male & $25-30$ \\
\hline PAR7 & Mende & Male & $19-25$ \\
\hline PAR8 & Mende & Male & $19-25$ \\
\hline PAR9 & Mende & Female & $25-30$ \\
\hline PAR10 & Loko & Female & $19-25$ \\
\hline
\end{tabular}

\section{Data Recording}

I audiotaped interviews using a recording device that was placed in plain sight before starting the interview. I used a Sony digital voice recorder to record each interview. Data security and disposal remains an integral part of the concerns in this study. 


\section{Data Security}

The digital voice recordings, signed consent forms, and copies of the formal responses, interview transcripts, were scanned to an encrypted password protected removable drive and physical copies shredded. Digital file will be saved in a locked box in which only I have access, and I destroyed the data after publication in accordance with the APA manual. The next section includes the data collection process for this transcendental phenomenological study.

\section{Data Collection}

The data collection tool for this study was an open-ended semi structured interview conducted in English. Each of the research participants and I agreed in advance of the time, place, and date of the individual interview via text message, email, and or phone. The data-collection process through semi-structured face-to-face interviews continued to the point of theoretical saturation when interviewees have no new insight into the phenomenon under review. The use of the transcendental phenomenological research method for this study allowed the use of interviews as a data collection tool for obtaining the lived experience of individuals with the first-account of a phenomenon (Moustakas 1994). To understand how student-orphans experienced post-Ebola case management, the data analysis process provided an insight into the phenomenon.

\section{Data Analysis}

For this transcendental phenomenological study, I employed the van Kaam's transcendental phenomenological analysis step-by-step guide proposed by Moustakas (1994) including, (a) recorded the statements of relevance related to the experience of the 
phenomenon being studied, a process Moustakas (1994) referred to as horizontalization, (b) removed duplicates and vague comments, (c) developed composite description that represents the essence of the phenomenon (essential invariant structure) during the structural descriptions process, (d) developed invariant horizons and list statements that remain, (e) grouped variant horizontal statements into theme, (f) organized textual description of developed themes with statement to create a story of the participant's lived experiences of the phenomenon, (g) constructed a structural description from my interpretation, (h) designed a textual-structural description that blends the themes from research participants and me the researcher, and (i) conducted a textual-structural synthesis of the experiences of the phenomenon (Chambers, 2013; Michael-Chadwell, 2011, Moustakas, 1994).

Moustakas (1994) noted that reflexivity throughout the research process provides the premium for the researcher to develop the essence of the lived experiences of research subjects. The descriptive themes developed through textural-structural syntheses provided an understanding of how post-Ebola student-orphans experienced specialized case management to enhance grades and graduation. Finally, member checking after the interviews followed as a purposeful process for the accuracy of interview notes consistent with the experience of post-Ebola student-orphans with how case management was experienced (Moustakas, 1994).

To facilitate coding and data analysis, I used NVivo 11, computer-assisted qualitative data analysis software. Tummons (2014) claimed that using the computerassisted software in qualitative data analysis increases the researcher's ability to manage, 
organize, and process the data accurately and efficiently. I uploaded the collected audio files to the NVivo 11 software with a protected password. I then coded using Moustakas's (1994) tiered approach. The acronyms and jargon in local dialects used in the interviews that have double meanings were then clarified and coded to avoid misunderstanding comments (Doody \& Noonan, 2013; McLellan, MacQueen \& Neidig, 2003).

\section{Member Checking}

I completed member checking after the interview with each of the research participants in person to promote the accuracy of the transcripts and increase the internal validity of the research method. I presented summarized transcripts to each research participant, allowing participants to make corrections and return the transcript. Schwandt, Guba, and Lincoln (2007) argued that member checking to gain and solicit reaction from research participants enhances validity and authenticate the reported applied meanings. Subsequently, I asked participants to review and possibly correct their interview transcripts. There were no changes in the transcripts as each participant signed the summarized form as transcribed.

\section{Validity}

A transcendental phenomenological approach supports the purpose of this study, which is to explore how post-Ebola student-orphans experienced specialized case management and post-disaster intervention while enrolled at a rural agricultural university in Sierra Leone (Moustakas, 1994). The validity of this study was examined through the following structures: 


\section{Methods}

This transcendental phenomenological study I engaged participants whose lived experiences provide them with in-depth insight into the phenomenon under investigation (Giorgi, 2012; Moustakas, 1994). Noble and Smith (2015) and Roth (2015) claimed that the use of inclusive criteria provides the researcher with a tool for recruiting participants with vital knowledge and experience of the phenomenon to increase the internal validity of the study. However, transcendental phenomenological methods have some limitations, including reflexivity and pre-dispositions to the data source, which affects how the interviewees and interviewer relate to each other and as such brew validity challenges (Brown, Roberts, Whiddon, Goossen \& Kacal, 2015; Finlay, 2014).

\section{Sources}

The young student-orphans targeted for this study present with an experience of trauma and are engaged with post-disaster case management and, therefore, have challenges recalling the events of the disaster or issue an erroneous account of the experience (Brewin \& Andrews, 2017). Additionally, the young research participants may or may not be dealing with trauma at the time of data collection, which may affect the nature and accuracy of the account of individual experiences (Valibhoy, Kaplan \& Szwarc, 2016). Furthermore, the case management services contained in the post-Ebola reconstruction may or may not have an affect on college life and grades.

\section{Analysis}

I used Moustakas's (1994) guidelines for phenomenological analysis in order to increase validity. I transcribed the interview verbatim and cross-checked the transcribed 
interviews summaries with participants for correction to also increase validity (Moustakas, 1994).

Although the process of epoché, experiencing the phenomenon in a pure state, may be difficult to achieve, through bracketing, I presented the meanings that the participants applied to constructs taking into consideration my personal ontology (Moustakas, 1994; Roth, 2015). Additionally, the direct interaction between the participants and me throughout the data collection process allowed for clarification of concepts and meanings. The synergy between the researcher and participants increased validation, as participants built on responses or explained statements, as well as by the continual re-examination of the material to ascertain meaning as intended by the participants (Noble \& Smith, 2015; Roth, 2015).

\section{Reliability}

For this transcendental phenomenological study, I sought to establish an accurate description of how post-Ebola student-orphans experienced case management and interventions aimed at enhancing grades and graduation while enrolled at a rural agricultural university. The protocol for face-to-face interviews within transcendental phenomenological research appeared to be replicable and reliable (Harvey, 2010). Reliability of this study was examined through the following constructions:

\section{Methods}

The transcendental phenomenological research methods outlined by Moustakas (1994), which I employed for this study, appeared to be replicable to examine how postEbola student-orphans experienced specialized case management. The sampling process 
for the selection of participants who met the inclusion criteria provided valuable data about the phenomenon under review (Moustakas, 1994).

\section{Sources}

According to the process described by Moustakas (1994), data was collected through 30-45-minute, individual semi-structured interviews, and research participants had the opportunity to ask questions and opt out of the study without consequence at any point (Doody \& Noonan, 2013; Moustakas, 1994). This data collection model appeared to be replicable.

\section{Analysis}

I adapted Moustakas' (1994) analytical method and adhered to related protocols, as the following analytical model appeared replicable. Emerging themes were generated concurrently with data collection and developed themes form the universal structures for analysis (Constantinou, Georgiou \& Perdikogianni, 2017; Hsieh \& Shannon, 2005; Moustakas, 1994) — a process which also appears to be replicable. The ensuing section contains the ethical protection of research participants for this transcendental phenomenological study.

\section{Ethical Protection of Participants}

I coded the identifying information of the research participants to maintain confidentiality, protect identity, and sustain and promote the integrity of the study (Rodner, 2015; Ali \& Yusof, 2011; Vaismoradi, Turunen \& Bondas, 2013). I assigned pseudonyms to each interviewee for confidentiality and privacy (Marshall et al., 2013). Each participant signed the informed consent after receiving full disclosure of the intent 
of the study and obligations of the researcher (Vaismoradi, Jones, Turunen \& Snelgrove, 2016; Doyle \& Buckley, 2017). The role of the research in this transcendental phenomenological study remained an important construct that will be examined in the next section.

\section{Role of the Researcher}

My role as the researcher in this phenomenological study was to recruit research participants who met the inclusion criteria and conduct interviews with the selected study participants. As the principal researcher, I collected and analyzed data, and provided a written report of research findings that reflected the voices of the participants (Fry, Scammell \& Barker, 2017). My focus as the researcher in this transcendental phenomenological study was to explore how post-Ebola student-orphans experienced case management, to capture the lived experiences of the research participants through the semi-structured interview while managing my perceptions and preconceived worldviews (Fry, Scammell \& Barker, 2017; Moustakas, 1994). My experience and professional relationships with crises and disasters bear link between the study participants and I. I relate to the lived experiences of specialized case management as I experienced firsthand the emotional, financial, and psychosocial affects experienced by the victims of crisis and disaster. I developed my own perceptions of experiencing postdisaster services during and after the ten years of civil war in Sierra Leone. I managed my researcher biases through awareness and bracketing my personal experiences. I used NVivo qualitative analysis software to reduce my subjectivity and biases and to 
determine relevant data and appropriate coding of data (Ross, 2017). Reliving traumatic experiencing could trigger the use of professional counseling service, as needed.

\section{Professional Counseling Services}

I understand that reliving traumatic lived experiences may evoke negative memories that cause distress; therefore, I used careful consideration and took the necessary safety measures to address possible problems with propinquity throughout the interview and study. Counseling sessions were made available as needed with Possible Harm Referrals (PHR) to the university's counseling department form to be completed as needed (see Appendix F). I did not utilize the university counseling facilities for any referral as participants did not show any stress during the interviews. Research participants did demonstrate some traumatic behaviors like shouting, tearing and long pausing between answering interview questions; however, participants continued the interview as such triggers for a referral to the university counseling services were not warranted. Additionally, participants received information about the availability of counseling services offered by the university. The next section contains compensation for participation in this transcendental phenomenological study.

\section{Compensation}

Participation in the transcendental phenomenological study was voluntary. Each research participant received a personal thank you note to each research participants and a $\$ 10$ gift card for allowing me to experience individualized personal stories of the lived experiences of post-Ebola case management. 


\section{Summary}

This chapter contains, (a) research methodology and justification, (b) research purpose, (c) research question, (d) theoretical framework including the transcendental philosophical viewpoint and post-positivistic ontology, ( e) ecological system theory, (f) participant search, participant contact , (g) sampling techniques, (h) participant consent (i) data collection, recording and analysis (j) member checking and (k) ethical protection of research participants including possible harm referral to counseling and (1) role of the researcher. The next chapter will contain (a) the research results, (b) description and analysis of data, and (c) interpretation of findings for this transcendental phenomenological study. 
Chapter 4: Data Analysis and Findings

\section{Background}

This chapter contains findings of the transcendental phenomenological research, deconstruction of data collection methods and processes, and examination of data transcription and description of the thematic matrices from the perspective of the information-rich sources to understand how post-Ebola student-orphans experienced specialized case management in rural Sierra Leone while enrolled at an agricultural university. Moustakas (1994) and Anderson and Eppard (1998) described van Kaam's $(1959,1966)$ modified method of phenomenological data analysis as a tool in which researchers seek to separate the essential biases to experience a phenomenon from participants' perspectives. I used the van Kaam's $(1959,1966)$ modified phenomenological data analysis to deconstruct participatory data for this transcendental phenomenological study. This chapter includes: (a) research purpose, (b) research method, (c) research question, (d) research findings, and (e) summary.

\section{Research Purpose}

Using a transcendental phenomenological research study, I explored the lived experiences of post-Ebola student-orphans enrolled at a rural agricultural university in Sierra Leone and engaged in a specialized case management intervention intended to enhance college grades and promote graduation. The information generated in the findings of this study may help human service program administrators, disaster response managers, community health care workers, and foster care parents, as well as government and nongovernmental organizations, to design, deliver and evaluate post disaster 
intervention services and supportive social schemes for the student-orphans enrolled in higher education relative to college activities. The research method included a baseline to investigate this phenomenon.

\section{Research Method}

This transcendental phenomenological research design included the framework that formed the lens to understand how student-orphans experienced specialized case management relative to college activities. The modalities of this methodology provided the benchmark to understand the lived experiences of information-rich sources of how case management was entertained in the post-Ebola intervention of Sierra Leone (Gros, 2017; Moustakas, 1994; Salmon, 2012). The transcendental phenomenological research method appeared to be the appropriate tool to explore how student-orphans experienced post-Ebola specialized case management. By using transcendental phenomenological research methods to guide this study, I was able to explore the lived experiences and analyze how student-orphans in higher education experienced post-Ebola case management in rural Sierra Leone (see Gros, 2017; Giorgi, 1997, 2012, Moustakas, 1994). Additionally, I was able to uncover themes across the research subjects' experiences of the phenomenon (Moustakas, 1994; Giorgi, 1997, 2012; Sterett, 2015).

Transcendental phenomenological design allowed the opportunity to: (a) examine and manage personal worldviews, (b) place emphasis on the phenomenological completeness from the lived experiences as advanced by the research subjects, (c) search for essence and meaning of the experiences through the restorying of the individual's unique experiences, and (d) obtain individualized accounts of the phenomenon 
(Moustakas, 1994). In summary, this design included a mechanism to understand how post-Ebola student-orphans experienced specialized case management (see ButlerO’Halloran, \& Guilfoyle, 2015; Moustakas, 1994; Park \& Kim, 2015). The ensuing section contains the research question and short answer for this transcendental phenomenological study.

\section{Research Question}

The research question for this transcendental phenomenological study was: What are the lived experiences of post-Ebola orphan-students engaged in case management activities while enrolled at a rural agricultural university in Sierra Leone? Studentorphans' lived experiences with specialized case management relative to higher education in post-Ebola Sierra Leone included three major categories: sadness, happiness, and anger. The characterization of case management lived experiences relating to sadness expressed and branded in the following manner ranging from self-blaming to poor service delivery and quality of such services by disaster relief managers. Poor service delivery and coordination at the onset of the disaster became evident as several organizational staff and government workers engaged in uncoordinated efforts to reach out to victims, some duplicating services and not complementing each other in the process and creating confusion (Gidado et al., 2015; Nuriddin et al., 2018). Secondly, the construct of happy experiences with case management became evident when participants knew that other individuals in the same group shared the same traumatic experiences. This empowered participants to seek in-group support mechanisms including (a) open discussions regarding grief and loss, (b) assistance with academic activities, and (c) trust that they can 
be accepted. Thirdly, research participants experienced case management through anger. The angry sentiments became evident with the poor communication and little information about the Ebola disease and programs.

Additionally, participants felt that post disaster relief managers appeared hopeless and helpless with the Ebola pandemic of 2014-2016, as such disaster response managers did not know how to approach Ebola victims. The fear of the unknown about the disease became the center of focus for human service administrators and government workers and such an attribute of fear affected the level of services provided to student-orphans (Gidado et al., 2015; Nuriddin et al., 2018; Shears \& O’Dempsey, 2015). Finally, research participants experienced case management through emotional contrition. Post disaster victims exhibited mild to moderate stress reactions in the early post-Ebola intervention phases up to the time of this study as victims recognized the severity of the disease and the associated traumatic events like shock, guilt, blame, anger, sadness, numbness, hopelessness, difficulty sleeping, or sustained fear complicated by the poor service offered by government agencies (Hugo et al., 2015; Jalloh et al., 2018; Shultz et al., 2015). Participants related to lived experiences of specialized case management including poor services, unreliable program supplies, nonpayment of college fees, and inconsistent group sessions. Therefore, the lived experiences of post-Ebola studentorphans to case management can be characterized into four significant elements including (a) sad feelings and expression, (b) mad and angry reactive feelings, (c) emotional feeling and contrition, and (d) happy dispositional sense (see Appendix A). The next section contains the findings for this transcendental phenomenological study. 
van Kaam's Analytical Tool: Presentation of Research Findings

I used the van Kaam's $(1959,1966)$ modified phenomenological data analysis as outlined by Moustakas (1994) for this transcendental phenomenological study. Moustakas (1994) classified the modified van Kaam's $(1959,1966)$ phenomenological data analysis into seven phases. The seven steps guided the data analysis for this transcendental phenomenological study resulting in the findings as discussed in the ensuing sections.

Step 1 is the initial process contained in this analysis; it comprises active listening and preliminary groupings of themes, a model Moustakas (1994, p.120) referred to as horizontalization. The process of listening to the interview scripts and cataloging initial themes into groupings allowed me to see the developing trends of how post-Ebola student-orphans experienced specialized case management while enrolled at a rural agricultural university in Sierra Leone. At this stage, ideas began to develop and inclinations of how participants experienced specialized case management started to surface.

Step 2, the next phase in the van Kaam's $(1959,1966)$ modified transcendental phenomenological data analysis, entails the reductions and elimination phase (Moustakas, 1994, p. 121). I examined the transcribed data to qualify if the statements that subjected the surfaced themes contained the moment of the lived experiences and constituted an understanding from the interviews. Moreover, I looked at the possibility of the statements to be abstracted and labeled, which included the horizon (see Moustakas, 1994). I eliminated the comments and expressions not meeting the above requirements. 
Additionally, statements that overlapped or were monotonous or vague were excluded or subjected in more descriptive terms or required clarification from research participants. Moustakas (1994) claimed that the horizons that remain after submitting the statement to the two questions are called invariant constitutions of the lived experiences of the research subjects to the phenomenon. This process allowed me to sort and arrange experiences from the transcripts and eliminates statements and quotes in the next stage of the van Kaam $(1959,1966)$ analysis (see Table 6). I decided on the elements of the interviews analyzed that represented close affinity to the phenomenon to retain and those of the analysis I should omit before moving on to the next stage of the van Kaam (1959, 1966) transcendental phenomenological analysis. The identified perceptions and lived experiences of post-Ebola student-orphans to specialized case management were marked as the invariant constituents (Moustakas, 1994). 
Table 6

Themes and Invariant Constituents with Clusters and Dominating Compositions

\begin{tabular}{|c|c|c|c|}
\hline Themes & Subthemes & Clusters & $\begin{array}{l}\text { Dominating } \\
\text { compositions }\end{array}$ \\
\hline $\begin{array}{l}\text { Case management } \\
\text { as a motivator }\end{array}$ & Resilience, joyful & Challenges & $\begin{array}{l}\text { Culture, tradition, } \\
\text { family values, } \\
\text { education, case } \\
\text { management }\end{array}$ \\
\hline $\begin{array}{l}\text { Disbelief and } \\
\text { frustration }\end{array}$ & Rejections & Isolation, self-blame & $\begin{array}{l}\text { Loss, grief, } \\
\text { loneliness }\end{array}$ \\
\hline $\begin{array}{l}\text { Hopelessness and } \\
\text { despair }\end{array}$ & Poor services & Overwhelmed & $\begin{array}{l}\text { Hopeful, better } \\
\text { future, security }\end{array}$ \\
\hline $\begin{array}{l}\text { Anxiety, fear, and } \\
\text { anger }\end{array}$ & Indigent, vulnerability & Uncertainty & $\begin{array}{l}\text { The absence of } \\
\text { information, poor } \\
\text { social network }\end{array}$ \\
\hline $\begin{array}{l}\text { Case management } \\
\text { is family }\end{array}$ & Social support, trust & Security & $\begin{array}{l}\text { Reconnection, } \\
\text { family values }\end{array}$ \\
\hline Hopefulness & $\begin{array}{l}\text { Hope for better } \\
\text { connection and } \\
\text { opportunities }\end{array}$ & $\begin{array}{l}\text { Family, friends, } \\
\text { Resources }\end{array}$ & $\begin{array}{l}\text { Motivation, shared } \\
\text { family values, } \\
\text { resource sharing }\end{array}$ \\
\hline $\begin{array}{l}\text { Safety and security } \\
\text { and trust }\end{array}$ & $\begin{array}{l}\text { Stable social contacts, } \\
\text { less treat from external } \\
\text { sources }\end{array}$ & $\begin{array}{l}\text { Strong reliance on } \\
\text { case management }\end{array}$ & $\begin{array}{l}\text { Assurance, } \\
\text { emotional bond }\end{array}$ \\
\hline Self-advocacy & $\begin{array}{l}\text { Feeling of belonging, } \\
\text { in-group support }\end{array}$ & Voice of the voiceless & $\begin{array}{l}\text { Promote dignity } \\
\text { and awareness }\end{array}$ \\
\hline $\begin{array}{l}\text { Inspiration in the } \\
\text { face of persisting } \\
\text { trauma }\end{array}$ & $\begin{array}{l}\text { Enduring challenges, } \\
\text { grief, and loss }\end{array}$ & $\begin{array}{l}\text { General anxiety, } \\
\text { tension }\end{array}$ & Restlessness \\
\hline Guilt, shame & $\begin{array}{l}\text { Unexpected changes, } \\
\text { no familiar contacts }\end{array}$ & $\begin{array}{l}\text { Death, poor } \\
\text { communication, }\end{array}$ & $\begin{array}{l}\text { Traditional, } \\
\text { cultures, values, } \\
\text { support }\end{array}$ \\
\hline
\end{tabular}


For Step 3, Moustakas (1994, p.121) argued that the modified van Kaam (1959, 1966) transcendental phenomenological analysis subjects the invariant constitutions to a deconstruction process that includes themes closely aligned to statements or phrases from the transcripts, a process called clustering and thematizing of the invariant constituents. At this stage, I assembled and clustered the invariant constituents relating to how studentorphans experienced specialized post-Ebola case management into themes that I labeled as the emerging main themes and used Nvivo 12 to organize the main themes and subthemes (Table 7). I only considered such themes as main themes when three or more occurrences became evident in the interview transcripts. The emerging main themes included: (a) case management as a motivating factor; (b) disbelief and frustration; (c) hopelessness and despair; (d) anxiety, fear and anger; (e) case management is family, (f) hopefulness, (g) safety, security, and trust; (h) self- advocacy; (i) motivating in the face of challenges; and (j) guilt and shame. 
Table 7

Major Units or Themes

Identified themes $\quad$ No. of participants $(N=10)$

1. Case Management as a Motivator 10

2. Disbelief and frustration $\quad 10$

$\begin{array}{ll}\text { 3. Hopelessness and despair } & 10\end{array}$

4. Anxiety, fear and anger 10

5. Case management is family $\quad 10$

$\begin{array}{ll}\text { 6. Hopefulness } & 10\end{array}$

7. Safety and security and trust 10

8. Self-advocacy 10

9. Inspiration in the face of persisting trauma 10

$\begin{array}{ll}\text { 10. Guilt, shame } & 10\end{array}$

\section{Main Theme 1: Case Management as a Motivator}

The coping mechanism with grief and loss especially to an unknown disease presented some difficulties for student-orphans in rural communities relying on cohesion with in-group support to understand and seek help for the new normal; such tendencies triggers internal interests and enhance motivation in some survivals (Bakhshi et al., 2014; Hong, 2016). This was evident in the responses by PAR1 "case management is a lifechanging intervention and motivator to me" Coping with the loss by the research participants PAR4 and PAR5 appeared to have created a catalyst and motivation to be engaged in some form of social justice and social change concepts by suggesting 
changing or have changed college majors to reflect that interest. PAR 4 said that I have changed my majors to Social Work so that I can make a difference in someone's life just as mine has been affected" PAR 5 "my parents will be happy that I am setting up an advocacy group for orphans across the country." Sanders, Laing, and Frost (2015) claimed that while crises and disasters related encounters provided challenges for victims, some victims find opportunities in the disaster as a motivation to move ahead of the limitations and devastation, while others remain stuck to the past causing cathartic residual traumas. PAR1 "I felt rejected and abandoned by my people, as such I concentrated on my education."

\section{Main Theme 2: Disbelief and Frustration}

College life can be stressful and can even be more challenging when one's safety social network is limited due to crises and disaster as presented in the post-Ebola circumstances of student-orphans (Beiter, et al., 2015; Hendrickx et al., 2016; Kumar, Bhukar \& Vaz, 2011). Participants presented disbelief in the challenges and encounter with case management. PAR 1 in the identification and disbelief with the absence of parents indicated "My parents were farmers and did all they could to get me here, and we

did well before all this happened." However, case management in post-Ebola intervention became a life support for student-orphans as evident in the following testament of PAR 3 "Life as I knew it is no more, my parents are dead, and my uncle who is the only breadwinner in the family on both side is afraid to come near me, this is very annoying, no one seems to care to help, the hospitals do not want to give us food, the shelter they 
took us to was not managed by professionals, but one zombie who was just waiting for us to die and be taken away".

Additionally, PAR 3, PAR 4 and, PAR 7 recalled that "case management services stopped nobody told us anything" PAR 1, PAR6, PAR 9 and PAR 10 in high tone and stressed voice "We are making the best out of this situation, even for fees we are struggling to make payment" PAR 2 suggested to avoid the problem "I sometimes do not want to even think of it, but just concentrate on my studies" The heightened alert to environmental normal stressors and anxiousness exhibited by research participants appeared to have compounded the frustration. This matrix was noted in PAR1, PAR 3, PAR5, PAR6, and PAR10 asserted that the experience with case management is that "case management is unpredictable."

\section{Main Theme 3: Hopelessness and Despair}

The conceptualization of an individuals' negative expectancy regarding the future after a disaster which encompasses the characterization of pessimistic expectations, negative emotions, and loss of pleasure in life denotes hopelessness (Marsiglia, Kulis, Perez \& Bermudez-Parsai, 2011; Niranjjan, Sarkar, Balajee \& Srinivasan, 2018; Wolmer, Laor \& Yazgan, 2003). The research participants enraged by the poor management and delivery of Ebola resources, intervention and communication, suffused hopeless attributes that the scheme was limited in nature, generated the notion of disrespect for cultural rites as traditions have dictated for centuries and fearful that the true story of the Ebola virus remains unexplained. The demonstrated assertions from PAR 3, PAR 5 and PAR 8 related to this theme explain the feelings of hopelessness, PAR3 "nobody knew 
what to do, and everyone was just dying." PAR 5 "Ebola is such a bad disease that kills without mercy and no cure more over the services provided were very inadequate and some not needed." PAR 8 added that "the disease and intervention in the early stages were chaotic and unplanned." While PAR3 affirmed that "I get frequent headaches, and when the place is very quiet I feel afraid, and when people talk in loud voices, it startles me."

\section{Main Theme 4: Anxiety, Fear, and Anger}

The physiological response of post-disaster victims is wrapped with the complex mechanism of anxiety and fear to defend, fight or flee as a defense mechanism to buffer the shock or loss to the Ebola (Schalinski, Elbert \& Schauer, 2011; Blevins, Weathers \& Witte, 2014). In post-disaster, victims are often at a heightened alert and very sensitive to the immediate surrounding which represented a factor in the experience of anxiety and fear (Rahill, Joshi, Lescano \& Holbert, 2015; Forbes et al., 2015; Shultz, Cooper et al., 2016). PAR 10 explained that "one could not help but feel angry and fearful that with the sudden cessation of case management poor communication, no one managed the situation well, no explanation of the disease, not even from the so-called experts, they wear zombie-like jackets and treat us like very contagious people what is there to like and feel good about case management but the food and college fees?" PAR 8 infused that "I certainly feel angry and mad as anyone could imagine at the treatment, level of care both in and out of the encampment and even when we returned to the university, we became the orphans and Ebola survivals nobody wanted to talk to us, touch us or even share our common space." Cui and Sim (2017) posited that fear could denote the threat to 
immediate personal space of the individual's environment, property, and safety and response generated an immediate physiological response of fear especially in disaster victims. PAR 1 said that "I was afraid of dying, contacting the disease or even getting sick as there was no detection mechanism in the early stages of the disease to separate malaria from Ebola" PAR 3 noted that "hunger and fear were two major factors in camp, to get out to locate food was difficult." PAR 5 indicated that the whole issue surrounding the Ebola management was mismanaged and initiated anxiety." PAR 7 "Life with Ebola is day by day with each day bringing me numbness and anxiety but hopeful for a better future."

\section{Main Theme 5: Case Management is Family}

Participating in case management services appeared as a new concept to respondents as reliance on community in-group support system, and traditional coping mechanism seemed to have been the bedrock of managing crises and disasters in the past. PAR 3 related to this construct as "I cannot hide the fact that I have lost my parents and this group" spearing his hands raised in the air "is the family, only family I have left" silence "I have relied on them for help, questions about homework and sometimes even food" PAR 4 described the experience as " case management was helpful to come to terms with our collective traumas that I have indeed lost my parents, I remember when we had the first session immediately after case manager started the meeting, I cannot remember his name came from the UN, or something and told me that I have to come with him into his car, and he took me to a building in the camp and told me that my parents died of Ebola and that he will refer me for benefits with a program at the college, 
that was strange and unexpected." pause "However, that was left of what I considered family." PAR 6 asserted that when all you have left is a group of people that share the same experience as you, you tend to cling onto them." PAR 9 described this relationship as "the workers did not manage the Ebola events enough to communicate the effect so that we can protect ourselves. We learned to protect each other in the group." Participants related to this construct of family in the following manner; PAR3, PAR4, PAR5, PAR6, PAR8 and PAR10 "It was good that we had others who were in the same situation which would provide support to me, life would have been difficult without them" PAR 9 cited case management as a "useful intervention" noting that "the case management services was indeed useful to all of us, we relied on each other for support and networking." PAR 5 pointed to the fact that parental death remains an unresolved issue claiming, "the memories of the death of my parents circles around me all the time and think of them every day, but case management services helped me to come to terms with my loss." PAR 3 reported that "I find comfort in participating in case management knowing that I am not alone." Participant PAR10 described the service as a "miracle" while participant PAR 8 described case management as "a blessing, but I get a headache all the time and do not sleep well" PAR 2 described case management as "reconnecting with people, real people, not individuals who suspect you of been infected with Ebola, case management helped me get stuff, school supplies, and reconnect with people." PAR 3 noted "home is no more as there is nobody at home, you know when my mother, an excellent cook would always bring the best to the table each day I love to be home, and it is an empty place" PAR 4 sensed that "each time I went to case management, I received food, clothing I 
think of my parents, it is painful to expect people to give you stuff, strangers, it is not right" Participant PAR 8 described case management as "getting a holiday present from a stranger, but this time the stranger become your only family" The case management services participant received were described as a positive experience, getting to talk about the losses, ability to engage with others.

Additionally, case management experiences with research participants exuded negative inclinations including a low understanding of complex needs of student-orphans in relationships with college experience. Although some case management delivery techniques promulgated negative feelings all participants agreed that case management provided the best option in the post-Ebola reconstruction, this behavior and feeling suggested that participants learned to integrate individual needs against the overall goal of the specialized post-Ebola intervention. The engagement of participants in the specialized case management, sharing familiar stories and building trust in post-Ebola reconstruction in Rural Sierra Leone increased the ability for social connectedness (Bower, Kraayenoord \& Carroll, 2015; Bower, Conroy \& Perz, 2017; Li et al., 2015). PAR 9 suggested that case with case management "we are now family, and that means we care for each other."

\section{Main Theme 6: Hopefulness}

Cloke and Conradson (2018) and Hechanova et al., (2018) claimed that in postdisaster intervention victims might exhibit anxiety and numbness which is characteristic of hopelessness. Seeking help in such situation from community sources and family was helpful in minimizing the stress, social support is essential in post-disaster recovery, 
where family and friends are the primary first stop sources. Finding external support from known survivals of disasters and examining what coping skills worked in the past provided comfort and routine interventional strategies (Gil-Rivas \& Kilmer, 2016; Hechanova, Waelde \& Ramos, 2016). PAR 6 indicated that "I feel empowered and adequate, knowing where and how to get help and what type of help I may need, this is very important when one is in crisis; information is power. I never felt so strong and hopeful of my future than now; I have an offer of employment already and just waiting to complete my studies." PAR9 assessed case management experience as "hopeful" and "valuable" in light of poor resource availability and poor access to counseling for higher education post-disaster victims." PAR 8 noted that "with case management, I can talk to someone freely without fear of the information reaching someone I do not want to hear and to voice my heart which I do not usually do." PAR 1 quoted that "in the process of managing and healing, I find support and see my future brighter, I changed my majors, and willing to help my community so that no one should have to lose their parents as I did." PAR 6, PAR 7 and PAR 10 indicated that "Case management prepares the missing piece for linking with school and finding oneself." Participants became comfortable with case management services as the construct became a movement and confident resource center; they became more open with each other and planned to stay in touch for continued support. PAR 3 echoed that "we will stay connected forever regardless of where we go after college" this sentiment was alluded to by PAR 4 and PAR 7 "We have planned to stay within the same community as some of my friends.” Participants PAR 1, 
PAR3 and PAR 5 experienced some emotional reactions during the interviews but agreed to continue the interview.

\section{Main Theme 7: Safety, Security, and Trust}

The social contract between the ingroup as it relates to trust is an important construct and an element that improves the relationships and enhance self-empowerment and wellbeing for post-disaster victims, these elements promotes a sense of security and safety (Brooks et al., 2015; Hommerich, 2012; Nappi \& Souza, 2015). Safety appeared relatively and loosely attributable to case management which interfaces with real-world challenges with the Ebola disease. PAR 3 related to this construct as "nobody is safe with Ebola and not even know what can make us safe, but case management provided a medium for safety by providing information to each other caring for each other and making sure the group's interest is protected." Participants PAR4, PAR 6 and PAR 9 shared that "knowing that participants in the specialized case management have a common interest with post-disaster losses provided the premise to build on group cohesion, promoting trust. It appears the knowledge of knowing that Ebola took our parents; with the pain and grief are now expressed to gain unity among us." Safety and security are important to the participants who built the tendency for trusting relationships in specialized case management. This was shared by PAR 1, PAR 3 and PAR 5 reflected on the "unique relationship between the senior students was still visible even when we all share the same challenges." pause "one cannot help but still feel that level of ownership and belongingness when one has a responsibility to provide protection for the group like ours, when providing others with help with college work and giving them directions this 
is very satisfying." The in-group bonding of individuals with the same experience tends to form cohesion and trust when there is a central emotional focus, for student -orphans in this transcendental phenomenological study collective grief formed the coefficient (Saunders et al., 2018; Sullivan, 2015; Wayment \& Silver, 2018).

\section{Main Theme 8: Self-Advocacy}

Post-Ebola student-orphans engaged in self-promotion in the face of the ensuing confusion with the disaster especially in limited resource situations where discussions and quarries about information, resources, and methods of program delivery became subjective to scrutiny. PAR 2 noted that "we had to ask the questions that are needed to explain to us the things that we needed to know" PAR3 "we are not specimens and would not wait for them to give us what they think is wrong with us" PAR9 "if we do not speak up for ourselves, nobody will, and this will not be a good thing for us. We had to stand up for what we believe in and get the leaders to understand our points." Some of the consideration and changes in the post-disaster intervention by human service administrators took some of the advocacy rejoinders of the victims as noted in the adaptation and design of a post-disaster secretariat in 2018 presented in the Ebola interventions and disaster mitigation (Abramowitz, Hipgrave, Witchard \& Heymann, 2018; Abramowitz et al., 2018; Bell et al., 2016; Harris, Wurie, Baingana, Sevalie \& Beynon, 2018; Shultz, Cooper et al., 2016) (see Figure 4). The process of self-and in group advocacy efforts became evident in the following exchanges with PAR6 "we did all we can get so that they will listen to us, hear what we need and what they provided was not needed will be left on the table and even foods that were provided." PAR 7 
"sometimes they would bring us things that we do not need, and they expect us to take it, we do not and will let them know." PAR8 noted that "we organized ourselves into a strong one voice with no leader, but our answers were the same and no matter the level of questions we remained true to the cause." Disaster victim yearned for that voice that provides a face and value to the needs and aspiration of the community, such demands can be mostly advanced by the victims and those that provide a pillar for that cause (Huss, Kaufman, Avgar \& Shuker, 2016; Plooy, Harms, Muir, Martin \& Ingliss, 2014). Such pressure on local human service managers led to the commissioning of the Disaster Management, and Intervention (DMI) Secretariat in Sierra Leone mandated to review, plan and evaluate vulnerable indices. 


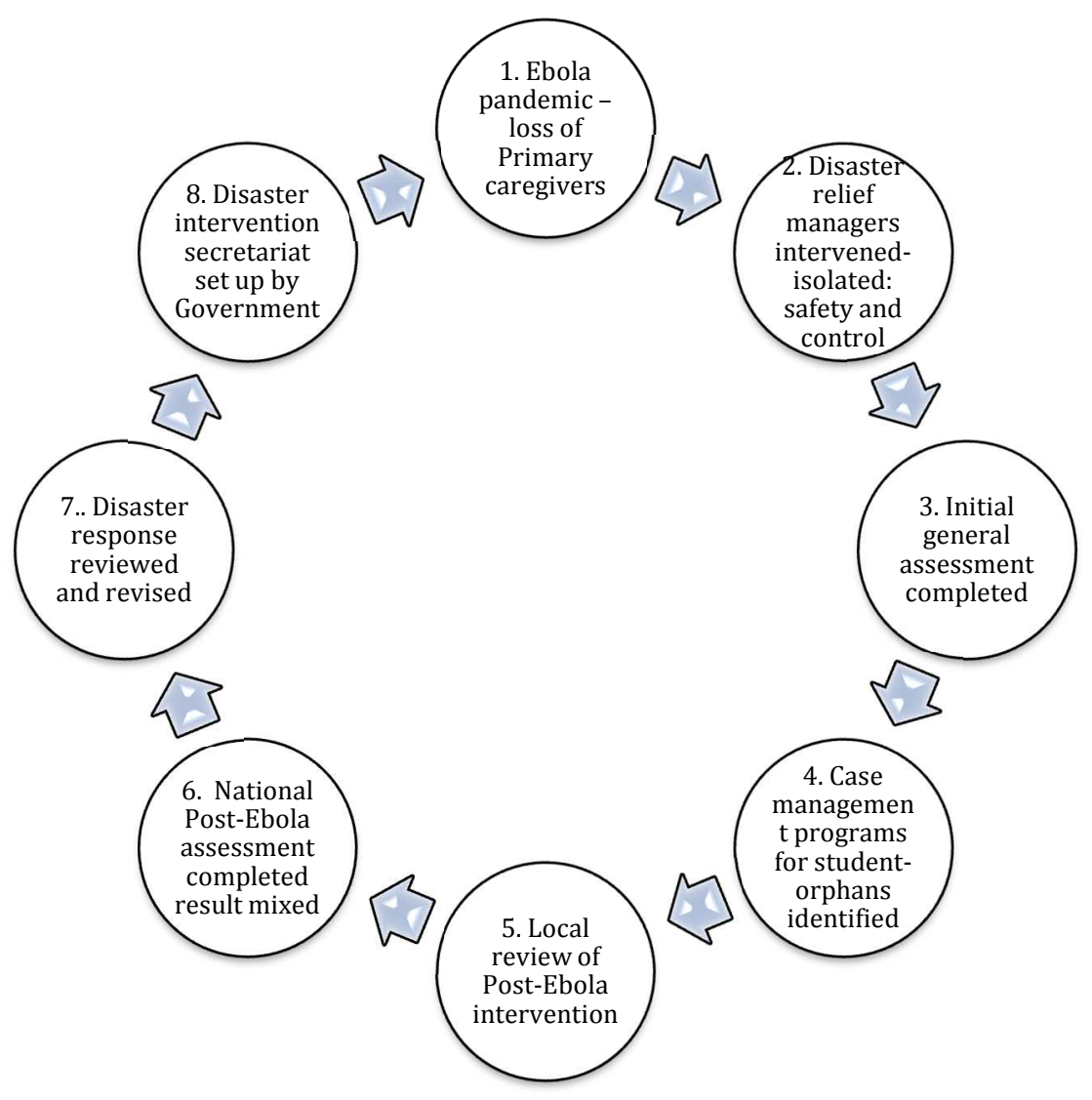

Figure 3. Ebola disaster intervention model in Sierra Leone.

\section{Main Theme 9: Inspiration in the Face of Persisting Trauma}

Student-orphans' encounter with past trauma referencing losses during the 20012004 civil, political upheavals and the Ebola pandemic presents challenges and opportunities in coping with Ebola disaster shocks, and known skills surfaced to enhance motivations for victims to face the new normal (Cadamuro, Versari, Vezzali, Giovannini \& Trifiletti, 2014; Hatch, Cherry, Kytola, Lu \& Marks, 2015). Losses and grief appeared to have a different meaning to research participants, loss due to the death of loved ones by Ebola, loss due to misinformation and or lack of information thereby making onerous 
the recovery process from the traumatic experiences and the healing process resulting in self-blaming which presented a cloud in understanding the meaning of losses. However, the quest for moving past this level of trauma and support through case management became a central focus for participants. PAR 1 alluded that "case management means something extraordinary to me, it is a lifesaving experience, it gives me hope and courage and to be able to live through the traumatic experiences, and there was a time when I was discriminated against, I am now able to understand how to handle my past losses, hoping to complete my education using this opportunity." PAR 3 stated that "I am hopeful for the future someday I will be proud of myself." Participant PAR3, PAR5, PAR8, and PAR10 shared "we now have the skills to move pass our traumas, as such cannot fail as we have lost all we had this is the only way that we can make it."

\section{Main Theme 10: Guilt and Shame}

Throughout the case, management experience research participants indicated that the feeling of guilt and shame persisted when other individuals in the same circumstance have not had the opportunity to receive the same services. Research participants responded that the feeling of guilt and shame and disbelief with the selective services in the death of parents was shameful. PAR 5 noted that "getting services while others equally affected by this disaster did not get it is shameful and I feel guilty" Although trauma associated losses for this transcendental phenomenological study focused on the death of parents, other types of losses to the research participants also remained pertinent to the recovery process and clouded the meaning and experience with case management such losses include: a), loss of friend b), loss of residence or property c), loss of income, 
and d) loss of known communities (Burden et al.,2016; Cherry et al., 2014;

Isaranuwatchai, Coyte, McKenzie \& Noh, 2016; Maschi, Viola, Morgen \& Koskinen, 2015; Pollack, Weiss \& Trung, 2016; Stotz, Elbert, Müller \& Schauer, 2015). Participants PAR 1, PAR 4 and PAR 6 also indicated the physical, emotional and psychological incapacitation "I experienced tiredness, sleeplessness, worried, lack of appetite, and lack of interest in activities which affected my grades." These feelings and attributes with the research participants can be categorized into four main groups: (a), cognitive feelings (b), emotional affect (c), physical distresses, and (d) relational variances (see Appendix D). PAR 4, "feeling guilty and shameful is ok except when you cannot manage and direct your anger to the appropriate channel." Eight of the ten participants related to case management experiences as essential to survival in life and to be made available to affected by this disaster and 20 percent noted that human service administrators must design any future intervention for a national audience.

Applying Step 4 of van Kaam's $(1959,1966)$ transcendental phenomenological analysis in this study involves the substantiation of the identified and established themes and invariant constituents of how post-Ebola student orphans experienced specialized case management occurred at this stage of data analysis. Moustakas (1994, p. 121) advanced three questions which major themes must qualify includes (a), the themes must be clearly expressed in the transcripts (b), if the expressions are not explicit, are they compatible with the phenomenon under review (c), if the themes are not explicitly stated and not consistent and not relevant to the lived experiences of the phenomenon they should be deleted. At this stage, I subjected the themes to the three-question test and 
revisited the scripts for clear statements relating to the phenomenon which resulted in the final main themes for this transcendental phenomenological study.

Step 5 of van Kaam's $(1959,1966)$ transcendental phenomenological analysis Moustakas (1994) posited as the individual textural description process. Moustakas (1994) described individual textural descriptions as a process of using the invariant constituents, and the main themes identified earlier in step one, and two and the validated themes from step four to become the baseline for the generation of individual textural descriptive tools of each of the research participants to relive the experiences of postEbola specialized case management. Participant experienced specialized case management with both positive and negative experiences (see Table 8). 
Table 8

Brief Summarized Textural Description of Feelings

\begin{tabular}{|c|c|c|c|}
\hline $\begin{array}{l}\text { Participant } \\
\text { code }\end{array}$ & $\begin{array}{l}\text { Brief summarized } \\
\text { textural description }\end{array}$ & $\begin{array}{l}\text { Participant } \\
\text { code }\end{array}$ & $\begin{array}{l}\text { Summarized textural } \\
\text { description }\end{array}$ \\
\hline PAR 1 & $\begin{array}{l}\text { Positive: "I found } \\
\text { support and my future is } \\
\text { better with case } \\
\text { management." }\end{array}$ & PAR 6 & $\begin{array}{l}\text { Positive: "Hopeful and } \\
\text { helped me." } \\
\text { Negative: "Brief support } \\
\text { and coordination." }\end{array}$ \\
\hline PAR 2 & $\begin{array}{l}\text { Negative: "struggling to } \\
\text { make payment after the } \\
\text { discontinuation of } \\
\text { services." }\end{array}$ & PAR 7 & $\begin{array}{l}\text { Positive: "Linking me with } \\
\text { core services." } \\
\text { Negative: "services } \\
\text { stopped with notice." }\end{array}$ \\
\hline PAR 3 & $\begin{array}{l}\text { Positive: Helped me to } \\
\text { go through my course." } \\
\text { Negative: "Services } \\
\text { were brief and short." }\end{array}$ & PAR 8 & $\begin{array}{l}\text { Positive: "received } \\
\text { financial assistance." } \\
\text { Negative: Hopelessly } \\
\text { coordinated and } \\
\text { inconsistent." }\end{array}$ \\
\hline PAR 4 & $\begin{array}{l}\text { Positive: "paid my } \\
\text { college fees and } \\
\text { supplies." } \\
\text { Negative: "Limited in } \\
\text { scope, unpredictable." }\end{array}$ & PAR 9 & $\begin{array}{l}\text { Positive: "a valuable } \\
\text { resource for me." } \\
\text { Negative: "poor } \\
\text { communication." }\end{array}$ \\
\hline PAR 5 & $\begin{array}{l}\text { Positive: "helped me } \\
\text { with support } \\
\text { financially." } \\
\text { Negative: "guilty } \\
\text { feelings about case } \\
\text { management." }\end{array}$ & PAR 10 & $\begin{array}{l}\text { Positive: "case } \\
\text { management was a } \\
\text { miracle." } \\
\text { Negative: "Brief service } \\
\text { and limited in scope." }\end{array}$ \\
\hline
\end{tabular}

At Step 6 in the data analysis process, I confirmed the creation of the individual structural descriptions that have met the rubric of the conditions as described by Moustakas, (1994, p. 121). As an instrument in the data analysis, I developed the individual structural description that helped to identify essences of the lived experiences 
of post-Ebola student-orphans to specialized case management while enrolled at agricultural university relative to college activities (Moustakas, 1994). This process permitted me to confirm the major themes to understand how student-orphans experienced post-Ebola case management (see Appendix C).

Moustakas (1994) described Step 7 of the modified van Kaam's phenomenological data analysis process as the integration of the developed themes and the invariant constituents where the meaning and essences provided the lived experiences of the research subjects. At this stage in the data analysis the student-orphans experienced specialized case management through four experiences: (a), sad feelings and expression (b), mad and angry reactive feelings (c), emotional feeling and contrition, and (d) happy dispositional sense (see Table 9). The next section contains the findings of the transcendental phenomenological study. 
Table 9

Case Management Feelings Experienced by Student-Orphans

\begin{tabular}{llll}
\hline $\begin{array}{l}\text { Sad feeling and } \\
\text { expression }\end{array}$ & $\begin{array}{l}\text { Mad reaction } \\
\text { feelings }\end{array}$ & $\begin{array}{l}\text { Emotional feelings } \\
\text { and contrition }\end{array}$ & $\begin{array}{l}\text { Happy } \\
\text { disposition } \\
\text { and feelings }\end{array}$ \\
\hline Distressed & Anger & Fearful & Joyful \\
Helpless & Rejections & isolation & $\begin{array}{l}\text { Someone to } \\
\text { talk to }\end{array}$ \\
Abandoned & Poor services & Overwhelmed & $\begin{array}{l}\text { Hopeful of } \\
\text { the future }\end{array}$ \\
Lonely & Uncertainty & $\begin{array}{l}\text { Glad that } \\
\text { people } \\
\text { cared }\end{array}$ \\
Loss and neglect & Hunger & \\
\hline
\end{tabular}

\section{Findings}

The significant finding of this transcendental phenomenological study included ten major themes including, (a) case management as a motivating factor, (b) disbelief and frustration, (c) hopelessness and despair, (d) anxiety, fear and anger, (e) case management is family, (f) hopefulness, (g) safety, security and trust, (h) self- advocacy, (i) motivating in the face of challenges, and (j) guilt and shame. Additionally, the finding of the research discovered that student-orphans experienced specialized case management case management with three characterizations: (a) sadness, (b) happiness, and (c) anger. This transcendental phenomenological research explored how post-Ebola studentorphans experienced case management; I interviewed ten student-orphans using a semistructured interview to the point of theoretical saturation and analyzed transcripts using 
the van Kaam's transcendental phenomenological analysis as justified by Moustakas (1994) (see Appendix B; Figures 1 and 2). Data collection process for this study continued between October 17, 2018, and October 23, 2018, while data analysis of transcribed interviews between October 24, 2018, and November 3, 2018.

Furthermore, member checking with each of the research participants was between November 4, 2018, and November 6,2018, resulting in the primary themes of this transcendental phenomenological study. The results of how student-orphans experienced specialized case management in the post-Ebola reconstruction of Sierra Leone while enrolled in an agricultural university in rural Province of the country was captured through a semi-structured interview with ten research participants to the point of theoretical saturation. Research participants in this transcendental phenomenological study mainly believed that case management experiences ranged from sadness, happiness, and anger, these three elements stood out clearly in the transcripts. In the composite textural structural description using van Kaam's data analytical methodology, I contained the meaning and essence of the experiences of the research participants based on the transcribed data confirmed through the member checking process. Research participants in this transcendental phenomenological study believed and experienced specialized case management with mixed feelings. Hundred percent expressed positive attributes and experiences with case management, and 100 percent of research participants experienced case management with some form of negative connotation. However, 40 percent of research participants experienced case management with angry feelings and disposition. 


\section{Summary}

This chapter summarized the findings for this transcendental phenomenological study generated from obtained data through a face-to-face semi-structured interview with ten research participants in rural Sierra Leone who qualified through predetermined inclusive criteria. The findings of the transcendental phenomenological study using the van Kaam's modified data analytical tools produced ten major themes with several invariant constituents. The lived experiences of post-Ebola student-orphans with specialized case management based on the findings of this transcendental phenomenological study noted that case management was experienced in three different formats, (a) sadness, (b) happiness, and (c) anger. Chapter 5 contains the discussion of key findings of this transcendental phenomenological study, provides an interpretation of the findings, reports on the limitations of the study, make recommendations for future research, describe the potential impact for positive social change, and advanced recommendations for future studies of this phenomenon. 
Chapter 5: Discussion, Conclusions, and Recommendations

\section{Background}

Post disaster student-orphans in rural communities and engaged in higher educational activities experience challenges different than others disaster victims, difficulties range from adjusting to the new normal, understanding collective trauma with losses, and the stress associated with college activities and navigating community resources (see Murthy, 2018; Sanderson, Gross, Sanon \& Janairo, 2016). Mejri, Menoni, Matias, and Aminoltaheri (2017) claimed that post disaster orphans are at higher risk to bear challenges to harness limited resources to endure frustration and disbelief after a disaster than any other group. As principal investigator for this transcendental phenomenological study, I was interested in discovering how student-orphans experienced case management relative to college activities during the post-Ebola reconstruction of rural Sierra Leone. The outcome of this transcendental phenomenological study provides resources and fills an academic gap for researchers, disaster relief managers, human service administrators, and foster care parents in designing, planning, and implementing post disaster case management protocols to university student-orphans. A transcendental phenomenological design provided an opportunity for an in-depth understanding of the lived experiences (Moustakas, 1994; Dedeurwaerdere, 2018; Wertz, 2016) of how student-orphans experienced specialized case management related to college activities in post disaster rural Sierra Leone.

The purpose of this transcendental phenomenological study was to explore how student-orphans experienced post-Ebola specialized case management relative to college 
activities while enrolled in higher education. Through a semi structured interviews with 10 research participants in rural Sierra Leone, the lived experiences of this phenomenon emerged from the information-rich sources. This chapter contains the following sections: (a) research findings, (b) limitation of this study, (c) the implication for social change, (d) implication of the study, (e) recommendations for future studies, and (f) conclusion. The next section contains the research finding of this transcendental phenomenological study.

\section{Research Findings}

The transcribed data from 10 research participants yielded 10 significant themes:

(a) case management as a motivator; (b), disbelief, frustration, hopelessness, and despair; (c), anxiety, fear, and anger; (d), case management is family; (e), hopefulness; (f), safety, security, and trust; (g), self-advocacy; (h), inspiration in the face of persisting trauma; and (i) guilt and shame (see Table 10). Though these results are unique to the population sampled for this transcendental phenomenological study, the interpretations of the findings may not be replicable to other populations in different settings and under different disaster recovery scenarios. Moustakas (1994) and Giorgi, (2012) posited that the findings in a transcendental phenomenological study might not be universally represented with other lived experiences. In as much as the findings may not be generalized to other populations and communities, the unique findings may help human service administrators, disaster relief managers, and community resource workers to understand lived experiences of student-orphans with specialized case management services in post disaster interventions. The understanding of how post disaster victims experience services may help to improve post disaster planning and delivery of services 
to this population to enhance college activities including (a) minimizing dropout rates, b) improving grades, and c) enhancing graduation rates. However, the findings of this transcendental phenomenological study are consistent with studies of post disaster orphans with specialized services to enhance recovery and reconstruction (Bledsoe, 1990; Davtyan, Brown, \& Folayan, 2014; Spreen \& Knapczyk, 2017; Tambo et al., 2017; Walque, 2011).

A total of 33 research participants meeting the initial research inclusive criteria from the list yielding 10 through a criterion-purposive sampling provided unique lived experiences of specialized case management generating the themes confirmed by participants through member checking. The 10 themes resulting from this transcendental phenomenological study appeared consistent with the literature reviewed in Chapter 2. Seven out of 10 research participants reported having experienced specialized case management with negative attributes while $30 \%$ reported positive feelings. Additionally, this study found that research participants sought strength and motivation through case management as a support system to enhance college activities. College graduation among student-orphans increases with support systems such as case management services which provided resource for the research population that may have enhanced college grades and graduation (Spreen \& Knapczyk, 2017). Although participants described case management as inadequate and poorly planned with other support systems for postdisaster intervention, they used community networks to adjust to the new normal, which closely aligns with the claims of Bronfenbrenner's EST $(1977,1986)$. The word frequency query results generated by Nvivo 12 provide a cloud of how student-orphans 
experienced specialized case management (see Figure 4). The next section contains the deconstruction of the major themes generated from this transcendental phenomenological study.

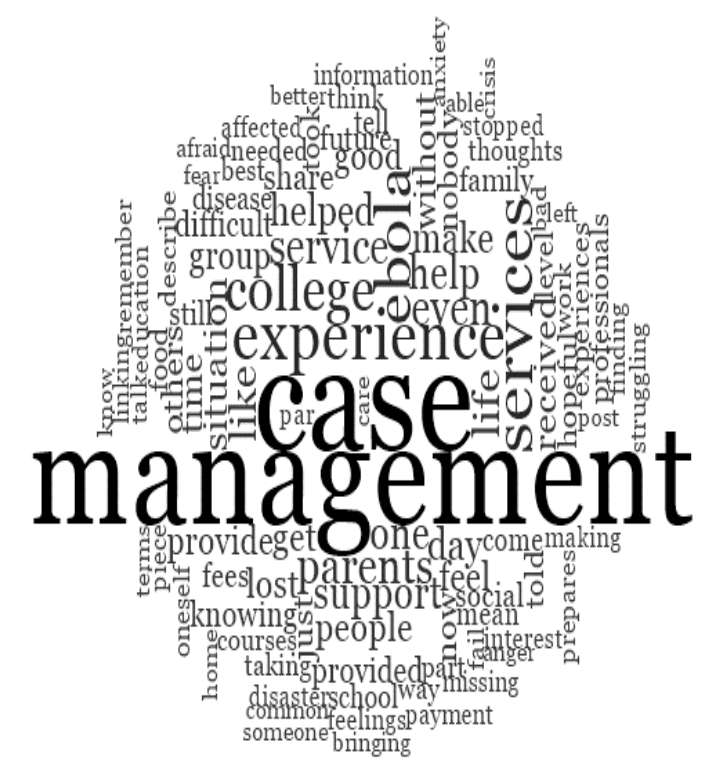

Figure 4. Word frequency query results. 
Table 10

Consider: Research Participant Characterizations of Case Management

\begin{tabular}{|c|c|c|c|}
\hline Cognitive Feelings & Emotional Affects & Physical Agony & Relational Variances \\
\hline $\begin{array}{l}\text { Impaired } \\
\text { concentration }\end{array}$ & Surprise & Feeling exhausted & Poor connections \\
\hline Confusion & Frustration & Hyper-arousal & Social isolation \\
\hline Self-blame & Irritation & $\begin{array}{l}\text { Experience of } \\
\text { physical pain }\end{array}$ & Poor grades \\
\hline Anxiety & Guilt & Loss of appetite & $\begin{array}{l}\text { Problem with self- } \\
\text { esteem }\end{array}$ \\
\hline $\begin{array}{l}\text { Dissociation } \\
\text { (spacey gazes) }\end{array}$ & Vulnerability & Headache & Increased distrust \\
\hline $\begin{array}{l}\text { Intrusive thought } \\
\text { processing }\end{array}$ & Loss of pleasure & Sleeplessness & Blaming others \\
\hline \multirow[t]{2}{*}{ Nightmares } & $\begin{array}{l}\text { Difficult feeling } \\
\text { happy }\end{array}$ & & Feeling of rejections \\
\hline & $\begin{array}{l}\text { Difficulty feeling } \\
\text { loved }\end{array}$ & & $\begin{array}{l}\text { Hypersensitive to } \\
\text { jokes }\end{array}$ \\
\hline
\end{tabular}

\section{Case Management as a Motivator}

The unexpected changes to the life of student orphans in the post Ebola reconstruction may have presented challenges and struggle for survival especially relating to collage activities. However, case management provided the opportunity for research participants. While some accepted the challenges to enroll in college and the sponsorship associated with the case management services, others engaged in therapy to resolve the grief and loss issues. The lived experiences with specialized case management from 
research participants directed the inner urge to adapt to the sudden change in the lifestyle of student-orphans. Student-orphans used case management as an adaptive tool to survive including learning to make new friends, eating foreign foods and anxiousness about the future, fear, and the urgency to meet college classes and expectations for homework and grades. In the lived experiences of PAR 1, "case management is a life-changing intervention and motivator to me." College life can be stressful and challenging when a person's safety social network is limited or diminishing (Beiter et al., 2015; Farrer, Gulliver, Bennett, Fassnacht \& Griffiths, 2016; Räsänen, Lappalainen, Muotka, Tolvanen \& Lappalainen, 2016). Lived experiences with case management with PAR 4 intertwined with the quest for social change and social justice. PAR 4 expressed that "I have changed my majors to Social Work so that I can make a difference in someone's life just as mine has been affected." A total of $60 \%$ of research participants posited that case management served as a motivating factor moving them to stay in college and study hard to make a passing grade; $20 \%$ changed majors to social services majors, while $80 \%$ experienced case management as a hopeful resource phenomenon. PAR 1 indicated that case management motivated the interest in initiating advocacy "in the process of managing and healing, I find support and see my future brighter, I changed my majors, and [became] willing to help my community so that no one should have to lose their parents as I did." PAR 6, PAR 7, and PAR 10 asserted that case management was more than services but provided the personal interest in the process. PAR 6 related that "Case management prepares the missing piece for linking with school and finding oneself." Family connections and relations are valued in each culture, and the rural communities 
tend to place a premium on such connections more than urban communities. Participants became comfortable with case management services presenting the scheme as a movement and resource center, they become more open with each other and planned to stay in touch for continued support. PAR 3, PAR 4, and PAR 7 pointed to the idea that staying connected will be good for the group as PAR 4 stated that "we will stay connected forever regardless of where we go after college"

\section{Disbelief and Frustration}

PAR 1 expressed that the experience with rejection from the community toward Ebola victims was key in investing in case management. PAR indicated that "I felt rejected and abandoned by my people, as such I concentrated on my education." The construct of getting handouts from the case management protocol appeared new to PAR 1, who linked case management with disbelief to the new normal and thoughts of past parental support. PAR 1 added that "My parents were farmers and did all they could to get me here, and we did well before all this happened." Persisting traumatic experiences with student-orphans as a result of the consequences of the 2014-2016 Ebola outbreak and the alternate burden on student-orphans created the void in the natural support systems. Additionally, fear and frustration from poor information about the disease limited extended family interractions with victims for fear of contracting the disease.

Therefore, community social support systems became impossible as such student-orphans relied on in-group support, even with the poor communication between systems yet this program became a life support for student-orphans at this university. This was evident in the testament from PAR 3: 
Life as I knew it is no more, my parents are dead, and my uncle who is the only breadwinner in the family on both sides is afraid to come near me. This is very annoying, no one seems to care to help, the hospitals do not want to give us food, the shelter they took us to was not managed by professionals, but one zombie who was just waiting for us to die and be taken away.

\section{Anxiety, Fear and Anger}

Avoiding thinking of traumatic events is common with post-disaster victims who generates anxious behaviour in which victims tend to avoid stressful feelings and situations in an effort to protect individual psychological stresses and recall of the loss associated with the disaster (Cadamuro, Versari, Vezzali, Giovannini \& Trifiletti, 2015; Vezzali, Cadamuro, Versari, Giovannini \& Trifiletti, 2015). Loo et al., (2016) posited that avoidance stress-coping conducts might generate stress and nervousness that may result in loss of self-confidence and increase anger and frustration which would result in harmful psychological impairment. The inconsistencies associated with specialized case management delivery clouded the positive experiences with the phenomenon as evident in the statements by PAR 1, PAR 3, PAR 5, PAR 6 and PAR 10 "case management is unpredictable." The participants recounted emotionally charged situations associated with case management tied to anxiety, some of these feelings felt intense and directive toward authority. The anxious feeling was evident in the expression of PAR 7 "Life with Ebola is day by day with each day bringing me numbness and anxiety but hopeful for a better future." Student-orphans experience acute emotional stress with uncertainties in postdisaster circumstance which exudes and develop behavioral problems, cumulatively 
providing a poor concentration in colleges which increase drop out and poor grades; however, reliance on community resources and peers may improve the grades and college activities (Day, Dworsky, Fogarty \& Damashek, 2011). The behavioral challenges reported by student- orphans included: (a) self-judgment, (b) poor sleeping habits, (c) low appetite, (d) poor physical health, (e) lack of exercise, (f) poor social connections resulting in isolation, and (g) poor self-esteem. These behaviors are consistent with findings relating to orphans in post-disaster interventions (Graham, Schellinger \& Vaughn, 2015; Salazar, Jones, Emerson \& Mucha, 2016). PAR 3 related to this construct of anxiety as "nobody is safe with Ebola and not even know what can make us safe, but case management provided a medium for safety by providing information to each other caring for each other and making sure the group's interest is protected."

Additionally, while others research participants used case management as a motivating element to stay in school and make the grades to graduate, some engaged in case management therapy sessions and community service, while other participants engaged in avoidance coping and relied on familiar skills to adjust to the new normal. Different coping mechanisms to the loss experienced by the research participants appeared to have created a catalyst and motivation to complete college as evident to the continued enrollment in college. Sanders, Laing, and Frost (2015) argued that while crises and disasters related encounters may provide challenges for victims, some find opportunities through motivation to move past the limitations and devastation; others remain stuck to the past causing cathartic residual traumas. The coping skills with grief and loss of both parents to an unknown disease proved to be even difficult for student-orphans in rural 
communities as community cohesion with an in-group support is significant to the existence and continued development of such communities and individuals (James \& Zagefka, 2017; Vollhardt, Nair \& Tropp, 2016). PAR 2 expressed that "I sometimes do not want to even think of it, but just concentrate on my studies."

\section{Hopelessness and Despair}

Participants expressed unique experiences with specialized case management as hopeless; this did not interface with the core belief of services acceptability and helpfulness. However, hopelessness attributed experienced by research participants geared towards the poor delivery and pattern of case management protocol. In the story

of PAR 1 ", I was afraid of dying, contacting the disease or even getting sick as there was no detection mechanism in the early stages of the disease to separate malaria from Ebola." PAR 3 associated the inadequacies with case management as the inability to service provided to understand how victims consume the services "hunger and fear were two major factors in camp, to get out locating food was difficult." The uncertainty and unreliability of the services associated with case management blurred the positive experiences of the phenomenon. Romero, Piña-Watson, and Toomey (2018) posited that hopelessness experiences by research participants geared toward the negative expectations with the belief that outcomes with the disaster will not be positive. These expectations coupled with negative feelings with case management breed an image that student-orphans associated with case management (Morselli, 2017; Marsiglia, Kulis, Perez \& Bermudez-Parsai, 2011; Lowe et al., 2015). 
On the other hand, a sense of hopelessness in services led to motivation as participants evaluated the new situations and determined that effective coping strategies inherent in victims bred new skills and behaviors (Kirkland, Sherman, Covert, Barlet \& Lichtveld, 2017). The research participants frustrated with the Ebola resources allocation, delivery, intervention, and communication, attributed lived experience with disrespect for the dead and cultural traditions. In the restorying of PAR 5 who related the uncertainty associated with case management in the lived experiences as "the whole issue surrounding the Ebola management was mismanaged and initiated anxiety." Individuals tend to build cohesion and trust when there is a central emotional bond in grief a construct often referred to as collective grief (Schultz et al., 2016; Wayment \& Silver, 2018). The risk and matrix of disaster survivals across the world are not limited to resources and communities but also on the individual's ability to adjust to the new normal and use the skills to navigate community resources (Schultz et al., 2016). The memories of the death of parents of disasters like Ebola especially in the uncertainties and confusion that surrounded the intervention provide a void that survival is encouraging further trauma associated with grief and loss (Lowe, Rhodes \& Waters, 2015; Silove, Ventevogel \& Rees, 2017). PAR 1 said "case management means something extraordinary to me, it is a life-saving experience, it gives me hope and courage and to be able to live through the traumatic experiences, and there was a time when I was discriminated against, I am now able to understand how to handle my past losses, hoping to complete my education using this opportunity." In inspiring hope, PAR 3 noted that "I am hopeful for the future someday I will be proud of myself." While PAR 3, PAR 5, 
PAR 8, and PAR 10 shared "we now have the skills to move past our traumas, as such cannot fail as we have lost all we had this is the only way that we can make it."

\section{Case Management is Family}

In post-Ebola reconstruction effort by human service managers to provide services to student -orphans challenged with stress and diverse backgrounds appeared to have found secured attachment with case management and these attachments were both in-group with parent-like figures. Such a relationship appeared to play a significant role in helping and nurturing healing (Glowacz \& Born, 2015; Mclaren \& Challis, 2009). Furthermore, younger student-orphans new in college environment legitimized parentlike authorities within the case management domain as older participants in the groups for helped younger participants with school work, mentoring and social networking.

Peer bonding patterns became evident in this transactional relationship with specialized case management which regulated awareness and improve case management experiences allowing research participants to gauge individual strengths and inabilities to manage behaviors that suits the social environment to advance advantages in educational activities (Naderi, Akbari \& Abbasi-Asl, 2016). Pagnini and Langer (2015) noted that the positive interpretation of the meaning of the crisis will also enhance case management needs and promote coping, while Pfefferbaum et al., (2016) claimed that when young orphaned students utilize creative problem-solving skills especially previously used experiences to resolve a hardship and better gain a better chance of coping with the crisis than those that may not have experienced the hardship. Post-disaster coping strategies may transform into many meanings and adaptions, depending on the environment culture 
and society where it is used and applied (Masten, 2014; Wright, Masten \& Narayan, 2013). Coping strategies in post-disaster period can be challenging to individuals in rural African communities as resources are concentrated in urban cities while victims in these areas rely on community resources (De, Gaillard, Friesen \& Smith, 2015; Smucker \& Wisner, 2008). The story of PAR 3 indicating that during the case management events "I cannot hide the fact that I have lost my parents and this group" spearing his hands raised in the air "is the family, only family I have left" silence "I have relied on them for help, questions about homework and sometimes even food." Sippel, Pietrzak, Mayes, and Southwick (2015) noted that the complex needs for post-disaster victims could be multifaceted with coping strategies and prior exposure to crisis playing a significant part in the intervention. PAR 4 described the experience as " case management was helpful to come to terms with our collective traumas that I have indeed lost my parents, I remember when we had the first session immediately after case manager started the meeting, I cannot remember his name came from the $\mathrm{UN}$, or something and told me that $\mathrm{I}$ have to come with him into his car, and he took me to a building in the camp and told me that my parents died of Ebola and that he will refer me for benefits with a program at the college, that was strange and unexpected." pause "However, that was left of what I considered family." PAR 6 inferred that the connections and relationships developed with peers in case management bred a new familiar relationship indicating that "when all you have left is a group of people that share the same experience as you, you tend to cling onto them." PAR 9 indicated that the vacuum left by the poor communication and services provided the strength to engage with peers "the workers did not manage the Ebola events enough 
to communicate the effect so that we can protect ourselves. We learned to protect each other in the group." While in the experience of PAR 9 case management became a haven "we are now family, and that means we care for each other." Although this new-found unity and central premise discovered through case management were expressed by $60 \%$ of the research participant $40 \%$ four of the ten participants indicated that the seniority of their peers still had some effect on their ability to freely communicate and relate to them regardless of the common denominator of loss. In the statements of PAR 4, PAR 6 and PAR 9 presented case management experiences as a promoter of trust "knowing that participants in the specialized case management have a common interest with postdisaster losses provided the premise to build on group cohesion, promoting trust. it appears the knowledge of knowing that Ebola took our parents the pain and grief are now expressed to gain unity among us." In the same light PAR 1, PAR 3 and PAR 5 asserted that relationships within the in-group developed to be more trusting adding that:

the unique relationship between the senior students was still visible even when we all share the same challenges. One cannot help but still feel that level of ownership and belongingness when one has a responsibility to provide protection for the group like ours, when providing others with help with college work and giving them directions this is very satisfying.

\section{Hopefulness}

Post-disaster victims appear to harbor grief, however, to attain emotional, psychic equilibrium, supportive services are required depending on several factors including (a),

age (b), gender, and (c) level and type of disaster; victims exhibited helpless and passivity 
with prolonging overwhelming catharsis (Bohleber, 2017; Zepinic, 2016). The sentiment of helplessness and sustained emotional instability with the research population became expressive through the individual unique experiences of student-orphans with specialized case management as in the lived experience of PAR 3, PAR 5 and PAR 8. PAR 3 "nobody knew what to do, and everyone was just dying." PAR 5 "Ebola is such a bad disease that kills without mercy and no cure more over the services provided were very inadequate and some not needed." Post-disaster student -orphans experienced case management with angry feelings wrapped in the face value of a poorly planned and executed case management programs. The poor service deliveries and interventions also included poor coordination of care with other agencies. PAR 8 added that "I certainly feel angry and mad as anyone could imagine at the treatment, level of care both in and out of the encampment and even when we returned to the university, we became the orphans and Ebola survivals nobody wanted to talk to us, touch us or even share our common space.” Gil-Rivas \& Kilmer (2016) and Boscarino (2015) claimed that community workers and human service administrators must be able and willing to assist studentorphans in the struggle with recovery and adapting to changes and the risk associated with the new life. However, Olu et al., (2016) posited that there must be a comprehensive approach to help student-orphans develop and maintain resilient skills to face challenges as they come to terms with post-disaster interventions through a professional team of experts including mentors, counselors, educators, spiritual leaders, opinion leaders, and peers. Within the framework of the Sierra Leonean experience, the finding of this transcendental phenomenological study demonstrated that student-orphans' reliance on 
the community, peers and case management resources provided a positive adaptation to the challenges and viewed case management in the same regard (Theron \& Theron, 2010; Wood, Theron \& Mayaba, 2012).

\section{Safety, Security and Trust}

Research participants primarily from rural areas exhibit cultures of self-reliance as such receiving case management appeared as a new concept to respondents as reliance on community in-group support system, and traditional coping mechanism seemed to have been the bedrock of managing challenges associated with crisis and disaster. PAR 3, PAR 4, PAR 5, PAR 6, PAR 8 and PAR 10 referenced that fact that "It was good that we had others who were in the same situation which would provide support to me, life would have been difficult without them" Participants linking traditional family to case management as a family unit relaying this as "useful intervention" noting that "the case management services was indeed useful to all of us, we relied on each other for support and networking." Research participants marveled in the traumatic loss of parents which case management continued to bring to bear, this loss was associated with the services of case management as expressed by PAR 5 who related that "the memories of the death of my parents circles around me all the time and think of them every day, but case management services helped me to come to terms with my loss." Additionally, PAR 3 expressed case management experiences as finding the space that brings tranquility "I find comfort in participating in case management knowing that I am not only." The construct of using physical elements as an object to grieve provides comfort to victims and serve as an instrument to lessen the pain associated with the loss, as such the 
participation in case management provided such an apparatus for student-orphans in this transcendental phenomenological study (Russo, 2018; Goulding, Kelemen \& Kiyomiya, 2018). The model of disaster intervention with post-disaster victims must be multifaceted and wrapped in motivational support mechanism to improve recovery (Breckenridge \& James, 2010; Ruzek, Kuhn, Jaworski, Owen \& Ramsey, 2016). Social relationships and more aligned psychological health and adaptable functioning among disaster victims tend to be established when motivational support is encouraged in the intervention (Goulding et al., 2018; Oktari, Shiwaku, Munadi \& Shaw, 2018).). PAR 10 described the case management service as a "miracle" and PAR 8 referenced to case management as an "a blessing, but I get a headache all the time and do not sleep well” PAR 2 described case management as "reconnecting with people, real people, not individuals who suspect you of been infected with Ebola, case management helped me get stuff, school supplies, and reconnect with people." PAR 8 experienced case management as trusting "with case management, I can talk to someone freely without fear of the information reaching someone I do not want to hear and to voice my heart which I do not usually do." In the same light PAR 6 experienced case management as a tool for empowerment, "I feel empowered and adequate, knowing where and how to get help and what type of help I may need, this is very important when one is in crisis; information is power. I never felt so strong and hopeful of my future than now; I have an offer of employment already and just waiting to complete my studies." In light of the positive experiences with case management PAR 9 asserted that case management is "hopeful" and "valuable" in light 
of poor resource availability and poor access to counseling for higher education postdisaster victims."

\section{Self-Advocacy}

The pressure in the midst of chaos and trauma, loss and grief participants found solace and hope, hoping against hope for a better future and consumed the supportive services to enhance that goal. PAR 3 noted "home is no more as there is nobody at home, you know when my mother, an excellent cook, would always bring the best to the table each day I love to be home, and it is an empty place" PAR 4 relived case management experience as "each time I went to case management, I received food, clothing I think of my parents, it is painful to expect people to give you stuff, strangers, it is not right." PAR 8 accessed case management experience as "getting a holiday present from a stranger, but this time the stranger became your only family" light of poor resource availability and poor access to counseling for higher education post-disaster student orphans in rural Sierra Leone and enrolled in higher education.

In promoting self-advocacy PAR 2 noted that "we had to ask the questions that are needed to explain to us the things that we needed to know" PAR 3 "we are not specimens and would not wait for them to give us what they think is wrong with us" PAR 9 "if we do not speak up for ourselves, nobody will, and this will not be a good thing for us. We had to stand up for what we believe in and get the leaders to understand our points." PAR 8 flatly indicated that "we organized ourselves into a strong one voice with no leader, but our answers were the same and no matter the level of questions we remained true to the cause." While PAR 5 directed the advocacy into designing and 
creating an orphan consultancy agency "my parents will be happy that I am setting up an advocacy group for orphans across the country."

\section{Inspiration in the Face of Persisting Trauma}

Social support is a crucial component to disaster recovery including family and friends which Bronfenbrenner (1977) claimed to be an important major resource. Support can also be harnessed from past survival of disasters in similar circumstances and learned skills in managing stress some of the combination of these inherent attributes in studentorphans helped in shaping waive the stressors associated with the post-Ebola saga including: (1) denial of the facts that parents died of an unknown disease, (2) hopefulness for the future now that crisis managers are interested in working with student-orphans, (3) interested in mutual and exclusivity of working to be involved in the planning, delivery and consumption of the service, (4) desire to succeed in school and help community rebuild, (5) reduced anxiety and worries about the future outbreak, and (6) reduced tension about poor understanding of the disease. The behaviors and construct expressed by research participants conform with the grief and loss model of victims in postdisasters who may linger in the healing and recovery process, grief and loss recovery take several parts to make the hole as there is no linear path or uniform model of acceptance of the new normal (Alston, Hargreaves \& Hazeleger, 2018; Sanders, Laing \& Frost, 2015). PAR 1, PAR 4 and PAR 6 "I experienced tiredness, sleeplessness, worried, lack of appetite, and lack of interest in activities which affected my grades." 


\section{Guilt and Shame}

The catharsis trauma with grief and loss with lingering memories emerged as a strong theme by the participants. There was a struggle to moving on, and participants referred to this as not been able to grief appropriately, proper traditional burial rites and cultures negated believed to have brought shame, guilt, and the lingering grief to the participants. Approximately $80 \%$ of the participants shared that for closure knowing the burial site may be a good mix in this journey. In the story of PAR 5 "getting services while others equally affected by this disaster did not get it is shameful, and I feel guilty." Student-orphans' personal experiences with trauma referencing loss during the 20012004 civil, political traumas and the Ebola pandemic presents distressing and catastrophic loss that may result in disaster shock and cloud the new normal with the Ebola disaster. In the related experience of PAR 6 noted that "the war was predictable, but the Ebola events are very unpredictable." Loss and grief associated with how post-Ebola studentorphans experienced case management appeared to have a different meaning to research participants loss due to the death of loved ones by Ebola, loss due to misinformation and or lack of information and loss of known communities continued to cloud the meaning of loss, this thereby extubated the traumatic experiences and the healing process resulting in self-blame, self-pity, anger, poor concentration in school and poor appetite. Although trauma associated losses for this transcendental phenomenological study focused on the death of parents, other types of losses to the research participants also remains pertinent to the recovery process and clouded the meaning and experience with case management such losses include: (a) loss of friend, (b) loss of residence or property, (c) loss of 
income, and (d) loss of known communities. Participants also indicated the physical, emotional and psychological incapacitation that resulted from these losses, including tiredness, sleeplessness, worried, lack of appetite, lack of interest in activities and hence low grades at school. However, the interest in participating in case management and the outcome including motivating inner interests propelled participants to remain in college. The ensuing section includes the implications for social change.

\section{Implications for Social Change}

The possible social change implication for this transcendental phenomenological study to understand the lived experiences of post - Ebola case management to enhance college performance may include the contribution of knowledge to human service administrators in designing post-disaster programs for college student-orphans in rural communities. The results from this study may include information helpful for administrators and staff that support college student-orphans in post-disaster interventions to gain insights into client lived experiences. The findings may also include information helpful for crisis and disaster program administrators and staff across similar circumstances. Furthermore, the research findings especially related to the lived experiences of case management (sadness, anger, and happiness) has a unique opportunity for policy planners and disaster managers to incorporate multi-faceted approach in designing and delivering case management services to post-disaster studentorphans.

The result may provide a useful insight to human service managers to enhance post-disaster intervention for student -orphans enrolled in higher education relative to 
college activities while dealing with complicated grief and loss issues and residual trauma Davtyan, et al., 2014; Spreen \& Knapczyk, 2017; Tambo et al., 2017; Walque, 2011). The identified long-term trauma associated with the research population provided some behavioral problems including headaches, avoidance numbing self-blaming which may affect the level of coping and healing (Graham, Schellinger \& Vaughn, 2015; Salazar et al., 2016). The next section contains the implications of the study.

\section{Implications of the Study}

The findings of this transcendental phenomenological study included that studentorphans experienced specialized case management in post-Ebola Sierra Leone, while enrolled in a university in three phases, (a) sadness, (b) happiness, and (c) anger. Although these interrelated experiences with case management appeared to have limited participants, the unique insight on how case management is experienced by studentorphans may give insight to human service administrators how to structure post-disaster intervention (Bledsoe, 1990; Davtyan, et al., 2014; Spreen \& Knapczyk, 2017; Tambo et al., 2017; Walque, 2011). Research participant cultivated coping skills learned how to harness resource in the in-group sessions and exploited these to enhance college activities. For this transcendental phenomenological study, the four defined subsystems mutually become evident in the adjustment of student-orphans to the post-Ebola intervention including the case management as such this case management became an exosystem intervention scheme that influenced the macro and micro and the meso systems. In this transcendental phenomenological study, research participants described case management lived experiences that directly related to having an inter-relationship 
with the ecosystem including the college activities, belonging to the therapy group, depending on strangers for support and educational case management (Bronfenbrenner, 1977). Bronfenbrenner's theory conceptualized that the individual and the environment mutually influence one another (Lerner, Johnson \& Buckingham, 2015; Perry $\square$ Jenkins \& Wadsworth, 2017; Zeldin, Krauss, Kim, Collura \& Abdullah, 2016). In critiquing the ecological model of adaptation to hardship in post-disaster challenges, Sippel et al., (2015) claimed that the model appears to make trauma coping as simple as achieving positive outcomes in the face of crisis, this assertion may not be applied across victims. Sippel et al., (2015) posited that for the theory to be applicable and outcomes be positive; there should be an inter-alignment of the systems for supportive mechanisms with the victims' ability to accept and entertain the services. The Sierra Leonean experience with post-Ebola student-orphans may be complex to understand in this study; it must be approached from a multiple system and multi-levels. Historically, the context of the Sierra Leonean student-orphans have been exposed to trauma for an extensive period of time, trauma including physical abuse, hunger poor of access to healthcare, and poverty these elements may have applicable coping schemes embedded in them and coupled with the cultural family systems youths are quick to adjust to any prevailing condition (Barra, 1988; Lombe, Mabikke, Enelamah \& Chu, 2017; Sanou et al., 2008). However, the residual trauma that was exhibited through anger, frustration, tension and emotional confusion related directly to the chronosystem at this stage in the mutual relationships the individual depends on the environment to vent the anger and emotion which the ecosystem takes and adjusts by providing the venues safe space for the transaction 
(Lorenz \& Dittmer, 2016; Boon, 2012; Tešliar, Kučeravcová \& Dzurdženík, 2016). Additionally, the positive feeling about case management as expressed by research participant appears to be influenced by the mesosystem including the relationship with other participants, gratefulness for the case management services, and interaction with the microsystem the case managers. The recommendations for future studies with this population as outlined in the next section may give a global understanding of how postdisaster student-orphans in higher educations may experience intervention relative to college activities.

\section{Recommendations for Further Studies}

The limited scope of this transcendental phenomenological study included students of rural Sierra Leone orphaned by the 2014-2016 Ebola pandemic, how targeted research participants experienced specialized case management while enrolled in higher education. This transcendental phenomenological study presented an in-depth view of how post-disaster rural student-orphans experienced specialized case management relative to college activities. To further explore the lived experiences of this phenomenon, one research recommendation is exploring the lived experiences of college studentorphans with specialized case management in rural and urban Sierra Leone. This comparative analysis may give program managers a comprehensive view of how postdisaster orphans experience case management regardless of the location. This research study only included information about rural college student's engagement in specialized case management it may be possible that the level of intervention with a relatively new disease may also new further studies. Therefore, I would recommend that further studies 
to explore the lived experiences of post-disaster services with younger population; adjusting the age limit to include younger population, exploring younger victims about this phenomenon may be interesting to know how younger post-disaster victims experience case management relative to other non-educational activities. Furthermore, I would recommend causal-comparative research on student - orphans to see if there are statistical relationships between case management experiences in rural areas and urban cities or among university students with the same circumstance.

\section{Summary}

Student-orphans experienced specialized case management with mixed feelings including (a) anger, (b) sadness, and (c) happiness. The participants lived experiences with specialized case management factorized into the environmental elements provided essences and ten themes and several sub-themes and demonstrated that case management was both painfully and happily experienced. In this transcendental phenomenological study 80 percent of research participants experienced specialized case management with some negative feelings and the same number experienced case management with highly positive feelings while 20 percent relied on some environmental boosts to get a positive feeling about the phenomenon. The result will provide foster care providers, government and non-governmental organizations insight into how to design wrap- around services, social support system and the construction of therapeutic needs of both the foster care children and their caregivers so that these student-orphans enrolled in higher education will use services relative to college activities to enhance grades and graduation. 
References

Abdullah, I. (2002). Youth culture and rebellion: Understanding Sierra Leone's wasted decade. Critical Arts, 16(2), 19-37. doi:10.1080/02560240285310121

Abdulmalik, J., Kola, L., \& Gureje, O. (2016). Mental health system governance in Nigeria: challenges, opportunities and strategies for improvement. Global Mental Health, 3. doi:10.1017/gmh.2016.2

Abramowitz, S. A., Bardosh, K. L., Leach, M., Hewlett, B., Nichter, M., \& Nguyen, V. (2015). Social science intelligence in the global Ebola response. Lancet,385(9965), 330. doi:10.1016/s0140-6736(15)60119-2

Abramowitz, S. A., Hipgrave, D. B., Witchard, A., \& Heymann, D. L. (2018). Lessons from the West Africa Ebola epidemic: A systematic review of Epidemiological and Social and Behavioral Science Research Priorities. Journal of Infectious Diseases. doi:10.1093/infdis/jiy387

Abramson, D. M., Grattan, L. M., Mayer, B., Colten, C. E., Arosemena, F. A., BedimoRung, A., \& Lichtveld, M. (2015). The resilience activation framework: A conceptual model of how access to social resources promotes adaptation and rapid recovery in post-disaster Settings. Journal of Behavioral Health Services \& Research, 42(1), 42 57-2 doi:10.1007/s11414-014-9410

Acemoglu, D., Chaves, I., Osafo-Kwaako, P., \& Robinson, J. (2014). Indirect rule and state weakness in Africa: Sierra Leone in comparative perspective. doi:10.3386/w20092

Adejuwon, G., \& Oki, S. (2011). Emotional well-being of orphans and vulnerable 
children in Ogun State orphanages Nigeria: Predictors and implications for policy. IFE, 19(1). doi:10.4314/ifep.v19i1.64571

Ager, A., Stark, L., Olsen, J., Wessells, M., \& Boothby, N. (2010). Sealing the past, facing the future: An evaluation of a program to support the reintegration of girls and young women formerly associated with armed groups and forces in Sierra Leone. Girlhood Studies, 3(1), 70-93. doi:10.3167/ghs.2010.030106

Agutter, K. (2016). Fated to be Orphans: The consequences of Australias post-war resettlement policy on refugee children. Children Australia, 41(03), 224-231. doi:10.1017/cha.2016.15

Ainsworth, M., \& Filmer, D. (2006). Inequalities in children's schooling: AIDS, orphanhood, poverty, and gender. World Development, 34(6), 1099-1128. doi:10.1016/j.worlddev.2005.11.007

Aitsi-Selmi, A., Egawa, S., Sasaki, H., Wannous, C., \& Murray, V. (2015). The Sendai framework for disaster risk reduction: Renewing the global commitment to people's resilience, health, and well-being. International Journal of Disaster Risk Science, 6(2), 164-176. oi:10.1007/s13753-015-0050-9

Akram, M., Anjum, F., \& Akram, N. (2015). Role of orphanages to uplift the socioeconomic status of orphans focusing on SOS Children's Villages in Punjab, Pakistan. Mediterranean Journal of Social Sciences, 6(3). doi:10.5901/mjss.2015.v6n3s2p177

Aldrich, D. P. (2017). The importance of social capital in building community resilience. In W. Wan, \& W. Galloway (Eds.), Rethinking resilience, adaptation and 
transformation in a time of change (pp. 357-364). New York, NY: Springer. doi:10.1007/978-3-319-50171-0_23

Alemu, M. M. (2016). Youth unemployment challenges and opportunities: The case of Sierra Leone. International Journal of Social Science Studies, 4(10). doi:10.11114/ijsss.v4i10.1818

Alesina, A., Giuliano, P., \& Nunn, N. (2013). On the origins of gender roles: Women and the plough. Quarterly Journal of Economics, 128(2), 469-530. doi:10.1093/qje/qjt005

Ali, H., Dumbuya, B., Hynie, M., Idahosa, P., Keil, R., \& Perkins, P. (2016). The social and political dimensions of the Ebola response: Global inequality, climate change, and infectious disease. In W. L. Filho, U. M. Azeiteiro, \& F Alves (Eds.), Climate Change Management Climate Change and Health (pp. 151-169). New York, NY: Springer. doi:10.1007/978-3-319-24660-4_10

Ali, A. M., \& Yusof, H. (2011). Quality in qualitative studies: The case of validity, reliability and generalizability. Issues in Social and Environmental Accounting, 5(1), 25-64. doi.org/10.22164/isea.v5i1.59

Alkire, S., Roche, J. M., Seth, S., \& Sumner, A. (2015). Identifying the poorest people and groups: Strategies using the global multidimensional poverty index. Journal of International Development, 27(3), 362-387. doi:10.1002/jid.3083

Alkire, S., \& Santos, M. E. (2014). Measuring acute poverty in the developing world: Robustness and scope of the multidimensional poverty index. World Development, 59, 251-274. doi:10.1016/j.worlddev.2014.01.026 
Allen, B. S., \& Vacca, J. S. (2011). Bring back orphanages-An alternative to foster care? Children and Youth Services Review, 33(7), 1067-1071. doi:10.1016/j.childyouth.2011.01.013

Althaus, C., Low, N., Musa, E., Shuaib, F., \& Gsteiger, S. (2015). Ebola virus disease outbreak in Nigeria: Transmission dynamics and rapid control. Epidemics, 11, 8084. doi:10.1016/j.epidem.2015.03.001

Alston, M., Hargreaves, D., \& Hazeleger, T. (2018). Postdisaster Social Work:

Reflections on the nature of place and loss. Australian Social Work, 71(4), 405416. doi:10.1080/0312407x.2017.1409776

Anderson, J., \& Eppard, J. (1998). Van Kaam's method revisited. Qualitative Health Research, 8(3), 399-403.doi:10.1177/104973239800800310

Anebonam, U., \& Ossai, O. (2016). Use of contact isolation to prevent spread: Ebola outbreak in a health workers base camp, Port Loko District, Sierra Leone, March 2015. International Journal of Infectious Diseases, 45, 216. doi:10.1016/j.ijid.2016.02.491

Ansumana, R., Jacobsen, K. H., Idris, M., Bangura, H., Boie-Jalloh, M., Lamin, J. M., . . . Sahr, F. (2015). Ebola in Freetown area, Sierra Leone-A case study of 581 patients. New England Journal of Medicine, 372(6), 587-588. doi:10.1056/nejmc1413685

Ardington, C., \& Leibbrandt, M. (2010). Orphanhood and schooling in South Africa: Trends in the vulnerability of orphans between 1993 and 2005. Economic Development and Cultural Change, 58(3), 507-536. doi:10.1086/650414 
Archibald, S., \& Richards, P. (2002). Converts to human rights? Popular debate about war and justice in rural central Sierra Leone. Africa, 72(03), 339-367. doi:10.3366/afr.2002.72.3.339

Armour, M., Rivaux, S. L., \& Bell, H. (2009). Using context to build rigor: Application to two hermeneutic phenomenological studies. Qualitative Social Work, 8(1), 101-122. doi:10.1177/1473325008100424

Asogwa, B. E. (2012). The challenge of managing electronic records in developing countries. Records Management Journal, 22(3), 198-211. doi:10.1108/09565691211283156

Ayub, T., Kumar, D., \& Shora, T. (2016). Psychosocial, demographic, educational and health characteristics of street children - a qualitative study. International Journal of Medical Science and Public Health, 5(8), 1702. doi:10.5455/ijmsph.2016.09122015290

Bakare, W. A., Ilesanmi, O. S., Nabena, E. P., \& Famuyide, T. (2016). Psychosocial stressors and support needs of survivors of Ebola virus disease, Bombali District, Sierra Leone, 2015. Healthcare in Low-Resource Settings, 3(2). doi:10.4081/hls.2015.5411

Bakhshi, S., Lynn-Nicholson, R., Jones, B., Amlôt, R., Greenberg, N., \& Rubin, G. J. (2014). Responding to a Radiological Crisis: Experiences of British Foreign Office staff in Japan after the Fukushima nuclear meltdown. Disaster Medicine and Public Health Preparedness, 8(05), 397-403. doi:10.1017/dmp.2014.98 
Baldé, Y. (2011). The impact of remittances and foreign aid on savings/investment in sub-Saharan Africa. African Development Review, 23(2), 247-262. doi:10.1111/j.1467-8268.2011.00284.x

Balding, C., Feng, Y., \& Atashband, A. (2015). Who wants to adopt and who wants to be adopted: A sample of American families and sub-Saharan African orphans. Health Policy and Planning, 30(10), 1320-1333. doi:10.1093/heapol/czv002

Baldwin, L. (2012). [Review of the book Raised by the church: Growing up in New York City's Catholic orphanages by E. Rohs \& J. Estrine]. American Catholic Studies, 123(3), 79-81. doi:10.1353/acs.2012.0032

Band-Winterstein, T., Doron, I., \& Naim, S. (2014). 'I take them with me'-reflexivity in sensitive research. Reflective Practice, 15(4), 530-539.

doi:10.1080/14623943.2014.900031

Banya, K. (1991). Economic decline and the education system: the case of Sierra Leone. Compare: A Journal of Comparative and International Education, 21(2), 127-143. doi:10.1080/0305792910210203

Banya, K., \& Fyle, C. M. (1995). The state and the provisions of social services in Sierra Leone since independence, 1961-1991. Canadian Journal of African Studies / Revue Canadienne des Études Africaines, 29(3), 509. doi:10.2307/486023

Barra, X. D. (1998). Poverty: The main cause of ill health in urban children. Health Education \& Behavior, 25(1), 46-59. doi:10.1177/109019819802500105 
Barrios-Tao, H., Siciliani-Barraza, J. M., \& Bonilla-Barrios, B. (2016). Education programs in post-conflict environments: a review from Liberia, Sierra Leone, and South Africa. Revista Electrónica Educare, 21(1), 1. doi:10.15359/ree.21-1.11

Baškarada, S., Shrimpton, D., \& Ng, S. (2016). Learning through foresight. Foresight, 18(4), 414-433. doi:10.1108/fs-09-2015-0045

Beegle, K., Filmer, D., Stokes, A., \& Tiererova, L. (2010). Orphanhood and the living arrangements of children in sub-Saharan Africa. World Development, 38(12), 1727-1746. doi:10.1016/j.worlddev.2010.06.015

Beegle, K., Weerdt, J. D., \& Dercon, S. (2006). Orphanhood and the long-run impact on children. American Journal of Agricultural Economics, 88(5), 1266-1272. doi:10.1111/j.1467-8276.2006.00943.x

Bell, B. P., Damon, I. K., Jernigan, D. B., Kenyon, T. A., Nichol, S. T., O’Connor, J. P., \& Tappero, J. W. (2016). Overview, control strategies, and lessons learned in the CDC response to the 2014-2016 Ebola epidemic. MMWR Supplements, 65(3), 411. doi:10.15585/mmwr.su6503a2

Bellows, J., \& Miguel, E. (2006). War and institutions: New evidence from Sierra Leone. American Economic Review, 96(2), 394-399. doi:10.1257/000282806777212323

Ben-Arieh, A. (2010). From child welfare to children well-being: The child indicators perspective. From Child Welfare to Child Well-Being, 9-22. doi:10.1007/978-90$481-3377-2 \_2$

Beiter, R., Nash, R., Mccrady, M., Rhoades, D., Linscomb, M., Clarahan, M., \& Sammut, S. (2015). The prevalence and correlates of depression, anxiety, and stress in a 
sample of college students. Journal of Affective Disorders, 173, 90-96.

doi:10.1016/j.jad.2014.10.054

Benedetti, R., Cohen, L., \& Taylor, M. (2013). “Theres really no other option”: Italian Australians' experiences of caring for a family member with dementia. Journal of Women \& Aging, 25(2), 138-164. doi:10.1080/08952841.2013.760330

Bennett, S., George, A., Rodriguez, D., Shearer, J., Diallo, B., Konate, M., . . Cliff, J. (2014). Policy challenges facing integrated community case management in subSaharan Africa. Tropical Medicine \& International Health, 19(7), 872-882. doi:10.1111/tmi.12319

Bernet, R. (2015). Transcendental phenomenology? Phenomenology in a New Key: Between Analysis and History Contributions to Phenomenology, 115-133. doi:10.1007/978-3-319-02018-1_7

Berry, K., \& Finnoff, D. (2016). Choosing between adaptation and prevention with an increasing probability of a pandemic. Journal of Economic Behavior \& Organization, 132, 177-192. doi:10.1016/j.jebo.2016.06.007

Bertone, M., Samai, M., Edem-Hotah, J., \& Witter, S. (2014). A window of opportunity for reform in post-conflict settings? The case of human resources for health policies in Sierra Leone, 2002-2012. Conflict and Health, 8(1), 11. doi:10.1186/1752-1505-8-11

Betancourt, T. S., Agnew-Blais, J., Gilman, S. E., Williams, D. R., \& Ellis, B. H. (2010). Past horrors, present struggles: The role of stigma in the association between war experiences and psychosocial adjustment among former child soldiers in Sierra 
Leone. Social Science \& Medicine, 70(1), 17-26.

doi:10.1016/j.socscimed.2009.09.038

Betancourt, T. S., Borisova, I. I., Soudière, M. D., \& Williamson, J. (2011). Sierra

Leones child soldiers: War exposures and mental health problems by gender.

Journal of Adolescent Health, 49(1), 21-28. doi:10.1016/j.jadohealth.2010.09.021

Betancourt, T. S., Borisova, I. I., Williams, T. P., Brennan, R. T., Whitfield, T. H.,

Soudiere, M. D., . . Gilman, S. E. (2010). Sierra Leone's former child soldiers: A follow-up study of psychosocial adjustment and community reintegration. Child Development, 81(4), 1077-1095. doi:10.1111/j.1467-8624.2010.01455.x

Betancourt, T. S., Brennan, R. T., Vinck, P., Vanderweele, T. J., Spencer-Walters, D., Jeong, J., . . Pham, P. (2016). Associations between mental health and Ebolarelated health behaviors: A regionally representative cross-sectional survey in post-conflict Sierra Leone. PLOS Medicine, 13(8).

doi:10.1371/journal.pmed.1002073

Betancourt, T. S., Simmons, S., Borisova, I., Brewer, S., Iweala, U., \& Soudière, M. D. (2008). High hopes, grim reality: Reintegration and the education of former child soldiers in Sierra Leone. Comparative Education Review, 52(4), 565-587. doi:10.1086/591298

Bhargava, A., \& Bigombe, B. (2003). Public policies and the orphans of AIDS in Africa. Bmj,326(7403), 1387-1389. doi:10.1136/bmj.326.7403.1387 
Bicego, G., Rutstein, S., \& Johnson, K. (2003). Dimensions of the emerging orphan crisis in sub-Saharan Africa. Social Science \& Medicine, 56(6), 1235-1247. doi:10.1016/s0277-9536(02)00125-9

Bledsoe, C. (1990). 'No success without struggle': Social mobility and hardship for foster children in Sierra Leone. Man, 25(1), 70. doi:10.2307/2804110

Blosnich, J., \& Bossarte, R. (2011). Low-level violence in schools: Is there an association between school safety measures and peer victimization? Journal of School Health, 81(2), 107-113. doi:10.1111/j.1746-1561.2010.00567.x

Blevins, C. A., Weathers, F. W., \& Witte, T. K. (2014). Dissociation and posttraumatic stress disorder: A Latent Profile Analysis. Journal of Traumatic Stress, 27(4), 388-396. doi:10.1002/jts.21933

Boon, H. J., Cottrell, A., King, D., Stevenson, R. B., \& Millar, J. (2012). Bronfenbrenner's bioecological theory for modelling community resilience to natural disasters. Natural Hazards, 60(2), 381-408. doi:10.1007/s11069-011$0021-4$

Borenstein, J., \& Mcnamara, P. (2012). Strengthening kinship families: scoping the provision of respite care in Australia. Child \& Family Social Work, 20(1), 50-61. doi:10.1111/cfs. 12055

Boscarino, J. A. (2015). Assessing community reactions to Ebola Virus Disease and other disasters: Using social psychological research to enhance public health and disaster communications. International Journal of Emergency Mental Health and Human Resilience, 17(1). doi:10.4172/1522-4821.1000147 
Bourdillon, M. (2017). Thinking about street children and orphans in Africa: Beyond survival. Children's Well-Being: Indicators and Research 'Children Out of Place' and Human Rights, 51-62. doi:10.1007/978-3-319-33251-2_4

Bower, M., Conroy, E., \& Perz, J. (2017). Australian homeless persons' experiences of social connectedness, isolation and loneliness. Health \& Social Care in the Community, 26(2). doi:10.1111/hsc.12505

Bower, J., Kraayenoord, C. V., \& Carroll, A. (2015). Building social connectedness in schools: Australian teachers' perspectives. International Journal of Educational Research, 70, 101-109. doi:10.1016/j.ijer.2015.02.004

Boylan, A. M. (1984). Women in groups: An analysis of women's benevolent organizations in New York and Boston, 1797-1840. Journal of American History, 71(3), 497. doi:10.2307/1887469

Breckenridge, J., \& James, K. (2010). Educating Social Work students in multifaceted interventions for trauma. Social Work Education, 29(3), 259-275. doi:10.1080/02615470902912250

Brett, P. T., \& Guida, R. (2013). Earthquake damage detection in urban areas using curvilinear features. IEEE Transactions on Geoscience and Remote Sensing, 51(9), 4877-4884. doi:10.1109/tgrs.2013.2271564

Brewin, C. R., \& Andrews, B. (2017). Creating memories for false autobiographical events in childhood: A systematic review. Applied Cognitive Psychology, 31(1), 2-23. doi:10.1002/acp.3220 
Briand, S., Bertherat, E., Cox, P., Formenty, P., Kieny, M. P., Myhre, J. K., . . Dye, C. (2014). The international Ebola emergency. New England Journal of Medicine, 371(13), 1180-1183. doi:10.1056/NEJMp1409858

Bronfenbrenner, U. (1977). Toward an experimental ecology of human development. American Psychologist, 32(7), 513-531. doi:10.1037//0003$066 x .32 .7 .513$

Bronfenbrenner, U. (1986). Ecology of the family as a context for human development: Research perspectives. Developmental Psychology, 22(6), 723-742. doi:10.1037//0012-1649.22.6.723

Bohleber, W. (2017). Treatment, trauma, and catastrophic reality. Psychoanalysis and Holocaust Testimony, 19-31. doi:10.4324/9781315717456-3

Brooks, S. K., Dunn, R., Sage, C. A., Amlôt, R., Greenberg, N., \& Rubin, G. J. (2015). Risk and resilience factors affecting the psychological wellbeing of individuals deployed in humanitarian relief roles after a disaster. Journal of Mental Health, 24(6), 385-413. doi:10.3109/09638237.2015.1057334

Broomhall, S. (2006). Understanding household limitation strategies among the sixteenth-century urban poor in France. French History, 20(2), 121-137. doi:10.1093/fh/cri056

Brown, N. R., Roberts, R., Whiddon, A. S., Goossen, C. E., \& Kacal, A. (2015). Paxton revisited: The essence of the lived experiences of urban agricultural education students. Journal of Agricultural Education, 56(1), 58-72. doi:10.5032/jae.2015.01058 
Brown, S., \& Wilderson, D. (2010). Homelessness prevention for former foster youth: Utilization of transitional housing programs. Children and Youth Services Review, 32(10), 1464-1472. doi:10.1016/j.childyouth.2010.07.002

Bruch, C. (2017). Disaster risk management: Assessing and leveraging existing capacities. Implications of Climate Change and Disasters on Military Activities NATO Science for Peace and Security Series C: Environmental Security, 79-82. doi:10.1007/978-94-024-1071-6_13

Bryant, M., \& Beard, J. (2016). Orphans and vulnerable children affected by human immunodeficiency virus in sub-Saharan Africa. Pediatric Clinics of North America, 63(1), 131-147. doi:10.1016/j.pcl.2015.08.007

Burden, C., Bradley, S., Storey, C., Ellis, A., Heazell, A. E., Downe, S., . . Siassakos, D. (2016). From grief, guilt pain and stigma to hope and pride - a systematic review and meta-analysis of mixed-method research of the psychosocial impact of stillbirth. BMC Pregnancy and Childbirth,16(1). doi:10.1186/s12884-016-0800-8

Burns, M. K., Warmbold-Brann, K., \& Zaslofsky, A. F. (2015). Ecological systems theory in school psychology review. School Psychology Review, 44(3), 249-261. doi:10.17105/spr-15-0092.1

Burton, R. (2015). Ebola: Lessons learned. South African Medical Journal, 105(9), 698. doi:10.7196/samjnew.8492

Buseh, A. G., Stevens, P. E., Bromberg, M., \& Kelber, S. T. (2015). The Ebola epidemic in West Africa: Challenges, opportunities, and policy priority areas. Nursing Outlook, 63(1), 30-40. doi:10.1016/j.outlook.2014.12.013 
Bush, A., Anthony, G., Barbato, A., Cunningham, S., Clement, A., Epaud, R., . . . Griese, M. (2013). Research in progress: put the orphanage out of business:

Table 1. Thorax, 68(10), 971-973. doi:10.1136/thoraxjnl-2012-203201

Butler-O'Halloran, B., \& Guilfoyle, A. M. (2015). The lived experience of finding support and care for perinatal mental health of new mothers in a rural area. The International Journal of Health, Wellness, and Society, 5(4), 15-30. doi:10.18848/2156-8960/cgp/v05i04/41139

Cadamuro, A., Versari, A., Vezzali, L., Giovannini, D., \& Trifiletti, E. (2015). Cognitive performance in the aftermath of a natural disaster: The role of coping strategies, theory of mind and peer social support. Child \& Youth Care Forum, 44(1), 93113. doi:10.1007/s10566-014-9272-z

Case, A., Paxson, C. H., \& Ableidinger, J. (2004). Orphans in Africa: Parental death, poverty, and school enrollment. Demography, 4l(3), 483-508. doi:10.1353/dem.2004.0019

Caserta, T. A., Punamäki, R., \& Pirttilä-Backman, A. (2016). The buffering role of social support on the psychosocial wellbeing of orphans in Rwanda. Social Development, 26(1), 204-224. doi:10.1111/sode.12190

Castelfranchi, C. (2015). Healing social sciences' psycho-phobia: Founding social action and structure on mental representations. Cognitive Foundations of Group Attitudes and Social Interaction, 25-57. doi:10.1007/978-3-319-21732-1_2

Chalk, M. (2017). The psychological effects of working at an Ebola treatment centre. British Journal of Nursing, 26(3), 178-179. doi:10.12968/bjon.2017.26.3.178 
Chambers, J. E. (2013). Survival-recovery effect: Military wives with soldier-husbands deployed to the operation Iraqi Freedom conflict. Journal of Psychological Issues in Organizational Culture, 4(1), 29-49. doi:10.1002/jpoc.21088

Charnley, S., Carothers, C., Satterfield, T., Levine, A., Poe, M. R., Norman, K., . . . Martin, K. S. (2017). Evaluating the best available social science for natural resource management decision-making. Environmental Science \& Policy, 73, 8088. doi:10.1016/j.envsci.2017.04.002

Cancedda, C., Davis, S. M., Dierberg, K. L., Lascher, J., Kelly, J. D., Barrie, M. B., .. . Farmer, P. E. (2016). Strengthening health systems while responding to a health crisis: Lessons learned by a nongovernmental organization during the Ebola Virus Disease epidemic in Sierra Leone. Journal of Infectious Diseases, 214(Suppl 3), S153-S163. doi:10.1093/infdis/jiw345

Cavallo, A., \& Ireland, V. (2014). Preparing for complex interdependent risks: A system of systems approach to building disaster resilience. International Journal of Disaster Risk Reduction, 9, 181-193. doi:10.1016/j.ijdrr.2014.05.001

Cheetham, D. (2012). Middle-class Victorian street Arabs: Modern re-creations of the Baker Street Irregulars. International Research in Children's Literature, 5(1), 3650. doi:10.3366/ircl.2012.0042

Chege, M. (2002). Sierra Leone: The state that came back from the dead. Washington Quarterly, 25(3), 147-160. doi:10.1162/01636600260046307

Cherry, K. E., Sampson, L., Nezat, P. F., Cacamo, A., Marks, L. D., \& Galea, S. (2014). Long-term psychological outcomes in older adults after disaster: Relationships to 
religiosity and social support. Aging \& Mental Health, 19(5), 430-443.

doi:10.1080/13607863.2014.941325

Chiodo, J. J., \& Meliza, E. (2014). Orphan trains: Teaching about an early TwentiethCentury social experiment. Social Studies, 105(3), 145-157. doi:10.1080/00377996.2013.859119

Chouliaraki, L. (2010). Post-humanitarianism: Humanitarian communication beyond a politics of pity. International Journal of Cultural Studies, 13(2), 107-126. doi: $10.1177 / 1367877909356720$

Chui, C., \& Jordan, L. P. (2016). The role of international non-governmental organizations in service delivery for orphans and abandoned children in China. International Social Work, 60(5), 1154-1168. doi:10.1177/0020872816660603

Chukwudozie, O., Feinstein, C., Jensen, C., O'kane, C., Pina, S., Skovdal, M., \& Smith, R. (2015). Applying community-based participatory research to better understand and improve kinship care practices. Family \& Community Health, 38(1), 108-119. doi:10.1097/fch.0000000000000052

Clark, A. M. (1998). The qualitative-quantitative debate: moving from positivism and confrontation to post-positivism and reconciliation. Journal of Advanced Nursing, 27(6), 1242-1249. doi:10.1046/j.1365-2648.1998.00651.x

Clark, D. V., Kibuuka, H., Millard, M., Wakabi, S., Lukwago, L., Taylor, A., . . Robb, M. L. (2015). Long-term sequelae after Ebola virus disease in Bundibugyo, Uganda: a retrospective cohort study. Lancet Infectious Diseases, 15(8), 905-912. doi:10.1016/s1473-3099(15)70152-0 
Cleary, M., Horsfall, J., \& Hayter, M. (2014). Data collection and sampling in qualitative research: does size matter? Journal of Advanced Nursing, 70(3), 473-475. doi:10.1111/jan.12163

Cloke, P., \& Conradson, D. (2018). Transitional organisations, affective atmospheres and new forms of being-in-common: Post-disaster recovery in Christchurch, New Zealand. Transactions of the Institute of British Geographers, 43(3), 360-376. doi:10.1111/tran. 12240

Collinson, M. A. (2010). Striving against adversity: the dynamics of migration, health and poverty in rural South Africa. Global Health Action, 3(1), 5080. doi:10.3402/gha.v3i0.5080

Comfort, L. K., Bert, J., \& Song, J. E. (2016). Wicked problems in real time: Uncertainty, information, and the escalation of Ebola. Information Polity, 21(3), 273-289. doi:10.3233/ip-160394

Constantinou, C. S., Georgiou, M., \& Perdikogianni, M. (2017). A comparative method for themes saturation (CoMeTS) in qualitative interviews. Qualitative Research, 146879411668665. doi:10.1177/1468794116686650

Cote, M., \& Nightingale, A. J. (2012). Resilience thinking meets social theory. Progress in Human Geography, 36(4), 475-489. doi:10.1177/0309132511425708

Cui, K., \& Sim, T. (2017). Older people's psychosocial needs in a post-disaster rural community of China: An exploratory study. Natural Hazards, 85(3), 1577-1590. doi:10.1007/s1 1069-016-2649-6 
Dabalen, A., Narayan, A., Saavedra-Chanduvi, J., Suarez, A. H., Abras, A., \& Tiwari, S. (2014). Measuring inequality of opportunities: The human opportunity index. Do African children have an equal chance?: A Human Opportunity Report for subSaharan Africa, 35-66. doi:10.1596/978-1-4648-0332-1_ch2

Dallatomasina, S., Crestani, R., Squire, J. S., Declerk, H., Caleo, G. M., Wolz, A., . . . Zachariah, R. (2015). Ebola outbreak in rural West Africa: epidemiology, clinical features and outcomes. Tropical Medicine \& International Health, 20(4), 448454. doi:10.1111/tmi.12454

Danhoundo, G., \& Khanlou, N. (2016). Family ties and mental health of orphans in Ouagadougou (Burkina Faso). Does the gender of the dead parent matter? International Journal of Mental Health and Addiction. doi:10.1007/s11469-016-9717-8

Davies, B. C., Bowley, D., \& Roper, K. (2015). Response to the Ebola crisis in Sierra Leone. Nursing Standard, 29(26), 37-41. doi:10.7748/ns.29.26.37. e9837

Davis, J. R., Wilson, S., Brock-Martin, A., Glover, S., \& Svendsen, E. R. (2010). The impact of disasters on populations with health and health care disparities. Disaster Medicine and Public Health Preparedness, 4(01), 30-38. doi:10.1017/s1935789300002391

Davtyan, M., Brown, B., \& Folayan, M. O. (2014). Addressing Ebola-related stigma: Lessons learned from HIV/AIDS. Global Health Action, 7(1), 26058. doi:10.3402/gha.v7.26058 
Day, A., Dworsky, A., Fogarty, K., \& Damashek, A. (2011). An examination of postsecondary retention and graduation among foster care youth enrolled in a fouryear university. Children and Youth Services Review, 33(11), 2335-2341. doi:10.1016/j.childyouth.2011.08.004

De, L. L., Gaillard, J. C., Friesen, W., \& Smith, F. M. (2015). Remittances in the face of disasters: A case study of rural Samoa. Environment, Development and Sustainability, 17(3), 653-672. doi:10.1007/s10668-014-9559-0

Dedeurwaerdere, T. (2018). From ecological psychology to four varieties of postpositivism in transdisciplinary science. Environment Systems and Decisions, 38(1), 79-83. doi:10.1007/s10669-017-9663-4

Denis-Ramirez, E., Sørensen, K. H., \& Skovdal, M. (2017). In the midst of a 'perfect storm': Unpacking the causes and consequences of Ebola-related stigma for children orphaned by Ebola in Sierra Leone. Children and Youth Services Review, 73, 445-453. doi:10.1016/j.childyouth.2016.11.025

Depinto, J. R. (2016). Corruption and the 2014 EVD crisis in Sierra Leone: Ebola as "total disease". Democratization and Human Security in Postwar Sierra Leone, 217-249. doi:10.1057/9781137486745_11

Dercon, S. (2002). Income risk, coping strategies, and safety nets. World Bank Research Observer, 17(2), 141-166. doi:10.1093/wbro/17.2.141

Disney, T. (2017). The orphanage as an institution of coercive mobility. Environment and Planning A, 49(8), 1905-1921. doi:10.1177/0308518x17711181 
Djalante, R. (2012). Identifying drivers, barriers and opportunities for integrating disaster risk reduction and climate change adaptation in Indonesia: An analysis based on the earth system governance framework. Climate Change Management Climate Change and Disaster Risk Management,131-147. doi:10.1007/978-3-642-311109_9

Doody, O., \& Noonan, M. (2013). Preparing and conducting interviews to collect data. Nurse Researcher, 20(5), 28-32. doi:10.7748/nr2013.05.20.5.28.e327

Dorjahn, V. R. (1966). Survey of the Limba people of northern Sierra Leone. R. H. Finnegan. American Anthropologist, 68(4), 1043-1044. doi:10.1525/aa.1966.68.4.02a00350

Dorsey, S., Lucid, L., Murray, L., Bolton, P., Itemba, D., Manongi, R., \& Whetten, K. (2015). A qualitative study of mental health problems among orphaned children and adolescents in Tanzania. Journal of Nervous and Mental Disease, 203(11), 864-870. doi:10.1097/nmd.0000000000000388

Doyle, E., \& Buckley, P. (2017). Embracing qualitative research: A visual model for nuanced research ethics oversight. Qualitative Research, 17(1), 95-117. doi:101177/1468794116661230

Drah, B. (2012). Orphans in sub-Saharan Africa: The crisis, the interventions, and the anthropologist. Africa Today, 59(2), 3. doi:10.2979/africatoday.59.2.3

Dumbuya, B., \& Nirupama, N. (2017). Disasters and long-term economic sustainability: a perspective on Sierra Leone. International Journal of Disaster Resilience in the Built Environment, 8(1), 58-76. doi:10.1108/ijdrbe-04-2016-0012 
Dückers, M. L., Witteveen, A. B., Bisson, J. I., \& Olff, M. (2017). The association between disaster vulnerability and post-disaster psychosocial service delivery across Europe. Administration and Policy in Mental Health and Mental Health Services Research, 44(4), 470-479. doi:10.1007/s10488-015-0671-8

Edwards, B., \& Yilmaz, S. (2016). Decentralization as a post-conflict stabilization tool: The case of Sierra Leone. Public Administration and Development, 36(5), 347358. doi:10.1002/pad.1784

Efevbera, Y., \& Betancourt, T. S. (2016). "Youth do all such things to survive here": A qualitative study of challenges facing war-affected youth in Sierra Leone. Peace and Conflict: Journal of Peace Psychology, 22(3), 254-261. doi:10.1037/pac0000174

Efron, S. E. (2008). Moral education between hope and hopelessness: The legacy of Janusz Korczak. Curriculum Inquiry, 38(1), 39-62. doi:10.1111/j.1467873x.2007.00397.x

Elston, J., Cartwright, C., Ndumbi, P., \& Wright, J. (2017). The health impact of the 2014-15 Ebola outbreak. Public Health, 143, 60-70. doi:10.1016/j.puhe.2016.10.020

Emerson, C. H. (2012). Crisis and disaster counseling: Lessons learned from Hurricane Katrina and other disasters. Journal of Family Psychotherapy, 23(1), 79-80. doi:10.1080/08975353.2012.654095

Enarson, E., \& Fordham, M. (2001). From women's needs to women's rights in disasters. Environmental Hazards, 3(3), 133-136. doi:10.3763/ehaz.2001.0314 
Etikan, I. (2016). Comparision of snowball sampling and sequential sampling technique. Biometrics \& Biostatistics International Journal, 3(1). doi:10.15406/bbij.2016.03.00055

Evans, D. K., \& Miguel, E. (2007). Orphans and schooling in Africa: A longitudinal analysis. Demography, 44(1), 35-57. doi:10.1353/dem.2007.0002

Evans, D. K., \& Popova, A. (2015a). Orphans and Ebola: Estimating the secondary impact of a public health crisis. Policy Research Working Papers. doi:10.1596/1813-9450-7196

Evans, D. K., \& Popova, A. (2015b). West African Ebola crisis and orphans. Lancet, 385(9972), 945-946. doi:10.1016/s0140-6736(15)60179-9

Fanthorpe, R. (2006). On the limits of liberal peace: Chiefs and democratic decentralization in post-war Sierra Leone. African Affairs, 105(418), 27-49. doi:10.1093/afraf/adi091

Fanthorpe, R., \& Maconachie, R. (2010). Beyond the 'crisis of youth'? mining, farming, a and civil society in post-war Sierra Leone. African Affairs, 109(435), 251-272. doi:10.1093/afraf/adq004

Farrar, J. J., \& Piot, P. (2014). The Ebola emergency_-Immediate action, ongoing strategy. New England Journal of Medicine, 371(16), 1545-1546. doi:10.1056/nejme1411471

Farrer, L. M., Gulliver, A., Bennett, K., Fassnacht, D. B., \& Griffiths, K. M. (2016). Demographic and psychosocial predictors of major depression and generalised 
anxiety disorder in Australian university students. BMC Psychiatry, 16(1). doi:10.1186/s12888-016-0961-z

Fimbel, C. (1994). The relative use of abandoned farm clearings and old forest habitats by primates and a forest antelope at Tiwai, Sierra Leone, West Africa. Biological Conservation, 70(3), 277-286. doi:10.1016/0006-3207(94)90173-2

Finlay, J. E., Fink, G., Mccoy, D. C., Tavárez, L. C., Chai, J., Danaei, G., . . F Fawzi, M. C. (2016). Stunting risk of orphans by caregiver and living arrangement in lowincome and middle-income countries. Journal of Epidemiology and Community Health, 70(8), 784-790. doi:10.1136/jech-2015-206346

Finlay, L. (2014). Engaging phenomenological analysis. Qualitative Research in Psychology, 11(2), 121-141. doi:10.1080/14780887.2013.807899

Fischer, F. (1998). Beyond empiricism: Policy inquiry in post positivist perspective. Policy Studies Journal, 26(1), 129-146. doi:10.1111/j.1541-0072.1998.tb01929.x

Fitzgerald, J. (2016). Orphans in Mediterranean antiquity and early Christianity. Acta Theologica, 23(1), 29. doi:10.4314/actat.v23i1s

Fivush, R., \& Merrill, N. (2016). An ecological systems approach to family narratives. Memory Studies, 9(3), 305-314. doi:10.1177/1750698016645264

Flood, A. (2010). Understanding phenomenology. Nurse Researcher, 17(2), 7-15. doi: $10.7748 / \mathrm{nr} 2010.01 \cdot 17.2 .7 . \mathrm{c} 7457$

Fluke, J. D., Goldman, P. S., Shriberg, J., Hillis, S. D., Yun, K., Allison, S., \& Light, E. (2012). Systems, strategies, and interventions for sustainable long-term care and 
protection of children with a history of living outside of family care. Child Abuse \& Neglect, 36(10), 722-731. doi:10.1016/j.chiabu.2012.09.005

Foege, W. H., Millar, J. D., \& Lane, J. M. (1971). Selective epidemiologic control in Smallpox eradication1. American Journal of Epidemiology, 94(4), 311-315. doi:10.1093/oxfordjournals.aje.a121325

Folayan, M., Haire, B., \& Brown, B. (2016). Critical role of ethics in clinical management and public health response to the West Africa Ebola epidemic. Risk Management and Healthcare Policy, 9, 55. doi:10.2147/rmhp.s83907

Folke, C. (2006). Resilience: The emergence of a perspective for social-ecological systems analyses. Global Environmental Change, 16(3), 253-267. doi:10.1016/j.gloenvcha.2006.04.002

Forbes, D., Alkemade, N., Waters, E., Gibbs, L., Gallagher, C., Pattison, P., . . Bryant, R. A. (2015). The role of anger and ongoing stressors in mental health following a natural disaster. Australian \& New Zealand Journal of Psychiatry, 49(8), 706713. doi: $10.1177 / 0004867414565478$

Forehand, R., \& Kotchick, B. A. (2016). Cultural diversity: A wake-up call for parent training-Republished article. Behavior Therapy, 47(6), 981-992. doi:10.1016/j.beth.2016.11.010

Forenza, B. (2016). Opportunity role structure, social support, and leadership: Processes of foster youth advisory board participation. Journal of Community Psychology, 44(7), 904-918. doi:10.1002/jcop.21817 
Forsman, H. (2015). Foster carers' experiences of a paired reading literacy intervention with looked-after children. Child \& Family Social Work, 22(1), 409-418. doi:10.1111/cfs. 12258

Frenkel, S., \& Western, J. (1988). Pretext or prophylaxis? Racial segregation and malarial mosquitos in a British Tropical Colony: Sierra Leone. Annals of the Association of American Geographers, 78(2), 211-228. doi:10.1111/j.14678306.1988.tb00203.x

Frieden, T. R., Damon, I., Bell, B. P., Kenyon, T., \& Nichol, S. (2014). Ebola 2014New challenges, new global response and responsibility. New England Journal of Medicine, 371(13), 1177-1180. doi:10.1056/nejmp1409903

Frimpong-Manso, K. (2013). From walls to homes: Child care reform and deinstitutionalisation in Ghana. International Journal of Social Welfare, 23(4), 402-409. doi:10.1111/ijsw.12073

Frith, H., \& Gleeson, K. (2011). Qualitative data collection: asking the right questions. Qualitative Research Methods in Mental Health and Psychotherapy, 55-67. doi:10.1002/9781119973249.ch5

Frost, J. L. (2005). Lessons from disasters: Play, work, and the creative arts. Childhood Education, 82(1), 2-8. doi:10.1080/00094056.2005.10521332

Fry, J., Scammell, J., \& Barker, S. (2017). Drowning in muddied waters or swimming downstream?: A critical analysis of literature reviewing in a phenomenological study through an exploration of the lifeworld, reflexivity and role of the 
researcher. Indo-Pacific Journal of Phenomenology, 17(1), 1-12.

doi:10.1080/20797222.2017.1293355

Fullerton, C. S., \& Ursano, R. J. (2005). Psychological and psychopathological consequences of disasters. Disasters and Mental Health, 13-36.

doi:10.1002/047002125x.ch2

Fyfe, C. (1987). 1787-1887-1987: Reflections on a Sierra Leone bicentenary. Africa, 57(04), 411-421. doi:10.2307/1159891

Gale, N. K., Heath, G., Cameron, E., Rashid, S., \& Redwood, S. (2013). Using the framework method for the analysis of qualitative data in multi-disciplinary health research. BMC Medical Research Methodology, 13(1), 117. doi:10.1186/14712288-13-117

Gallopín, G. C. (2006). Linkages between vulnerability, resilience, and adaptive capacity. Global Environmental Change, 16(3), 293-303.

doi:10.1016/j.gloenvcha.2006.02.004

Gamble, D. P. (1963). The Temne family in a modern town (Lunsar) in Sierra Leone. Africa, 33(03), 209-226. doi:10.2307/1157416

Garbarino, J. (1980). The ecology of human development: Experiments by nature and design. Children and Youth Services Review, 2(4), 433-438. doi:10.1016/0190409(80)90036-5

Gardner, L. A. (2010). Decentralization and corruption in historical perspective: Evidence from tax collection in British Colonial Africa. Economic History of Developing Regions, 25(2), 213-236. doi:10.1080/20780389.2010.527695 
Garoff, F. (2015). Psychosocial support during the Ebola outbreak in Kailahun, Sierra Leone. Intervention, 13(1), 76-81. doi:10.1097/wtf.0000000000000077

Geiger, J. M., Hayes, M. J., \& Lietz, C. A. (2013). Should I stay or should I go? A mixed methods study examining the factors influencing foster parents' decisions to continue or discontinue providing foster care. Children and Youth Services Review, 35(9), 1356-1365. doi:10.1016/j.childyouth.2013.05.003

Gellman, M. (2015). Teaching silence in the schoolroom: whither national history in Sierra Leone and El Salvador? Third World Quarterly, 36(1), 147-161. doi:10.1080/01436597.2014.976027

Ghali, N. (2014). Resiliency in youth who have been exposed to violence. In S. PrinceEmbury \& D. H. Saklofske (Series Eds.), The Springer Series on Human Exceptionality: Resilience Interventions for Youth in Diverse Populations (pp. 279-297). New York, NY: Springer. doi:10.1007/978-1-4939-0542-3_13

Gibbs, J. M. (2017). [Book review of Treating the public: Charitable theater and civic health in the early modern Atlantic World by R. Ball]. Treating the public: Charitable theater and civic health in the early modern Atlantic World. By Racheal Ball. Journal of Social History. doi:10.1093/jsh/shx076

Gidado, S., Oladimeji, A. M., Roberts, A. A., Nguku, P., Nwangwu, I. G., Waziri, N. E., . . Poggensee, G. (2015). Public knowledge, perception and source of information on Ebola virus disease-Lagos, Nigeria; September, 2014. PLoS Currents. doi:10.1371/currents.outbreaks.0b805cac244d700a47d6a3713ef2d6db 
Gil-Rivas, V., \& Kilmer, R. P. (2016). Building community capacity and fostering disaster resilience. Journal of Clinical Psychology, 72(12), 1318-1332. doi:10.1002/jclp.22281

Giorgi, A. (1997). The theory, practice, and evaluation of the phenomenological method as a qualitative research procedure. Journal of Phenomenological Psychology, 28(2), 235-260. doi:10.1163/156916297x00103

Giorgi, A. (2012). The descriptive phenomenological psychological method. Journal of Phenomenological Psychology, 43(1), 3-12. doi:10.1163/156916212x632934

Glowacz, F., \& Born, M. (2015). 18 Away from delinquency and crime: Resilience and protective factors. Development of Criminal and Antisocial Behavior, 283-294. doi:10.1007/978-3-319-08720-7_18

Goenjian, A. K., Walling, D., Steinberg, A. M., Karayan, I., Najarian, L. M., \& Pynoos, R. (2005). A prospective study of posttraumatic stress and depressive reactions among treated and untreated adolescents 5 years after a catastrophic disaster. American Journal of Psychiatry, 162(12), 2302-2308. doi:10.1176/appi.ajp.162.12.2302

Goldberg, R. E., \& Short, S. E. (2016). What do we know about children living with HIV-infected or AIDS-ill adults in sub-Saharan Africa? A systematic review of the literature. AIDS Care, 28(Sup2), 130-141. doi:10.1080/09540121.2016.1176684 
González, F., \& Miguel, E. (2015). War and local collective action in Sierra Leone: A comment on the use of coefficient stability approaches. Journal of Public Economics, 128, 30-33. doi:10.1016/j.jpubeco.2015.05.004

Goodman-Scott, E., Carlisle, R., Clark, M., \& Burgess, M. (2016). “A powerful tool”: A phenomenological study of school counselors experiences with social stories (Featured Research). Professional School Counseling, 20(1), 25-35. doi:10.5330/1096-2409-20.1.25

Goodman, L. A. (2011). Comment: On respondent-driven sampling and snowball sampling in hard-to-reach populations and snowball sampling not in hard-to-reach populations. Sociological Methodology, 41(1), 347-353. doi:10.1111/j.14679531.2011.01242.x

Goulding, C., Kelemen, M., \& Kiyomiya, T. (2018). Community based response to the Japanese tsunami: A bottom-up approach. European Journal of Operational Research, 268(3), 887-903. doi:10.1016/j.ejor.2017.11.066

Govender, K., Reardon, C., Quinlan, T., \& George, G. (2014). Children’s psychosocial wellbeing in the context of HIV/AIDS and poverty: a comparative investigation of orphaned and non-orphaned children living in South Africa. BMC Public Health, 14(1), 165. doi:10.1186/1471-2458-14-615

Graham, K. E., Schellinger, A. R., \& Vaughn, L. M. (2015). Developing strategies for positive change: Transitioning foster youth to adulthood. Children and Youth Services Review, 54, 71-79. doi:10.1016/j.childyouth.2015.04.014 
Grant, M. J., \& Yeatman, S. (2012). The relationship between orphanhood and child fostering in sub-Saharan Africa, 1990s-2000s. Population Studies, 66(3), 279295. doi:10.1080/00324728.2012.681682

Gray, C. L., Ariely, S., Pence, B. W., \& Whetten, K. (2017). Why institutions matter: Empirical data from five low- and middle-income countries indicate the critical role of institutions for orphans. Child Maltreatment in Residential Care, 379-400. doi:10.1007/978-3-319-57990-0_18

Gray, C. L., Whetten, K., Messer, L. C., Whetten, R. A., Ostermann, J., O'donnell, K., .. . Pence, B. W. (2016). Potentially traumatic experiences and sexual health among orphaned and separated adolescents in five low- and middle-income countries. AIDS Care, 28(7), 857-865. doi:10.1080/09540121.2016.1147013

Gray, N., Stringer, B., Bark, G., Perache, A. H., Jephcott, F., Broeder, R., . . Samba, T. T. (2018). 'When Ebola enters a home, a family, a community': A qualitative study of population perspectives on Ebola control measures in rural and urban areas of Sierra Leone. PLOS Neglected Tropical Diseases, 12(6). doi:10.1371/journal.pntd.0006461

Greca, A. M., Silverman, W. K., Lai, B., \& Jaccard, J. (2010). Hurricane-related exposure experiences and stressors, other life events, and social support: Concurrent and prospective impact on children's persistent posttraumatic stress symptoms. Journal of Consulting and Clinical Psychology, 78(6), 794-805. doi:10.1037/a0020775 
Greenaway, E. S., \& Heckert, J. (2013). Does the orphan disadvantage "spill over"? An analysis of whether living in an area with a higher concentration of orphans is associated with children's school enrollment in sub-Saharan Africa. Demographic Research, 28, 1167-1198. doi:10.4054/demres.2013.28.40

Gros, A. E. (2017). Alfred Schutz on phenomenological psychology and transcendental phenomenology. Journal of Phenomenological Psychology, 48(2), 214-239. doi:10.1163/15691624-12341329

Guarte, J. M., \& Barrios, E. B. (2006). Estimation under purposive sampling. Communications in Statistics-Simulation and Computation, 35(2), 277-284. doi:10.1080/03610910600591610

Guy, D. J. (2004). Womens organizations and Jewish orphanages in Buenos Aires, 19181955. Jewish History, 18(1), 75-93. doi:10.1023/b:jehi.0000005737.07142.ab

Hacsi, T. A. (2013). Book review: Child care in black and white: Working parents and the history of orphanages. Journal of Family History, 38(2), 246-248. doi:10.1177/0363199013483739

Halkos, G., Managi, S., \& Tzeremes, N. G. (2015). The effect of natural and man-made disasters on countries' production efficiency. Journal of Economic Structures, 4(1). doi:10.1186/s40008-015-0019-2

Hamblen, J. L., Norris, F. H., Symon, K. A., \& Bow, T. E. (2016). Cognitive behavioral therapy for post disaster distress: A promising transdiagnostic approach to treating disaster survivors. Psychological Trauma: Theory, Research, Practice, and Policy. Advance online publication. doi:10.1037/tra0000221 
Hamer, M. J., Jordan, J. J., Reed, P. L., Greulich, J. D., Gaye, D. B., \& Beadling, C. W. (2016). Republic of Senegal Disaster preparedness and response exercise: Lessons learned and progress toward key goals. Disaster Medicine and Public Health Preparedness, 11(02), 183-189. doi:10.1017/dmp.2016.113

Hanlon, J. (2005). Is the international community helping to recreate the preconditions for war in Sierra Leone? Round Table, 94(381), 459-472. doi:10.1080/00358530500243641

Hareven, T. K. (2015). Family and kinship, history of. International Encyclopedia of the Social \& Behavioral Sciences, 738-744. doi:10.1016/b978-0-08-097086-8.62113X

Hartmann-Boyce, J., Boylan, A., Jebb, S. A., Fletcher, B., \& Aveyard, P. (2017). Cognitive and behavioural strategies for self-directed weight loss: Systematic review of qualitative studies. Obesity Reviews, 18(3), 335-349. doi:10.1111/obr.12500

Harvey, W. S. (2010). Methodological approaches for interviewing elites. Geography Compass, 4(3), 193-205. doi:10.1111/j.1749-8198.2009.00313.x

Hatch, T. G., Cherry, K. E., Kytola, K. L., Lu, Y., \& Marks, L. D. (2015). Loss, chaos, survival, and despair: The storm after the storms. Traumatic Stress and LongTerm Recovery,231-245. doi:10.1007/978-3-319-18866-9_13

Hawkins, R. L., \& Maurer, K. (2010). 'You fix my community, you have fixed my life': The disruption and rebuilding of ontological security in New Orleans. Disasters, 35(1), 143-159. doi:10.1111/j.1467-7717.2010.01197.x 
Hechanova, M. R., Docena, P. S., Alampay, L. P., Acosta, A., Porio, E. E., Melgar, I. E., \& Berger, R. (2018). Evaluation of a resilience intervention for Filipino displaced survivors of Super Typhoon Haiyan. Disaster Prevention and Management: An International Journal, 27(3), 346-359. doi:10.1108/dpm-01-2018-0001

Hechanova, M. R., Waelde, L. C., \& Ramos, P. A. (2016). Evaluation of a group-based resilience intervention for Typhoon Haiyan Survivors. Journal of Pacific Rim Psychology, 10. doi:10.1017/prp.2016.9

Heckathorn, D. D., \& Cameron, C. J. (2017). Network sampling: From snowball and multiplicity to respondent-driven sampling. Annual Review of Sociology, 43(1), 101-119. doi:10.1146/annurev-soc-060116-053556

Helleringer, S., \& Noymer, A. (2015). Magnitude of Ebola relative to other causes of death in Liberia, Sierra Leone, and Guinea. Lancet Global Health, 3(5). doi:10.1016/s2214-109x(15)70103-8

Hendrickx, M. M., Mainhard, M., Boor-Klip, H. J., Cillessen, A. H., \& Brekelmans, M. (2016). Social dynamics in the classroom: Teacher support and conflict and the peer ecology. Teaching and Teacher Education, 53, 30-40.

doi:10.1016/j.tate.2015.10.004

Hewlett, B. L., \& Hewlett, B. S. (2005). Providing care and facing death: Nursing during Ebola outbreaks in Central Africa. Journal of Transcultural Nursing, 16(4), 289297. doi:10.1177/1043659605278935 
Hill, L., Taylor, J., Richards, F., \& Reddington, S. (2014). 'No-one runs away for no reason': Understanding safeguarding issues when children and young people go missing from home. Child Abuse Review, 25(3), 192-204. doi:10.1002/car.2322

Hillson, R., Alejandre, J. D., Jacobsen, K. H., Ansumana, R., Bockarie, A. S., Bangura, U., . . Stenger, D. A. (2014). Methods for determining the uncertainty of Population estimates derived from satellite imagery and limited survey data: A case study of Bo City, Sierra Leone. PLoS ONE, 9(11). doi:10.1371/journal.pone.0112241

Himelhoch, S., \& Njie-Carr, V. (2016). “God loves me no matter how I am”: A phenomenological analysis of the religious and spiritual experiences of HIVinfected African-American women with depression. Mental Health, Religion \& Culture, 19(2), 178-191. doi:10.1080/13674676.2016.1138934

Hommerich, C. (2012). Trust and subjective well-being after the great East Japan Earthquake, Tsunami and nuclear meltdown: Preliminary results. International Journal of Japanese Sociology,21(1), 46-64. doi:10.1111/j.14756781.2012.01169.x

Hong, Y. (2017). Research on the strategies of assisting dealing with grief for loss of single family by community work personnel. DEStech Transactions on Social Science, Education and Human Science,(Asshm). doi:10.12783/dtssehs/asshm2016/8385 
Horrell, S., \& Humphries, J. (1995). Women's labour force participation and the transition to the male-breadwinner family, 1790-1865. Economic History Review, 48(1), 89. doi:10.2307/2597872

Hounmenou, C. (2016). Exploring child prostitution in a major city in the West African region. Child Abuse \& Neglect, 59, 26-35. doi:10.1016/j.chiabu.2016.07.003

Hsieh, H., \& Shannon, S. E. (2005). Three approaches to qualitative content analysis. Qualitative Health Research, 15(9), 1277-1288. doi:10.1177/1049732305276687

Hugo, M., Declerck, H., Fitzpatrick, G., Severy, N., Gbabai, O. B., Decroo, T., \& Herp, M. V. (2015). Post-traumatic stress reactions in Ebola virus Disease survivors in Sierra Leone. Emergency Medicine: Open Access,05(06). doi:10.4172/21657548.1000285

Humphries, J. (2013). Childhood and child labour in the British industrial revolution1. Economic History Review, 66(2), 395-418. doi:10.1111/j.14680289.2012.00651.x

Huss, E., Kaufman, R., Avgar, A., \& Shuker, E. (2016). Arts as a vehicle for community building and post-disaster development. Disasters, 40(2), 284-303. doi:10.1111/disa.12143

Isaranuwatchai, W., Coyte, P. C., Mckenzie, K., \& Noh, S. (2016). The 2004 tsunami and mental health in Thailand: A longitudinal analysis of one-and two-year postdisaster data. Disasters, 41(1), 150-170. doi:10.1111/disa.12188 
Jackson, P. (2007). Reshuffling an old deck of cards? The politics of local government reform in Sierra Leone. African Affairs, 106(422), 95-111. doi:10.1093/afraf/ad1038

Jalloh, M. F., Li, W., Bunnell, R. E., Ethier, K. A., O’Leary, A., Hageman, K. M., . . Redd, J. T. (2018). Impact of Ebola experiences and risk perceptions on mental health in Sierra Leone, July 2015. BMJ Global Health,3(2). doi:10.1136/bmjgh2017-000471

James, T. K., \& Zagefka, H. (2017). The importance of national identities and intergroup relations in disaster aid. Intergroup Helping, 269-285. doi:10.1007/978-3-31953026-0_13

Jaycox, L. H., Cohen, J. A., Mannarino, A. P., Walker, D. W., Langley, A. K., Gegenheimer, K. L., . . . Schonlau, M. (2010). Children's mental health care following Hurricane Katrina: A field trial of trauma-focused psychotherapies. Journal of Traumatic Stress. doi:10.1002/jts.20518

Jefferson, A. M., \& Buch Segal, L. (2019). The confines of time-On the ebbing away of futures in Sierra Leone and Palestine. Ethnos, 84(1), 96-112. doi:10.1080/00141844.2018.1548497

Jiménez, D., Mediavilla, D. M., Portús, P. O., López, V. P., \& Vicente, F. J. (2015). Maths: From distance to e-learning. International Journal of Interactive Multimedia and Artificial Intelligence, 3(4), 5. doi:10.9781/ijimai.2015.341 
Johnson, A. (2008a). Improving quality basic education: an evaluation of World Bank support to education in Sierra Leone. Sophia: An African Journal of Philosophy, 9(2). doi:10.4314/sophia.v9i2.38790

Johnson, A. (2008b). Higher education sector in post-war Sierra Leone: Promise and challenges. Sophia: An African Journal of Philosophy, 9(2). doi:10.4314/sophia.v9i2.38780

Jones, M. B. (1993). Decline of the American orphanage, 1941-1980. Social Service Review, 67(3), 459-480. doi:10.1086/603999

Kadak, M. T., Nasıroğlu, S., Boysan, M., \& Aydın, A. (2013). Risk factors predicting posttraumatic stress reactions in adolescents after 2011 Van earthquake. Comprehensive Psychiatry, 54(7), 982-990. doi:10.1016/j.comppsych.2013.04.003

Kaifala, J. (2016). Granville Sharp's fight to free the slaves. Free Slaves, Freetown, and the Sierra Leonean Civil War, 33-58. doi:10.1057/978-1-349-94854-3_3

Kamanda, M. (2016). Does community poverty reduce children's school attendance more at primary education than at secondary education? Evidence from post-conflict Sierra Leone. Compare: A Journal of Comparative and International Education, 46(3), 435-456. doi:10.1080/03057925.2014.1002077

Kamanda, M., Madise, N., \& Schnepf, S. (2016). Does living in a community with more educated mothers enhance children's school attendance? Evidence from Sierra Leone. International Journal of Educational Development, 46, 114-124. doi:10.1016/j.ijedudev.2015.09.008 
Kamara, S., Walder, A., Duncan, J., Kabbedijk, A., Hughes, P., \& Muana, A. (2017). Mental health care during the Ebola virus disease outbreak in Sierra Leone. Bulletin of the World Health Organization, 95(12), 842-847. doi:10.2471/blt.16.190470

Kanyako, V. (2011). The check is not in the mail: How local civil-society organizations cope with funding volatility in post conflict Sierra Leone. Africa Today, 58(2), 216. doi:10.2979/africatoday.58.2.3

Kazeem, A., \& Jensen, L. (2017). Orphan status, school attendance, and relationship to household head in Nigeria. Demographic Research, 36, 659-690. doi:10.4054/demres.2017.36.22

Keefer, K. H. (2017). The first Missionaries of the Church Missionary Society in Sierra Leone, 1804-1816: A Biographical Approach. History in Africa, 1-37. doi:10.1017/hia.2017.5

Kidman, R., \& Anglewicz, P. (2016). Are adolescent orphans more likely to be HIVpositive? A pooled data analyses across 19 countries in sub-Saharan Africa. Journal of Epidemiology and Community Health, 70(8), 791-797. doi:10.1136/jech-2015-206744

Kim, E. J. (2010). "Waifs" and "orphans". Adopted Territory, 43-81. doi: $10.1215 / 9780822392668-003$

Kiraly, M., \& Humphreys, C. (2013). Perspectives from young people about family contact in kinship care: "Don't push us-listen more”. Australian Social Work, 66(3), 314-327. doi:10.1080/0312407x.2012.715658 
Kirkland, K., Sherman, M., Covert, H., Barlet, G., \& Lichtveld, M. (2017). A framework for integrating environmental and occupational health and primary care in a postdisaster context. Journal of Public Health Management and Practice, 23. doi:10.1097/phh.0000000000000656

Kline, P. M., \& Mone, E. (2003). Child and adolescent Social Work Journal, 20(5), 321333. doi:10.1023/a:1026091712028

Kumar, S., Bhukar, J., \& Vaz, W. (2011). A comparison of stress stimuli \& coping strategy among college students. PsycEXTRA Dataset. doi:10.1037/e631452013218

Kuppens, L., \& Langer, A. (2016). To address or not to address the violent past in the classroom? That is the question in Côte d'Ivoire. Journal of Peace Education,13(2), 153-171. doi:10.1080/17400201.2016.1205002

Krueger, A., Thompstone, G., \& Crispin, V. (2013). Learning from child protection systems mapping and analysis in West Africa: Research and policy implications. Global Policy, 5(1), 47-55. doi:10.1111/1758-5899.12047

Lautze, S., Leaning, J., Raven-Roberts, A., Kent, R., \& Mazurana, D. (2004). Assistance, protection, and governance networks in complex emergencies. The Lancet, 364(9451), 2134-2141. doi:10.1016/s0140-6736(04)17555-7

Lauver, L. S. (2010). The lived experience of foster parents of children with special needs living in rural Areas. Journal of Pediatric Nursing, 25(4), 289-298. doi:10.1016/j.pedn.2009.04.004 
Laverack, G., \& Manoncourt, E. (2016). Key experiences of community engagement and social mobilization in the Ebola response. Global Health Promotion, 23(1), 79-82. doi:10.1177/1757975915606674

Lee-Kwan, S. H., Deluca, N., Adams, M., Dalling, M., Drevlow, E., Gassama, G., \& Davies, T. (2014, December 19). Support services for survivors of Ebola virus disease-Sierra Leone, 2014. Morbidity and Mortality Weekly Report. Retrieved May 3, 2017, from http:/www.highbeam.com/doc/1G1395845381.html?refid=easy_hf

Lemarchand, R. (2013). Coping Strategies and Genocide Prevention. Genocide, Risk and Resilience, 36-48. doi:10.1057/9781137332431_3

Leone, S. S. (2014). ICF International. Sierra Leone demographic and health survey 2013; SSL and ICF International: Freetown. Sierra Leone.

Lerner, R. M., Johnson, S. K., \& Buckingham, M. H. (2015). Relational developmental systems-based theories and the study of children and families: Lerner and Spanier (1978) Revisited. Journal of Family Theory \& Review, 7(2), 83-104. doi:10.1111/jftr.12067

Levasseur, J. J. (2003). The problem of bracketing in phenomenology. Qualitative Health Research, 13(3), 408-420. doi:10.1177/1049732302250337

Li, Y., Hofstetter, C. R., Wahlgren, D., Irvin, V., Chhay, D., \& Hovell, M. F. (2015). Social networks and immigration stress among first-generation Mandarinspeaking Chinese immigrants in Los Angeles. International Journal of Social Welfare,24(2), 170-181. doi:10.1111/ijsw.12103 
Lindenfeld, D. F. (2005). Indigenous encounters with Christian missionaries in China and West Africa, 1800-1920: A comparative study. Journal of World History, 16(3), 327-369. doi:10.1353/jwh.2006.0006

Lindsay, S., Mcdougall, C., Menna-Dack, D., Sanford, R., \& Adams, T. (2015). An ecological approach to understanding barriers to employment for youth with disabilities compared to their typically developing peers: views of youth, employers, and job counselors. Disability and Rehabilitation, 37(8), 701-711. doi:10.3109/09638288.2014.939775

Lombe, M., Mabikke, H., Enelamah, N. V., \& Chu, Y. (2017). Conceptualizing the African child as orphan and vulnerable: A label in need of redefinition? International Social Work, 62(1), 62-75. doi: $10.1177 / 0020872817710546$

Loo, G. T., Dimaggio, C. J., Gershon, R. R., Canton, D. B., Morse, S. S., \& Galea, S. (2015). Coping behavior and risk of post-traumatic stress disorder among Federal disaster esponders. Disaster Medicine and Public Health Preparedness, 10(01), 108-117. doi:10.1017/dmp.2015.141

Lorenz, D. F., \& Dittmer, C. (2016). Resilience in catastrophes, disasters and emergencies. New Perspectives on Resilience in Socio-Economic Spheres, 25-59. doi:10.1007/978-3-658-13328-3_3

Lowe, S. R., Rhodes, J. E., \& Waters, M. C. (2015). Understanding resilience and other trajectories of psychological distress: A mixed-methods study of low-income 
mothers who survived hurricane Katrina. Current Psychology, 34(3), 537-550. doi:10.1007/s12144-015-9362-6

Lowes, L., \& Prowse, M. A. (2001). Standing outside the interview process? The illusion of objectivity in phenomenological data generation. International Journal of Nursing Studies, 38(4), 471-480. doi:10.1016/s0020-7489(00)00080-8

Lorenz, W. (2016). European policy developments and their impact on social work. European Journal of Social Work, 20(1), 17-28. doi:10.1080/13691457.2016.1185707

Lumbroso, D., Brown, E., \& Ranger, N. (2016). Stakeholders' perceptions of the overall effectiveness of early warning systems and risk assessments for weather-related hazards in Africa, the Caribbean and South Asia. Natural Hazards, 84(3), 21212144. doi:10.1007/s11069-016-2537-0

Lusk, M. W. (1992). Street children of Rio de Janeiro. International Social Work,35(3), 293-305. doi:10.1177/002087289203500302

Lynch, K., Maconachie, R., Binns, T., Tengbe, P., \& Bangura, K. (2013). Meeting the urban challenge? Urban agriculture and food security in post-conflict Freetown, Sierra Leone. Applied Geography, 36, 31-39. doi:10.1016/j.apgeog.2012.06.007

Madsen, W., \& O'mullan, C. (2016). Perceptions of community resilience after natural disaster in a rural Australian Town. Journal of Community Psychology,44(3), 277-292. doi:10.1002/jcop.21764 
Madhavan, S. (2004). Fosterage patterns in the age of AIDS: Continuity and change. Social Science \& Medicine, 58(7), 1443-1454. doi:10.1016/s02779536(03)00341-1

Malterud, K., Siersma, V. D., \& Guassora, A. D. (2016). Sample size in qualitative interview studies: Guided by information power. Qualitative Health Research, 26(13), 1753-1760. doi:10.1177/1049732315617444

Marais, F., Minkler, M., Gibson, N., Mwau, B., Mehtar, S., Ogunsola, F., . . Corburn, J. (2015). A community-engaged infection prevention and control approach to Ebola. Health Promotion International, 31(2), 440-449. doi:10.1093/heapro/dav003

Marsh, J. R. (2005). Recent judicial decisions regarding the Adoption and Safe Families Act. Adoption Quarterly, 8(4), 75-88. doi:10.1300/j145v08n04_04

Marshall, B., Cardon, P., Poddar, A., \& Fontenot, R. (2013). Does sample size matter in qualitative research?: A review of qualitative interviews in is research. Journal of Computer Information Systems, 54(1), 11-22.

doi:10.1080/08874417.2013.11645667

Martin, F. S., \& Zulaika, G. (2016). Who cares for children? A descriptive study of carerelated data available through global household surveys and how these could be better mined to inform policies and services to strengthen family care. Global Social Welfare, 3(2), 51-74. doi:10.1007/s40609-016-0060-6

Marín, A., Bodin, Ö, Gelcich, S., \& Crona, B. (2015). Social capital in post-disaster recovery trajectories: Insights from a longitudinal study of tsunami-impacted 
small-scale fisher organizations in Chile. Global Environmental Change, 35, 450462. doi:10.1016/j.gloenvcha.2015.09.020

Maschi, T., Viola, D., Morgen, K., \& Koskinen, L. (2015). Trauma, stress, grief, loss, and separation among older adults in prison: The protective role of coping resources on physical and mental well-being. Journal of Crime and Justice, 38(1), 113-136. doi:10.1080/0735648x.2013.808853

Masten, A. S. (2011). Resilience in children threatened by extreme adversity: Frameworks for research, practice, and translational synergy. Development and Psychopathology, 23(02), 493-506. doi:10.1017/s0954579411000198

Masten, A. S. (2014). Global perspectives on resilience in children and youth. Child Development, 85(1), 6-20. doi:10.1111/cdev.12205

Masten, A. S., Cutuli, J. J., Herbers, J. E., Hinz, E., Obradović, J., \& Wenzel, A. J. (2014). Academic risk and resilience in the context of homelessness. Child Development Perspectives, 8(4), 201-206. doi:10.1111/cdep.12088

Masten, A. S., \& Narayan, A. J. (2012). Child development in the context of disaster, war, and terrorism: Pathways of risk and resilience. Annual review of psychology, 63(1), 227-257. doi:10.1146/annurev-psych-120710-100356

Masten, A. S., \& Obradović, J. (2008). Disaster preparation and recovery: Lessons from research on resilience in human development. Ecology and Society, 13(1). doi:10.5751/es-02282-130109

Maclure, R., \& Denov, M. (2009). Reconstruction versus transformation: Post-war education and the struggle for gender equity in Sierra Leone. International 
Journal of Educational Development, 29(6), 612-620.

doi:10.1016/j.ijedudev.2008.11.001

Marsiglia, F. F., Kulis, S., Perez, H. G., \& Bermudez-Parsai, M. (2011). Hopelessness, family stress, and depression among Mexican-Heritage mothers in the Southwest. Health \& Social Work, 36(1), 7-18. doi:10.1093/hsw/36.1.7

Mclaren, S., \& Challis, C. (2009). Resilience among men farmers: The protective roles of social support and sense of belonging in the depression-suicidal ideation relation. Death Studies,33(3), 262-276. doi:10.1080/07481180802671985

McLellan, E., MacQueen, K. M., \& Neidig, J. L. (2003). Beyond the qualitative interview: Data preparation and transcription. Field Methods, 15(1), 63-84. doi: $10.1177 / 1525822 \times 02239573$

M'Cormack-Hale, F. A., \& Mcgough, F. M. (2016). Promises and pitfalls of the free health care initiative in Sierra Leone: An early analysis. Democratization and Human Security in Postwar Sierra Leone, 199-215. doi:10.1057/9781137486745_10

McCall, R. B. (2013). Review: The consequences of early institutionalization: Can institutions be improved? Should they? Child and Adolescent Mental Health, 18(4), 193-201. doi:10.1111/camh.12025

Mcdonald, L. (2010). Psychosocial rehabilitation of civilians in conflict-affected settings. Trauma Rehabilitation After War and Conflict, 215-245. doi:10.1007/978-1-4419-5722-1_10 
Mcmahon, S. A., Ho, L. S., Brown, H., Miller, L., Ansumana, R., \& Kennedy, C. E. (2016). Healthcare providers on the frontlines: a qualitative investigation of the social and emotional impact of delivering health services during Sierra Leone's Ebola epidemic. Health Policy and Planning, 31(9), 1232-1239. doi:10.1093/heapol/czw055

Mcmanus, J. L., \& Saucier, D. A. (2012). Helping natural disaster victims depends on characteristics and perceptions of victims. A response to "who helps natural disaster victims?”. Analyses of Social Issues and Public Policy, 12(1), 272-275. doi:10.1111/j.1530-2415.2012.01287.x

Measham, T., Guzder, J., Rousseau, C., Pacione, L., Blais-Mcpherson, M., \& Nadeau, L. (2014). Refugee children and their families: Supporting psychological well-being and positive adaptation following migration. Current Problems in Pediatric and Adolescent Health Care, 44(7), 208-215. doi:10.1016/j.cppeds.2014.03.005

Meinck, F., Fry, D., Ginindza, C., Wazny, K., Elizalde, A., Spreckelsen, T. F., . . . Dunne, M. P. (2017). Emotional abuse of girls in Swaziland: prevalence, perpetrators, risk and protective factors and health outcomes. Journal of Global Health, 7(1). doi:10.7189/jogh.07.010410

Mejri, O., Menoni, S., Matias, K., \& Aminoltaheri, N. (2017). Crisis information to support spatial planning in post disaster recovery. International Journal of Disaster Risk Reduction, 22, 46-61. doi:10.1016/j.ijdrr.2017.02.007 
Michael-Chadwell, S. (2011). Examining the underrepresentation of underserved students in gifted programs from a transformational leadership vantage point. Journal for the Education of the Gifted, 34(1), 99-130. doi:10.1177/016235321003400105

Miyagishima, K. (2016). Education inequality among different social groups. Revista Hacienda pública Española, 217(2), 11-35. doi:10.7866/hpe-rpe.16.2.1

Monasch, R., \& Boerma, J. T. (2004). Orphanhood and childcare patterns in sub-Saharan Africa. Aids, 18(Supplement 2), S55-S65. doi:10.1097/00002030-20040600200007

Moon, S., Leigh, J., Woskie, L., Checchi, F., Dzau, V., Fallah, M., . . Jha, A. K. (2017). Post-Ebola reforms: ample analysis, inadequate action. Bmj, 356, J280. doi:10.1136/bmj.j280

Moon, S., Sridhar, D., Pate, M. A., Jha, A. K., Clinton, C., Delaunay, S., . . Piot, P. (2015). Will Ebola change the game? Ten essential reforms before the next pandemic. The report of the Harvard-LSHTM Independent Panel on the Global Response to Ebola. Lancet, 386(10009), 2204-2221. doi:10.1016/s01406736(15)00946-0

Morse, J. M., Barrett, M., Mayan, M., Olson, K., \& Spiers, J. (2002). Verification strategies for establishing reliability and validity in qualitative research. International Journal of Qualitative Methods, 1(2), 13-22. doi:10.1177/160940690200100202 
Morselli, D. (2017). Contextual determinants of hopelessness: Investigating socioeconomic factors and emotional climates. Social Indicators Research, 133(1), 373-393. doi:10.1007/s11205-016-1346-x

Mouser, B. (2009). Origins of church missionary society accommodation to imperial policy: The Sierra Leone quagmire and the closing of the Susu Mission, 180417. Journal of Religion in Africa, 39(4), 375-402. doi:10.1163/002242009x12537559494278

Motha, K. C., \& Frempong, G. (2013). The lived experiences of orphaned learners in South Africa: implications for the provision of quality education. International Journal of Inclusive Education, 18(7), 686-697. doi:10.1080/13603116.2013.817616

Moustakas, C. (1994). Phenomenological research methods (Monograph). doi: $10.4135 / 9781412995658$

Moyi, P. (2013). An examination of primary school attendance and completion among secondary school age adolescents in post-conflict Sierra Leone. Research in Comparative and International Education, 8(4), 524. doi:10.2304/rcie.2013.8.4.524

Muller, B., Munslow, B., \& Odempsey, T. (2015). When community reintegration is not the best option: interethnic violence and the trauma of parental loss in South Sudan. The International Journal of Health Planning and Management,32(1), 91109. doi:10.1002/hpm.2311 
Muriuki, A. M., \& Moss, T. (2016). The impact of para-professional social workers and community health care workers in Côte dIvoire: Contributions to the protection and social support of vulnerable children in a resource poor country. Children and Youth Services Review, 67, 230-237. doi:10.1016/j.childyouth.2016.06.018

Murray, L. K., \& Jordans, M. J. (2016). Rethinking the service delivery system of psychological interventions in low and middle income countries. $B M C$ Psychiatry, 16(1). doi:10.1186/s12888-016-0938-y

Murray, R., Drew, L., Memmott, C., Bangura, Y., \& Maring, E. (2017). Surviving Ebola in Sierra Leone: A community's experience during and after the epidemic - A qualitative study. Annals of Global Health, 83(1), 158-159. doi:10.1016/j.aogh.2017.03.355

Murthy, R. S. (2018). Disaster mental health and social psychiatry: Challenges and opportunities. Indian Journal of Social Psychiatry, 34(4), 323. doi:10.4103/ijsp.ijsp_84_18

Nabwire, V. K., \& Owino, A. A. (2015). Types of family adopting orphaned learners-A reflection on challenges and coping strategies of orphaned learners in public primary schools in Kenya. Advances in Social Sciences Research Journal, 2(8). doi:10.14738/assrj.28.1346

Naderi, H., Akbari, A., \& Abbasi-Asl, R. (2016). Mediating role of resilience in relationship between attachment style dimensions and quality of life in high school students. International Journal of School Health, 3(4). doi:10.17795/intjsh-36096 
Nappi, M. M., \& Souza, J. C. (2015). Disaster management: Hierarchical structuring criteria for selection and location of temporary shelters. Natural Hazards, 75(3), 2421-2436. doi:10.1007/s11069-014-1437-4

Nathan, G. (2012). Orphanages. The encyclopedia of ancient history. Wiley Online Library: Hoboken, NJ. doi:10.1002/9781444338386.wbeah22212

Neal, J. W., \& Neal, Z. P. (2013). Nested or networked? Future directions for Ecological Systems Theory. Social Development. doi:10.1111/sode.12018

Nelson, J. (2011). Gender, age, and the abandonment of children in Eighteenth-Century Dijon, France. Journal of the History of Childhood and Youth, 4(1), 116-135. doi:10.1353/hcy.2011.0007

Netting, F., \& O’Connor, M. (2016). The Intersectionality of religion and social welfare: Historical development of Richmond's nonprofit health and human services. Religions, 7(2), 13. doi:10.3390/rel7010013

Niranjjan, R., Sarkar, S., Balajee, K., \& Srinivasan, M. (2018). Psychological distress, hopelessness and health service needs of late adolescents in rural Pondicherry, South India. International Journal Of Community Medicine And Public Health, 5(3), 1109-1115. doi:10.18203/2394-6040.ijcmph20180769

Nishimuko, M. (2009). The role of non-governmental organisations and faith-based organisations in achieving Education for All: the case of Sierra Leone. Compare: A Journal of Comparative and International Education, 39(2), 281-295. doi:10.1080/03057920902750525 
Noble, H., \& Smith, J. (2015). Issues of validity and reliability in qualitative research. Evidence Based Nursing, 18(2), 34-35. doi:10.1136/eb-2015-102054

Norris, F. H., Stevens, S. P., Pfefferbaum, B., Wyche, K. F., \& Pfefferbaum, R. L. (2008). Community resilience as a metaphor, theory, set of capacities, and strategy for disaster readiness. American Journal of Community Psychology, 41(1-2), 127-150. doi:10.1007/s10464-007-9156-6

Novelle, M. A., \& Gonyea, J. G. (2016). The availability and role of non-parental identity agents for institutionalized male adolescent social orphans in Colombia. Children and Youth Services Review,61, 51-60. doi:10.1016/j.childyouth.2015.11.024

Novelli, M., \& Higgins, S. (2016). The violence of peace and the role of education: insights from Sierra Leone. Compare: A Journal of Comparative and International Education, 47(1), 32-45. doi:10.1080/03057925.2015.1119650

Nuriddin, A., Jalloh, M. F., Meyer, E., Bunnell, R., Bio, F. A., Jalloh, M. B., . . Morgan, O. (2018). Trust, fear, stigma and disruptions: Community perceptions and experiences during periods of low but ongoing transmission of Ebola virus disease in Sierra Leone, 2015. BMJ Global Health, 3(2). doi:10.1136/bmjgh2017-000410

Oleke, C., Blystad, A., \& Rekdal, O. B. (2005). "When the obvious brother is not there": Political and cultural contexts of the orphan challenge in northern Uganda. Social Science \& Medicine, 61(12), 2628-2638. doi:10.1016/j.socscimed.2005.04.048 
Omelicheva, M. Y. (2011). Natural disasters: triggers of political instability? International Interactions, 37(4), 441-465. doi:10.1080/03050629.2011.622653

Oktari, R. S., Shiwaku, K., Munadi, K., Syamsidik, \& Shaw, R. (2018). Enhancing community resilience towards disaster: The contributing factors of schoolcommunity collaborative network in the tsunami affected area in Aceh. International Journal of Disaster Risk Reduction, 29, 3-12. doi:10.1016/j.ijdrr.2017.07.009

Orui, M., Harada, S., \& Hayashi, M. (2017). Practical report on long-term disaster mental health services following the Great East Japan Earthquake: Psychological and social background of evacuees in Sendai City in the mid- to long-term postdisaster period. Disaster Medicine and Public Health Preparedness, 11(04), 439450. doi:10.1017/dmp.2016.157

Ostrom, E. (2009). A general framework for analyzing sustainability of social-ecological systems. Science, 325(5939), 419-422. doi:10.1126/science.1172133

Osuteye, E., Johnson, C., \& Brown, D. (2017). The data gap: An analysis of data availability on disaster losses in sub-Saharan African cities. International Journal of Disaster Risk Reduction, 26, 24-33. doi:10.1016/j.ijdrr.2017.09.026

Padilla-Díaz, M. (2015). Phenomenology in educational qualitative research: Philosophy as science or philosophical science? International Journal of Educational Excellence, 1(2), 101-110. doi:10.18562/ijee.2015.0009 
Palinkas, L. A., Horwitz, S. M., Green, C. A., Wisdom, J. P., Duan, N., \& Hoagwood, K. (2013). Purposeful sampling for qualitative data collection and analysis in mixed method implementation research. Administration and Policy in Mental Health and Mental Health Services Research, 42(5), 533-544. doi:10.1007/s10488-013-0528$\mathrm{y}$

Pao, A. (2014). The red and the purple: Reflections on the intercultural imagination and multicultural casting. Contemporary Theatre Review, 24(4), 467-474. doi:10.1080/10486801.2014.946926

Park, J. Y., \& Kim, Y. S. (2015). An exploratory study on indicators in qualitative evaluation of case management with children: Focusing on experiences of children and their parents. Journal of community welfare, 54(4), 103. doi:10.15300/jcw.2015.54.4.103

Pasura, D. (2010). [Book review of Catholic women of Congo-Brazzaville: Mothers and sisters in troubled times by P. M. Martin]. African Affairs, 109(437), 685-686. doi:10.1093/afraf/adq054

Pelling, M., \& Dill, K. (2010). Disaster politics: tipping points for change in the adaptation of sociopolitical regimes. Progress in Human Geography, 34(1), 21 37. doi:10.1177/0309132509105004

Pereira, H. R. (2012). Rigour in phenomenological research: Reflections of a novice nurse researcher. Nurse Researcher, 19(3), 16-19. doi:10.7748/nr2012.04.19.3.16.c9054 
Perry-Jenkins, M., \& Wadsworth, S. M. (2017). Capturing complexities in work and family theory and research. Journal of Family Theory \& Review, 9(2), 253-256. doi:10.1111/jftr. 12190

Peter, N., Pandit, H., Le, G., Nduhiu, M., Moro, E., \& Lavy, C. (2016). Delivering a sustainable trauma management training programme tailored for low-resource settings in East, Central and Southern African countries using a cascading course model. Injury, 47(5), 1128-1134. doi:10.1016/j.injury.2015.11.042

Petrowski, N., Cappa, C., \& Gross, P. (2017). Estimating the number of children in formal alternative care: Challenges and results. Child Abuse \& Neglect. doi:10.1016/j.chiabu.2016.11.026

Phrampus, P. E., O’Donnell, J. M., Farkas, D., Abernethy, D., Brownlee, K., Dongilli, T., \& Martin, S. (2016). Rapid development and deployment of Ebola readiness training across an academic health system. Simulation in Healthcare, 11(2), 8288. doi:10.1097/sih.0000000000000137.

Phua, K. (2015). Meeting the challenge of Ebola virus disease in a holistic manner by taking into account socioeconomic and cultural factors: The experience of West Africa. Infectious Diseases: Research and Treatment, 8, 39-44. doi:10.4137/idrt.s31568

Plooy, L. D., Harms, L., Muir, K., Martin, B., \& Ingliss, S. (2014). "Black Saturday” and its aftermath: Reflecting on post disaster Social Work interventions in an Australian Trauma Hospital. Australian Social Work, 67(2), 274-284. doi:10.1080/0312407x.2013.862558 
Pollack, A. A., Weiss, B., \& Trung, L. T. (2016). Mental health, life functioning and risk factors among people exposed to frequent natural disasters and chronic poverty in Vietnam. BJPsych Open,2(03), 221-232. doi:10.1192/bjpo.bp.115.002170

Porter, A. T. (1953). Religious affiliation in Freetown, Sierra Leone. Africa, 23(01), 3-14. doi:10.2307/1156028

Porter, S. L. (2014). The Charleston orphan house: Childrens lives in the first public orphanage in America. Journal of American History, 101(2), 581-582. doi:10.1093/jahist/jau374

Pratt, M. (1970). A model for social welfare national development. International Social Work, 13(1), 2-11. doi:10.1177/002087287001300102

Pronyk, P., Rogers, B., Lee, S., Bhatnagar, A., Wolman, Y., Monasch, R., . . Chopra, M. (2016). The effect of community-based prevention and care on Ebola transmission in Sierra Leone. American Journal of Public Health, 106(4), 727732. doi:10.2105/ajph.2015.303020

Pullan, B. (2016). Foundlings and orphans: an introduction. Tolerance, Regulation and Rescue, 125-139. doi:10.7228/manchester/9781784991296.003.0008

Qureshi, A. I. (2016). Ebola virus disease. Ebola Virus Disease, 139-157. doi:10.1016/b978-0-12-804230-4.00010-8

Rahill, G. J., Joshi, M., Lescano, C., \& Holbert, D. (2015). Symptoms of PTSD in a sample of female victims of sexual violence in post-earthquake Haiti. Journal of Affective Disorders, 173, 232-238. doi:10.1016/j.jad.2014.10.067 
Rapeli, M., Cuadra, C., Dahlberg, R., Eydal, G. B., Hvinden, B., Ómarsdóttir, I. L., \& Salonen, T. (2017). Local social services in disaster management: Is there a Nordic model? International Journal of Disaster Risk Reduction. doi:10.1016/j.ijdrr.2017.07.018

Räsänen, P., Lappalainen, P., Muotka, J., Tolvanen, A., \& Lappalainen, R. (2016). An online guided ACT intervention for enhancing the psychological wellbeing of university students: A randomized controlled clinical trial. Behaviour Research and Therapy, 78, 30-42. doi:10.1016/j.brat.2016.01.001

Richards, P. (1996). The state and the provision of social services in Sierra Leone since independence, 1961-91. African Affairs, 95(378), 139-141. doi:10.1093/oxfordjournals.afraf.a007702

Richards, P., Amara, J., Ferme, M. C., Kamara, P., Mokuwa, E., Sheriff, A. I., . . Voors, M. (2015). Social pathways for Ebola Virus disease in rural Sierra Leone, and some implications for containment. PLOS Neglected Tropical Diseases, 9(4). doi:10.1371/journal.pntd.0003567

Riley, G., \& Holt, M. I. (1993). The orphan trains: Placing out in America. History of Education Quarterly, 33(3), 450. doi:10.2307/368232

Rivera, F. I., \& Kapucu, N. (2015). Disaster resilience in rural communities. Disaster Vulnerability, Hazards and Resilience, 121-134. doi:10.1007/978-3-319-164533_9

Rizk, H. I., Rifai, N. M., \& Aboulghar, H. M. (2017). Health problems among street children seeking care in the center for social and preventive medicine in 
Egypt. World Journal of Pediatrics, 13(5), 503-507. doi:10.1007/s12519-0170028-3

Roberts, K. D., \& Hitchcock, C. H. (2017). Impact of culturally aligned supports on Native Hawaiian high school students' college attendance: A qualitative perspective. Community College Journal of Research and Practice, 1-13. doi:10.1080/10668926.2017.1284698

Rodner, V. (2015). Finding the perfect fit—Paradigmatic choices for novice and experienced qualitative researchers. Symbolic Interaction, 38(1), 161-164. doi:10.1002/symb. 140

Roelen, K., Delap, E., Jones, C., \& Chettri, H. K. (2017). Improving child wellbeing and care in sub-Saharan Africa: The role of social protection. Children and Youth Services Review, 73, 309-318. doi:10.1016/j.childyouth.2016.12.020

Romera, Y. (2015). In Sierra Leone, getting back to school? on the airwaves. Retrieved from https://www.unicef.org/emergencies/ebola/75941_76352.html

Romero, A. J., Piña-Watson, B., \& Toomey, R. B. (2018). When is bicultural stress associated with loss of hope and depressive symptoms? Variation by ethnic identity status among Mexican descent youth. Journal of Latina/o Psychology, $6(1), 49$.

Ross, L. E. (2017). An account from the inside: Examining the emotional impact of qualitative research through the lens of "Insider" research. Qualitative Psychology. doi:10.1037/qup0000064 
Rotabi, K. S., Roby, J. L., \& Bunkers, K. M. (2016). Altruistic exploitation: Orphan tourism and global Social Work. British Journal of Social Work, 47(3), 648-665. doi:10.1093/bjsw/bcv147

Roth, W. (2015). Rigorous data analysis: Beyond “anything goes”. doi:10.1007/978-946209-998-2_2

Russo, F. (2018). Our stuff, ourselves. Scientific American, 318(5), 66-71. doi:10.1038/scientificamerican0518-66

Ruzek, J. I., Kuhn, E. E., Jaworski, B. K., Owen, J. E., \& Ramsey, K. M. (2016). Mobile mental health interventions following war and disaster. MHealth. doi:10.21037/mhealth.2016.08.06

Sadala, M. L., \& Adorno, R. D. (2002). Phenomenology as a method to investigate the experience lived: A perspective from Husserl and Merleau Pontys thought. Journal of Advanced Nursing,37(3), 282-293. doi:10.1046/j.13652648.2002.02071.x

Sadler, G. R., Lee, H., Lim, R. S., \& Fullerton, J. (2010). Research article: Recruitment of hard-to-reach population subgroups via adaptations of the snowball sampling strategy. Nursing \& Health Sciences, 12(3), 369-374. doi:10.1111/j.14422018.2010.00541.x

Salama, P., Laurence, B., \& Nolan, M. L. (1999). Health and human rights in contemporary humanitarian crises: is Kosovo more important than Sierra Leone? Bmj, 319(7224), 1569-1571. doi:10.1136/bmj.319.7224.1569 
Salazar, A. M., Roe, S. S., Ullrich, J. S., \& Haggerty, K. P. (2016). Professional and youth perspectives on higher education-focused interventions for youth transitioning from foster care. Children and Youth Services Review, 64, 23-34. doi:10.1016/j.childyouth.2016.02.027

Salazar, A. M., Jones, K. R., Emerson, J. C., \& Mucha, L. (2016). Postsecondary strengths, challenges, and supports experienced by foster care alumni college graduates. Journal of College Student Development, 57(3), 263-279. doi:10.1353/csd.2016.0029

Salloum, A., \& Overstreet, S. (2008). Evaluation of individual and group grief and trauma interventions for children post disaster. Journal of Clinical Child \& Adolescent Psychology, 37(3), 495-507. doi:10.1080/15374410802148194

Salloum, A., \& Overstreet, S. (2012). Grief and trauma intervention for children after disaster: Exploring coping skills versus trauma narration. Behaviour Research and Therapy, 50(3), 169-179. doi:10.1016/j.brat.2012.01.001

Salmon, J. (2012). The use of phenomenology in nursing research. Nurse Researcher, 19(3), 4-5. doi:10.7748/nr.19.3.4.s2

Salmon, S., Mclaws, M., \& Fisher, D. (2015). Community-based care of Ebola virus disease in West Africa. Lancet Infectious Diseases, 15(2), 151-152. doi:10.1016/s1473-3099(14)71080-1

Sanders, D., Laing, J., \& Frost, W. (2015). Exploring the role and importance of postdisaster events in rural communities. Journal of Rural Studies, 41, 82-94. doi:10.1016/j.jrurstud.2015.08.001 
Sanderson, R. C., Gross, S., Sanon, J. G., \& Janairo, R. (2016). Building resilience in children and their communities following disaster in a developing country: Responding to the 2010 earthquake in Haiti. Journal of Child \& Adolescent Trauma, 9(1), 31-41. doi:10.1007/s40653-015-0077-5

Sanou, D., Turgeon-Obrien, H., Ouedraogo, S., \& Desrosiers, T. (2008). Caring for orphans and vulnerable children in a context of poverty and cultural transition: A case study of a group foster homes program in Burkina Faso. Journal of Children and Poverty, 14(2), 139-155. doi:10.1080/10796120802335862

Sapienza, J. K., \& Masten, A. S. (2011). Understanding and promoting resilience in children and youth. Current Opinion in Psychiatry, 24(4), 267-273. doi:10.1097/yco.0b013e32834776a8

Saunders, B., Sim, J., Kingstone, T., Baker, S., Waterfield, J., Bartlam, B., . . Jinks, C. (2018). Saturation in qualitative research: Exploring its conceptualization and operationalization. Quality \& Quantity, 52(4), 1893-1907. doi:10.1007/s11135017-0574-8

Schalinski, I., Elbert, T., \& Schauer, M. (2011). Female dissociative responding to extreme sexual violence in a chronic crisis setting: The case of Eastern Congo. Journal of Traumatic Stress, 24(2), 235-238. doi:10.1002/jts.20631

Schalk, R. (2017). From orphan to artisan: apprenticeship careers and contract enforcement in The Netherlands before and after the guild abolition. The Economic History Review, 70(3), 730-757. doi:10.1111/ehr.12422 
Schenk, K. D. (2009). Community interventions providing care and support to orphans and vulnerable children: a review of evaluation evidence. AIDS Care, 21(7), 918942. doi:10.1080/09540120802537831

Schenk, K. D., Michaelis, A., Sapiano, T. N., Brown, L., \& Weiss, E. (2010). Improving the lives of vulnerable children: Implications of horizons research among Orphans and other children affected by AIDS. Public Health Reports, 125(2), 325-336. doi:10.1177/003335491012500223

Schleussner, C., Donges, J. F., Donner, R. V., \& Schellnhuber, H. J. (2016). Armedconflict risks enhanced by climate-related disasters in ethnically fractionalized countries. Proceedings of the National Academy of Sciences, 113(33), 9216-9221. doi:10.1073/pnas.1601611113

Schultz, K., Cattaneo, L. B., Sabina, C., Brunner, L., Jackson, S., \& Serrata, J. V. (2016). Key roles of community connectedness in healing from trauma. Psychology of Violence, 6(1), 42-48. doi:10.1037/vio0000025

Schwandt, T. A., Lincoln, Y. S., \& Guba, E. G. (2007). Judging interpretations: But is it rigorous? Trustworthiness and authenticity in naturalistic evaluation. New Directions for Evaluation, 2007(114), 11-25. doi:10.1002/ev.223

Scotland, J. (2012). Exploring the philosophical underpinnings of research: Relating ontology and epistemology to the methodology and methods of the scientific, interpretive, and critical research paradigms. English Language Teaching, 5(9). doi:10.5539/elt.v5n9p9 
Shackman, J., \& Price, B. K. (2013). Mental health capacity building in northern Sierra Leone. Intervention, 11(3), 261-275. doi:10.1097/wtf.0000000000000010

Sharma, M., Fine, S. L., Brennan, R. T., \& Betancourt, T. S. (2017). Coping and mental health outcomes among Sierra Leonean war-affected youth: Results from a longitudinal study. Development and Psychopathology, 29(01), 11-23. doi: $10.1017 / \mathrm{s} 0954579416001073$

Shaman, J., Yang, W., \& Kandula, S. (2014). Inference and forecast of the current West African Ebola outbreak in Guinea, Sierra Leone and Liberia. PLoS Currents 6. doi:10.1371/currents.outbreaks.3408774290b1a0f2dd7cae877c8b8ff6

Sharer, M., Cluver, L., Shields, J. J., \& Ahearn, F. (2016). The power of siblings and caregivers: under-explored types of social support among children affected by HIV and AIDS. AIDS care, 28(sup2), 110-117.

Doi.org/10.108/09540121.2016.1178942

Shears, P., \& O’Dempsey, T. (2015). Ebola virus disease in Africa: Epidemiology and nosocomial transmission. Journal of Hospital Infection, 90(1), 1-9. doi:10.1016/j.jhin.2015.01.002

Shepler, S. (2010). Youth music and politics in post-war Sierra Leone. Journal of Modern African Studies, 48(04), 627-642. doi:10.1017/s0022278x10000509

Shepler, S. (2014). Youth in Sierra Leone. Childhood Deployed, 21-54. doi:10.18574/nyu/9780814724965.003.0002 
Shetler, J. B. (2016). Elizabeth A. Eldredge. Kingdoms and Chiefdoms of Southeastern Africa: Oral traditions and history, 1400-1830. American Historical Review, 121(2), 689-690. doi:10.1093/ahr/121.2.689

Shetty, A. K., \& Powell, G. (2003). Children orphaned by AIDS: A global perspective. Seminars in Pediatric Infectious Diseases, 14(1), 25-31. doi:10.1053/spid.2003.127214

Shibl, R., Lawley, M., \& Debuse, J. (2013). Factors influencing decision support system acceptance. Decision Support Systems, 54(2), 953-961. doi:10.1016/j.dss.2012.09.018

Shoko, M., \& Ibisomi, L. (2016). Orphanhood prevalence, living arrangements and orphanhood reporting in Lesotho, Malawi and Zimbabwe. Child Indicators Research. doi:10.1007/s12187-016-9404-0

Shorter, M., \& Stayt, L. C. (2010). Critical care nurses' experiences of grief in an adult intensive care unit. Journal of Advanced Nursing, 66(1), 159-167 doi:10.1111/j.1365-2648.2009.05191.x

Shultz, J. M., Baingana, F., \& Neria, Y. (2015). The 2014 Ebola outbreak and mental health. Jama, 313(6), 567-568. doi:10.1001/jama.2014.17934

Shultz, J. M., Cooper, J. L., Baingana, F., Oquendo, M. A., Espinel, Z., Althouse, B. M., . . Rechkemmer, A. (2016). The role of fear-related behaviors in the 2013-2016 West Africa Ebola virus disease outbreak. Current Psychiatry Reports, 18(11). doi:10.1007/s11920-016-0741-y 
Shultz, J. M., Espinola, M., Rechkemmer, A., Cohen, M. A., \& Espinel, Z. (2016). Prevention of disaster impact and outcome cascades. The Cambridge Handbook of International Prevention Science, 492-519. doi:10.1017/9781316104453.022

Silove, D., Ventevogel, P., \& Rees, S. (2017). The contemporary refugee crisis: An overview of mental health challenges. World Psychiatry, 16(2), 130-139. doi:10.1002/wps.20438

Sim, F., \& Mackie, P. (2017). Climate change, hurricanes and public health. Public Health, 152. doi:10.1016/j.puhe.2017.10.009

Simpson, A., \& Che, S. M. (2016). A phenomenological study of middle grade female and male students' single-sex mathematical experiences. RMLE Online, 39(2), 113. doi:10.1080/19404476.2016.1138727

Sinha, A., Lombe, M., Saltzman, L. Y., Whetten, K., \& Whetten, R. (2016). Exploring factors associated with educational outcomes for orphan and abandoned children in India. Global Social Welfare, 3(1), 23-32. doi:10.1007/s40609-016-0043-7

Sippel, L. M., Pietrzak, R. H., S, C. D., Mayes, L. C., \& Southwick, S. M. (2015). How does social support enhance resilience in the trauma-exposed individual? Ecology and Society, 20(4). doi:10.5751/es-07832-200410

Smucker, T. A., \& Wisner, B. (2008). Changing household responses to drought in Tharaka, Kenya: Vulnerability, persistence and challenge. Disasters, 32(2), 190215. doi:10.1111/j.1467-7717.2007.01035.x 
Sodhi, M. S. (2016). Natural disasters, the economy and population vulnerability as a vicious cycle with exogenous hazards. Journal of Operations Management, 45, 101-113. doi:10.1016/j.jom.2016.05.010

Sprecher, A., Herp, M. V., \& Rollin, P. E. (2017). Clinical management of Ebola virus disease patients in low-resource settings. Current Topics in Microbiology and Immunology Marburg- and Ebolaviruses, 93-113.doi:10.1007/82_2017_18

Spreen, C. A., \& Knapczyk, J. J. (2017). Measuring quality beyond test scores: The impact of regional context on curriculum implementation (in Northern Uganda). Forum for International Research in Education, 4(1). doi:10.18275/fire201704011110

Ssewamala, F. M., Karimli, L., Han, C., \& Ismayilova, L. (2010). Social capital, savings, and educational performance of orphaned adolescents in sub-Saharan Africa. Children and Youth Services Review, 32(12), 1704-1710. doi:10.1016/j.childyouth.2010.07.013

Staab, S. (2016). Opportunities and constraints on gender-egalitarian policy change: Michelle Bachelet's Social Protection Agenda (2006-2010). Gender, Institutions, and Change in Bachelet's Chile, 121-146. doi:10.1057/9781137501981_6

Stark, L., Tan, T. M., Muldoon, K. A., King, D., Lamin, D. F., Lilley, S., \& Wessells, M. G. (2015). Family structure and sexual and reproductive health outcomes among adolescents in rural Sierra Leone. Global Public Health, 11(3), 309-321. doi:10.1080/17441692.2015.1031155 
Sterett, S. M. (2015). Disaster, displacement, and casework: Uncertainty and assistance after Hurricane Katrina. Law \& Policy, 37(1-2), 61-92. doi:10.1111/1apo.12029

Stoler, A. L. (2001). Tense and tender ties: The politics of comparison in North American History and (post) colonial studies. Journal of American History, 88(3), 829. doi: $10.2307 / 2700385$

Stotz, S. J., Elbert, T., Müller, V., \& Schauer, M. (2015). The relationship between trauma, shame, and guilt: Findings from a community-based study of refugee minors in Germany. European Journal of Psychotraumatology, 6(1), 25863. doi:10.3402/ejpt.v6.25863

Sullivan, G. B. (2015). Collective emotions. Social and Personality Psychology Compass, 9(8), 383-393. doi:10.1111/spc3.12183

Suri, H. (2011). Purposeful sampling in qualitative research synthesis. Qualitative Research Journal, 11(2), 63-75. doi:10.3316/qrj1102063

Svärd, P. (2010). The international community and post-war reconciliation in Africa: A case study of the Sierra Leone Truth and Reconciliation Commission. African Journal on Conflict Resolution, 10(1). doi:10.4314/ajcr.v10i1.59306

Swanke, J. R., Yampolskaya, S., Strozier, A., \& Armstrong, M. I. (2016). Mental health service utilization and time to care: A comparison of children in traditional foster care and children in kinship care. Children and Youth Services Review, 68, 154158. doi:10.1016/j.childyouth.2016.06.029 
Szente, J. (2016). Assisting children caught in disasters: Resources and suggestions for practitioners. Early Childhood Education Journal, 44(3), 201-207. doi:10.1007/s10643-015-0709-2

Szreter, S., Kinmonth, A. L., Kriznik, N. M., \& Kelly, M. P. (2016). Health, welfare, and the state - the dangers of forgetting history. Lancet, 388(10061), 2734-2735. doi:10.1016/s0140-6736(16)32429-1

Tabutin, D., \& Schoumaker, B. (2004). The demography of Africa South of the Sahara from the 1950 s to the 2000s. Population, 59(3), 521-622. doi:10.3917/popu.403.0521

Tambo, E., Chengho, C. F., Ugwu, C. E., Wurie, I., Jonhson, J. K., \& Ngogang, J. Y. (2017). Rebuilding transformation strategies in post-Ebola epidemics in Africa. Infectious Diseases of Poverty, 6(1). doi:10.1186/s40249-017-0278-2

Team, W. E. R. (2014). Ebola virus disease in West Africa-The first 9 months of the epidemic and forward projections. New England Journal of Medicine, 371(16), 1481-1495. doi:10.1056/nejmoa1411100

Tefera, B. (2015). The situation of street children in selected cities of South Sudan: Magnitude, causes, and effects. Eastern Africa Social Science Research Review, 31(1), 63-87. doi:10.1353/eas.2015.0004

Tešliar, J., Kučeravcová, A., \& Dzurdženík, J. (2016). Role of coordination in building spatial resilience after disasters. Spatial Planning and Resilience Following Disasters, 277-294. doi:10.1332/policypress/9781447323587.003.0015 
Theron, L. C., \& Theron, A. M. (2010). A critical review of studies of South African youth resilience, 1990-2008. South African Journal of Science, 106(7/8). doi:10.4102/sajs.v106i7/8.252

Thieme, T. A. (2017). The hustle economy. Progress in Human Geography, 42(4). doi:10.1177/0309132517690039

Thurman, T. R., Kidman, R., \& Taylor, T. M. (2015). Bridging the gap: The impact of home visiting programs for orphans and vulnerable children on social grant uptake in South Africa. Children and Youth Services Review, 48, 111-116. doi:10.1016/j.childyouth.2014.12.002

Trani, J., Browne, J., Kett, M., Bah, O., Morlai, T., Bailey, N., \& Groce, N. (2011). Access to health care, reproductive health and disability: A large scale survey in Sierra Leone. Social Science \& Medicine, 73(10), 1477-1489. doi:10.1016/j.socscimed.2011.08.040

Trost, J. (2013). Child care in black and white: Working parents and the history of orphanages. Journal of American History, 100(2), 544-545. doi:10.1093/jahist/jat204

Tufford, L., \& Newman, P. (2012). Bracketing in qualitative research. Qualitative Social Work, 11(1), 80-96. doi:10.1177/1473325010368316

Tummons, J. (2014). Using software for qualitative data analysis: Research outside paradigmatic boundaries. In M. Hand \& S. Hillyard (Series Eds.), Studies in qualitative methodology: Vol. 13. Big data? Qualitative approaches to digital research (pp. 155-177). doi:10.1108/s1042-319220140000013010 
Ungar, M. (2014). Resilience and culture: The diversity of protective processes and positive adaptation. Youth Resilience and Culture Cross-Cultural Advancements in Positive Psychology, 37-48. doi:10.1007/978-94-017-9415-2_3

Ungar, M., Ghazinour, M., \& Richter, J. (2013). Annual research review: What is resilience within the social ecology of human development? Journal of Child Psychology and Psychiatry, 54(4), 348-366. doi:10.1111/jcpp.12025

Van Kaam, A. (1966). Existential Foundations of Psychology. Philosophy and Phenomenological Research, 28(1), 140. doi:10.2307/2105343

Van Kaam, A. (1959) Phenomenal analysis: Exemplified by a study of the experience of "really feeling understood". Journal of Individual Psychology, 15(1), 66.

Vaismoradi, M., Turunen, H., \& Bondas, T. (2013). Content analysis and thematic analysis: Implications for conducting a qualitative descriptive study. Nursing \& Health Sciences, 15(3), 398-405. doi:10.1111/nhs.12048

Vaismoradi, M., Jones, J., Turunen, H., \& Snelgrove, S. (2016). Theme development in qualitative content analysis and thematic analysis. Journal of Nursing Education and Practice, 6(5), 100-110. doi:10.5430/jnep.v6n5p100

Valerio, M. A., Rodriguez, N., Winkler, P., Lopez, J., Dennison, M., Liang, Y., \& Turner, B. J. (2016). Comparing two sampling methods to engage hard-to-reach communities in research priority setting. BMC Medical Research Methodology, 16(1). doi:10.1186/s12874-016-0242-z

Valibhoy, M. C., Kaplan, I., \& Szwarc, J. (2016). "It comes down to just how human someone can be": A qualitative study with young people from refugee 
backgrounds about their experiences of Australian mental health services. Transcultural Psychiatry, 54(1), 23-45. doi:10.1177/1363461516662810

Vassberg, D. E. (1998). Orphans and adoption in early modern Castilian villages. History of the Family, 3(4), 441-458. doi:10.1016/s1081-602x(99)80257-7

Ventevogel, P., \& Spiegel, P. (2015). Psychological treatments for orphans and vulnerable children affected by traumatic events and chronic adversity in subSaharan Africa. Jama, 314(5), 511-512.

Verhoef, H. (2005). 'A child has many mothers': Views of child fostering in northwestern Cameroon. Childhood, 12(3), 369-390. doi:10.1177/0907568205054926

Vetter, P., Kaiser, L., Schibler, M., Ciglenecki, I., \& Bausch, D. G. (2016). Sequelae of Ebola virus disease: the emergency within the emergency. Lancet Infectious Diseases, 16(6), e82-e91. doi:10.1016/s1473-3099(16)00077-3

Vezzali, L., Cadamuro, A., Versari, A., Giovannini, D., \& Trifiletti, E. (2015). Feeling like a group after a natural disaster: Common ingroup identity and relations with outgroup victims among majority and minority young children. British Journal of Social Psychology, 54(3), 519-538. doi:10.1111/bjso.12091.

Vollhardt, J. R., Nair, R., \& Tropp, L. R. (2016). Inclusive victim consciousness predicts minority group members' support for refugees and immigrants. Journal of Applied Social Psychology, 46(6), 354-368. doi:10.1111/jasp.12368

Wai, Z. (2015). Elections and the challenges of democratization in Sierra Leone. National Democratic Reforms in Africa, 219-265. doi:10.1057/9781137518828_8 
Walque, D. D. (2011). Conflicts, Epidemics, and Orphanhood: The impact of extreme events on the health and educational achievements of children. No Small Matter, 85-113. doi:10.1596/9780821386774_ch03

Wasserman, E., Chatlosh, D., \& Neunaber, D. (1983). Perception of causal relations in humans: Factors affecting judgments of response-outcome contingencies under free-operant procedures. Learning and Motivation, 14(4), 406-432. doi:10.1016/0023-9690(83)90025-5

Wayment, H. A., \& Silver, R. C. (2018). Grief and solidarity reactions 1 week after an on-campus shooting. Journal of Interpersonal Violence, 088626051876643. doi: $10.1177 / 0886260518766431$

Webster, R. D., Wente, J., Parris, S. R., \& Rus, A. V. (2017). Congregate care settings in the United States. Child Maltreatment in Residential Care, 461-475. doi:10.1007/978-3-319-57990-0_21broom

Weinmann, S., \& Koesters, M. (2016). Mental health service provision in low and middle-income countries. Current Opinion in Psychiatry, 29(4), 270-275. doi: $10.1097 /$ yco.0000000000000256

Wertz, F. J. (2005). Phenomenological research methods for counseling psychology. Journal of Counseling Psychology, 52(2), 167-177. doi:10.1037/0022-0167.52.2.167

Wertz, F. J. (2016). Outline of the relationship among transcendental phenomenology, phenomenological psychology, and the sciences of persons. Schutzian Research, 8, 139-162. doi:10.5840/schutz201688 
Winn, J. S. (2016). An existential-phenomenological investigation of the experience of being accepted in individuals who have undergone psychiatric institutionalization [Supplemental material]. Indo-Pacific Journal of Phenomenology, 16, 1-14. doi:10.1080/20797222.2016.1164992

Winter, A. (2010). Abandoned in Brussels, delivered in Paris: Long-distance transports of unwanted children in the Eighteenth Century. Journal of Family History, 35(3), 232-248. doi:10.1177/0363199010367973

Wolff, P. H., \& Fesseha, G. (1998). The orphans of Eritrea: Are orphanages part of the problem or part of the solution? American Journal of Psychiatry, 155(10), 13191324. doi:10.1176/ajp.155.10.1319

Wolmer, L., Laor, N., \& Yazgan, Y. (2003). School reactivation programs after disaster: could teachers serve as clinical mediators? Child and Adolescent Psychiatric Clinics of North America, 12(2), 363-381. doi:10.1016/s1056-4993(02)00104-9

Wolz, A. (2014). Face to face with Ebola-An emergency care center in Sierra Leone. New England Journal of Medicine, 371(12), 1081-1083. doi:10.1056/nejmp1410179

Wood, L., Theron, L., \& Mayaba, N. (2012). Collaborative partnerships to increase resilience among AIDS orphans: Some unforeseen challenges and caveats. Africa Education Review, 9(1), 124-141. doi:10.1080/18146627.2012.683631

Wright, M. O., Masten, A. S., \& Narayan, A. J. (2013). Resilience processes in development: four waves of research on positive adaptation in the context of 
adversity. Handbook of Resilience in Children, 15-37. doi:10.1007/978-1-46143661-4_2

Wu-Chi, L. (1953). The original orphan of China. Comparative Literature, 5(3), 193. doi: $10.2307 / 1768912$

Yoder, H. N., Tol, W. A., Reis, R., \& Joop T. V. M. De Jong. (2016). Child mental health in Sierra Leone: a survey and exploratory qualitative study. International Journal of Mental Health Systems, 10(1). doi:10.1186/s13033-016-0080-8

Yovsi, R. D. (2013). Parenting among the Nso of the Northwest Province of Cameroon. Science Across Cultures: The History of Non-Western Science Parenting Across Cultures, 253-266. doi:10.1007/978-94-007-7503-9_19

Yüksel, P., \& Y1ldırım, S. (2015). Theoretical frameworks, methods, and procedures for conducting phenomenological studies. Turkish Online Journal of Qualitative Inquiry, 6(1). doi:10.17569/tojqi.59813

Zack-Williams, A. B. (2001). Child soldiers in the civil war in Sierra Leone. Review of African Political Economy, 28(87), 73-82. doi:10.1080/03056240108704504

Zeanah, C. H., Humphreys, K. L., Fox, N. A., \& Nelson, C. A. (2017). Alternatives for abandoned children: insights from the Bucharest early intervention project. Current Opinion in Psychology, 15, 182-188. doi:10.1016/j.copsyc.2017.02.024

Zeldin, S., Krauss, S. E., Kim, T., Collura, J., \& Abdullah, H. (2016). Pathways to youth empowerment and community connectedness: A study of youth-adult partnership in Malaysian after-school, co-curricular programs. Journal of Youth and Adolescence, 45(8), 1638-1651. doi:10.1007/s10964-015-0320-2 
Zepinic, V. (2016). Disintegration of the self-structure caused by severe trauma. Psychology and Behavioral Sciences, 5(4), 83. doi:10.11648/j.pbs.20160504.12

Ziakas, V., \& Boukas, N. (2014). Contextualizing phenomenology in event management research. International Journal of Event and Festival Management, 5(1), 56-73. doi:10.1108/ijefm-08-2012-0023

Zinn, A. (2016). Kinship family relatedness, nuclear family contact, and social support among foster youth. Journal of Public Child Welfare, 11(1), 1-26. doi:10.1080/15548732.2016.1208134

Zuilkowski, S. S., \& Betancourt, T. S. (2014). School persistence in the wake of war: Wartime experiences, reintegration supports, and dropout in Sierra Leone. Comparative Education Review, 58(3), 457-481. doi:10.1086/675905

Zulu, L., \& Wilson, S. (2012). Whose minerals, whose development? Rhetoric and reality in post-conflict Sierra Leone. Development and Change, 43(5), 1103-1131. doi:10.1111/j.1467-7660.2012.01788.x 
Appendix A

List of Research Participants 


\begin{tabular}{|c|c|c|c|c|c|c|}
\hline No. & Name & I.D. No. & Programme & Year & Telephone No. & Email Address \\
\hline 1 & & & B.Sc. Sociology & 4 & & \\
\hline 2 & & & B.Sc. Sociology & 3 & & \\
\hline 3 & & & B.Sc. Economics & 3 & & \\
\hline 4 & & & B.Sc. Sociology & 2 & & \\
\hline 5 & & & $\begin{array}{l}\text { B.Sc. Peace \& } \\
\text { Development }\end{array}$ & 3 & & \\
\hline 6 & & & $\begin{array}{l}\text { B.Sc. Peace \& } \\
\text { Development }\end{array}$ & 2 & & \\
\hline 7 & & & B.Sc. Economics & 4 & & \\
\hline 9 & & & B.Sc. Economics & 2 & & \\
\hline 10 & & & B.A (Ling/Lit) & 2 & & \\
\hline 11 & & & B.Sc. Economics & 2 & & \\
\hline 12 & & & B.Sc. Sociology & 2 & & \\
\hline 13 & & & $\begin{array}{l}\text { B.Sc. Peace \& } \\
\text { Development }\end{array}$ & 1 & & \\
\hline 14 & & & B.Sc. PADS & 2 & & \\
\hline 15 & & & B.Sc. Acc & 2 & & \\
\hline 16 & & & $\begin{array}{l}\text { B.Sc. Social } \\
\text { Work }\end{array}$ & 4 & & \\
\hline 17 & & & B.Sc. BAF & 3 & & \\
\hline 18 & & & B.Sc. Acc & 1 & & \\
\hline 19 & & & HTC (H/Ed) & 1 & & \\
\hline 20 & & & HTC (Secry) & 3 & & \\
\hline 21 & & & B.Sc. Sociology & 3 & & \\
\hline 22 & & & B.Sc. Economics & 3 & & \\
\hline 23 & & & B.Sc. S Work & 4 & & \\
\hline 24 & & & HTC Primary & 3 & & \\
\hline 25 & & & B.Sc. Economics & 2 & & \\
\hline 26 & & & B.Ed & 2 & & \\
\hline 27 & & & B.Sc. S Work & 3 & & \\
\hline 28 & & & B.Ed & 3 & & \\
\hline 29 & & & SRN & 4 & & \\
\hline 30 & & & $\begin{array}{l}\text { B.Sc. Social } \\
\text { Work }\end{array}$ & 2 & & \\
\hline 31 & & & B.Sc. PADS & 3 & & \\
\hline 32 & & & B.Sc. Sociology & 3 & & \\
\hline 33 & & & B.Sc. Economics & 2 & & \\
\hline
\end{tabular}


Appendix B

Partner University Institutional Review Board Approval 


\section{IRB00008861 FWA00026712}

FROM: Chair, NUIRB

TO: Mr. Augustine Frazer, PhD Candidate, Walden University, USA

DATE: 7th July 2018

Dear Mr. Frazer,

RE: Post-Ebola Case Management for College Students and Orphaned Young Adults in Rural Sierra Leone

The Institutional Review Board, having reviewed your $\mathrm{PhD}$ research protocol grants approval for same. You are however required to report to the NUIRB about:

i) The dates that the research starts, pauses or ends.

ii) Any amendments to your current protocol before implementation;

iii) Research related injury;

iv) Final Research Reports.

It is imperative for data collectors to have ethics training certificates which can be obtained freely from the following site, https://phrp.nihtraining.com or from the CITI site: https://about.citiprogram.org/en/series/human-subjects-research-hsr/.

This approval is valid for one year only. On the anniversary date of this approval you should apply for ethical clearance including updates and any desired amendments, for the protocol to remain active. The approval is voided if you fail to comply with the requirements stipulated above.

Yours Sincerely, 
Appendix C:

Walden University Institutional Review Board Approval 
The Walden University Institutional Review Board approval number for this study was 10-09-18-0130477. 
Appendix D

Sierra Leone Ethics Committee Approval 


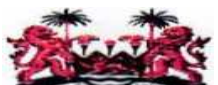

GOVERNMENT OF SIERRA LEONE

Office of the Sierra Leone Ethics and Scientific Review Committee Directorate of Policy, Planning and Information

5th Floor, Youyi Building Brookfields, Freetown Ministry of Health and Sanitation

TO: Augustine Frazer ( $\mathrm{PhD}$ Candidate) $\quad$ Principal Investigator
augustine.frazer@walden.edu

22nd August,2018
\end{abstract}

Study Title: Post-Ebola Case Management in Student-Orphans in Rural Sierra Leone

Version: $\quad 05 / 16 / 2018$

Supervisor

Submission Type: $\quad$ First protocol version submitted for Review

Committee Action: Expedited Review

Approval Date: $\quad 22$ August, 2018

The Sierra Leone Ethics and Scientific Review Committee (SLESRC) having conducted an expedited review of the above study protocol and determined that it presents minimal risk to subjects, hereby grants ethical and scientific approval for it to be conducted in Sierra Leone. The approval is valid for the period, 22 August, 2018 - 21 August, 2019. It is your responsibility to obtain re-approval/extension for any on-going research prior to its expiration date. The request for re-approval/extension must be supported by a progress report.

\title{
Review Comments:
}

Amendments: Intended changes to the approved protocol such as the informed consent documents, study design, recruitment of participants and key study personnel, must be submitted for approval by the SLESRC prior to implementation.

Termination of the study: When study procedures and data analyses are fully complete, please inform the SLESRC that you are terminating the study and submit a brief report covering the protocol activities. Individual identifying information should be destroyed unless there is sufficient justification to retain, approved by the SLESRC. All findings should be based on deidentified aggregate data and all published results in aggregate or group form. A copy of any publication be submitted to the SLESRC for its archive. 
Appendix E

Interview Questions 
1. Tell me about the case management services that you received from Social Service professionals while taking college courses? Why? How?

2. What does a case management service mean to you? Why? How?

3. Describe your experience with case management services. How? why? If not how? Why?

4. How do you experience case management services as part of your college experience?

5. Do you have any other thoughts of your experiences with case management experience that you would like to share with me? 
Appendix F

Referral to Counseling and Psychological Services 


\section{Referral to Counseling and Psychological Services}

Student Information

Student's Name:

ID\#:

E-mail:

Telephone \#:

Marital Status: [] Married [] Single [] Divorced [] Widowed

Gender

[] Male [] Female

\section{Education}

College year: Year 1 [] year 2 [] year 3 [] year 4 [] Graduate School []

Program Specialization:

\section{Referring Office Information}

Name of Referring Professional:

Phone\#:

E-Mail:

Other:

\section{Reason for Referral:}

(Please check all that apply)

Student requests help for psychological distress

Professional perceives student need for help

Professional concerned about student's safety

Age

19-25

Student Signature

Date

Signature of referring Professional

Date 